\title{
A Comprehensive Experimental and Simulation Study of the Ignition Delay Time Characteristics of Binary Blended Methane, Ethane, and Ethylene Over a Wide Range of Temperature, Pressure, Equivalence ratio, and Dilution
}

\author{
Mohammadreza Baigmohammadi ${ }^{a,}$, Vaibhav Patel ${ }^{a}$, Shashank Nagaraja ${ }^{a}$, Ajoy \\ Ramalingam $^{b}$, Sergio Martinez ${ }^{a}$, Snehasish Panigrahy ${ }^{a}$, Ahmed Abd El-Sabor Mohamed ${ }^{a}$, \\ Kieran P. Somers ${ }^{a}$, Ultan Burke $^{a}$, Karl A. Heufer ${ }^{b}$, Andrzej Pekalski ${ }^{c}$ Henry J. Curran ${ }^{a}$ \\ ${ }^{a}$ Combustion Chemistry Centre, School of Chemistry, Ryan Institute, National University of Ireland Galway, University \\ Road, Galway, H91 TK33, Ireland \\ ${ }^{b}$ Physico-Chemical Fundamentals of Combustion, RWTH Aachen University, 52056 Aachen, Germany \\ ${ }^{c}$ Shell research limited, Shell Centre London, London SE1 7NA, United Kingdom \\ *Corresponding author: mohammadreza.baigmohammadi@nuigalway.ie
}

\section{Table of Contents}

$1 \quad$ Design of experiments ...................................................................................................

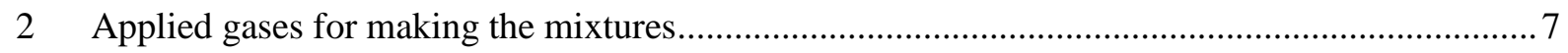

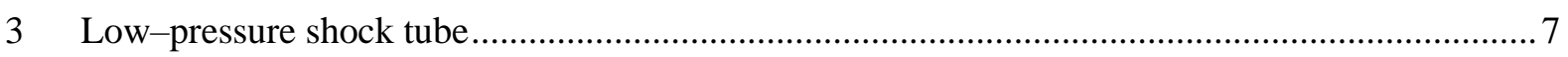

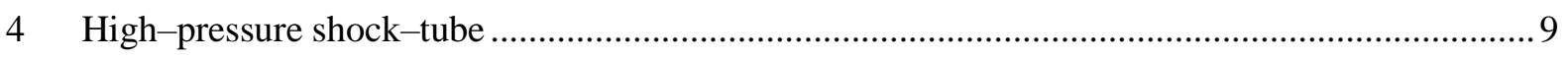

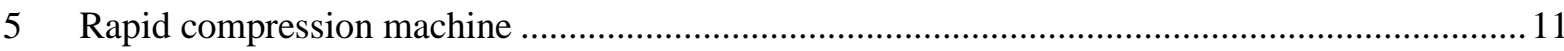

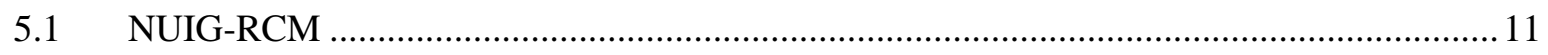

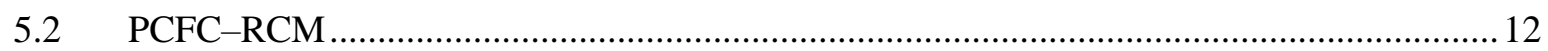

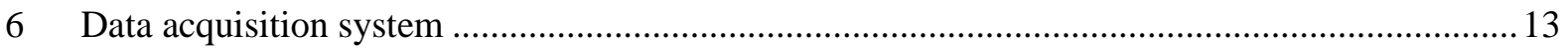

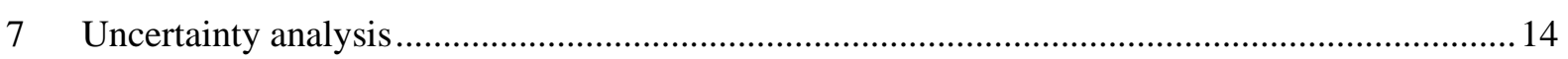

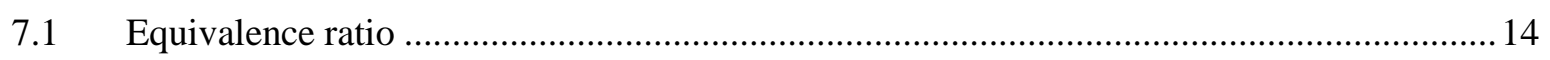

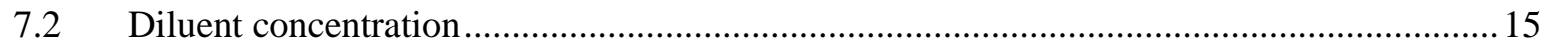

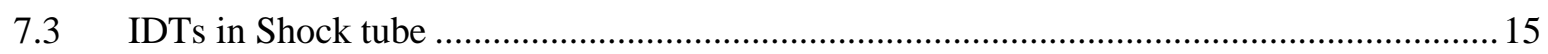

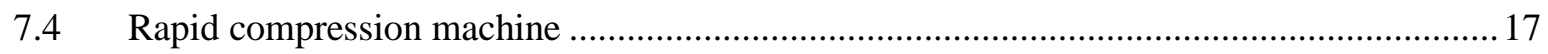

8 Pressure profiles of the applied rapid compression machines (RCMs) ...................................... 19 


\section{Supporting Information}

9 Comparing the performances of NUIGMech1.0 versus other available mechanisms ..................30

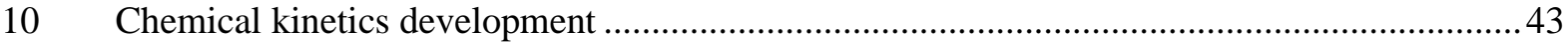

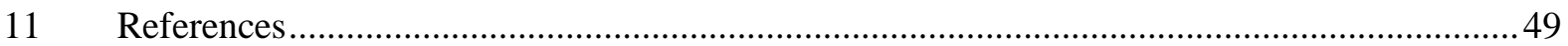




\section{Supporting Information}

\section{Table of Tables}

Table S1. Applied factors/variables and levels for designing the current experiments using the Taguchi method.

Table S2. Specifications of the applied low-pressure shock tube

Table S3. Number of installed PCB sensors on the driven section of LPST shock tube and their distances from the end-wall

Table S4. Specifications of the applied high-pressure shock tube.

Table S5. Number of installed PCB sensors on the driven section of the shock-tube and their distances from the end-wall. 10

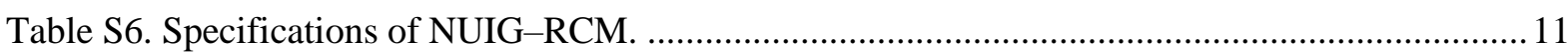

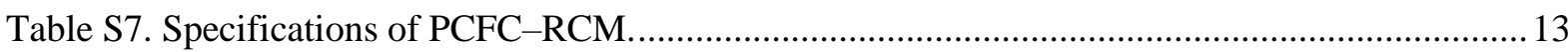

Table S8. Applied sensors and detectors for measuring during the current study (NUIG-HPST/RCM and PCFC-RCM)

Table S9. Correlation variables of the studied experimental datasets for different fuels in shock tubes.

Table S10. Correlation variables of the studied experimental datasets for different fuels in RCMs.... 18

Table S11. Applied chemical mechanisms. .31 


\section{Supporting Information}

\section{Table of Figures}

Figure S1. Applied definition for measuring IDT in the NUIG-shock tube: (a) using Kistler pressure trace mounted on the end-wall of the endcap; (b) using PDA- $\mathrm{CH}^{*}$ trace mounted on the side wall of the end-cap.

Figure S2. Applied definition for measuring IDT in the NUIG-RCM: (a) using Kistler pressure trace; (b) using both pressure and PMT- $-\mathrm{CH}^{*}$ trace mounted on the side wall of the reaction chamber. 12 Figure S3. Pressure history of tested reactive and non-reactive mixtures of P5C2 case alongside the simulation's profile for initial temperature of $338 \mathrm{~K}$.

Figure S4. Pressure history of tested reactive and non-reactive mixtures of $\mathrm{P} 5 \mathrm{C} 2$ case alongside the simulation's profile for initial temperature of $353 \mathrm{~K}$.

Figure S5. Pressure history of tested reactive and non-reactive mixtures of $\mathrm{P} 5 \mathrm{C} 2$ case alongside the simulation's profile for initial temperature of $368 \mathrm{~K}$. .20

Figure S6. Pressure history of tested reactive and non-reactive mixtures of $\mathrm{P} 5 \mathrm{C} 2$ case alongside the simulation's profile for initial temperature of $383 \mathrm{~K}$.

Figure S7. Pressure history of tested reactive and non-reactive mixtures of P5C6 case alongside the simulation's profile for initial temperature of $368 \mathrm{~K}$.

Figure S8. Pressure history of tested reactive and non-reactive mixtures of P5C7 case alongside the simulation's profile for initial temperature of $323 \mathrm{~K}$.

Figure S9. Pressure history of tested reactive and non-reactive mixtures of P5C7 case alongside the simulation's profile for initial temperature of $338 \mathrm{~K}$.

Figure S10. Pressure history of tested reactive and non-reactive mixtures of P5C7 case alongside the simulation's profile for initial temperature of $353 \mathrm{~K}$.

Figure S11. Pressure history of tested reactive and non-reactive mixtures of P5C7 case alongside the simulation's profile for initial temperature of $383 \mathrm{~K}$.

Figure S12. Pressure history of tested reactive and non-reactive mixtures of $\mathrm{P} 8 \mathrm{C} 2$ case alongside the simulation's profile for initial temperature of $338 \mathrm{~K}$.

Figure S13. Pressure history of tested reactive and non-reactive mixtures of P8C2 case alongside the simulation's profile for initial temperature of $353 \mathrm{~K}$.

Figure S14. Pressure history of tested reactive and non-reactive mixtures of P8C2 case alongside the simulation's profile for initial temperature of $368 \mathrm{~K}$.

Figure S15. Pressure history of tested reactive and non-reactive mixtures of P8C2 case alongside the simulation's profile for initial temperature of $378 \mathrm{~K}$.

Figure S16. Pressure history of tested reactive and non-reactive mixtures of P8C3 case alongside the simulation's profile for initial temperature of $349.5 \mathrm{~K}$.

Figure S17. Pressure history of tested reactive and non-reactive mixtures of P8C3 case alongside the simulation's profile for initial temperature of $349.6 \mathrm{~K}$. .26 


\section{Supporting Information}

Figure S18. Pressure history of tested reactive and non-reactive mixtures of P8C4 case alongside the simulation's profile for initial temperature of $349.8 \mathrm{~K}$.

Figure S19. Pressure history of tested reactive and non-reactive mixtures of P8C4 case alongside the simulation's profile for initial temperature of $349.7 \mathrm{~K}$.

Figure S20. Pressure history of tested reactive and non-reactive mixtures of P8C4 case alongside the simulation's profile for initial temperature of $349.6 \mathrm{~K}$. 28

Figure S21. Pressure history of tested reactive and non-reactive mixtures of P8C7 case alongside the simulation's profile for initial temperature of $338 \mathrm{~K}$. .28

Figure S22. Pressure history of tested reactive and non-reactive mixtures of P8C7 case alongside the simulation's profile for initial temperature of $353 \mathrm{~K}$.

Figure S23. Pressure history of tested reactive and non-reactive mixtures of P8C7 case alongside the simulation's profile for initial temperature of $368 \mathrm{~K}$.

Figure S24. Pressure history of tested reactive and non-reactive mixtures of P8C7 case alongside the simulation's profile for initial temperature of $378 \mathrm{~K}$.

Figure S25. Pressure history of tested reactive and non-reactive mixtures of P8C8 case alongside the simulation's profile for initial temperature of $346.5 \mathrm{~K}$.

Figure S26. Performance of NUIGMech1.0 for predicting LBVs in comparison to AramcoMech 3.0 and JetSurf II. ${ }^{30}$

Figure S27. Performance of NUIGMech1.0 for predicting methane's speciation in comparison to AramcoMech 3.0 and JetSurf II..$^{31,32}$

Figure S28. Performance of NUIGMech1.0 for predicting ethane's speciation in comparison to AramcoMech 3.0 and JetSurf II. ${ }^{33,34}$

Figure S29. Performance of NUIGMech1.0 for predicting ethylene's speciation in comparison to AramcoMech 3.0 and JetSurf II. ${ }^{32,35,36}$

Figure S30. Performance of NUIGMech1.0 for predicting methane + ethylene's IDTs at 1 bar in comparison to the other examined chemical mechanisms. .35

Figure S31. Performance of NUIGMech1.0 for predicting methane + ethylene's IDTs at 20 bar in comparison to the other examined chemical mechanisms.

Figure S32. Performance of NUIGMech1.0 for predicting methane + ethylene's IDTs at 40 bar in comparison to the other examined chemical mechanisms.

Figure S33. Performance of NUIGMech1.0 for predicting methane + ethane's IDTs in comparison to the other examined chemical mechanisms. ${ }^{37-39}$

Figure S34. Performance of NUIGMech1.0 for predicting methane + ethane's IDTs in comparison to the other examined chemical mechanisms. . $^{37,38,40,41}$

Figure S35. Performance of NUIGMech1.0 for predicting ethane + ethylene's IDTs at 1 bar in comparison to the other examined chemical mechanisms. .40 


\section{Supporting Information}

Figure S36. Performance of NUIGMech1.0 for predicting ethane + ethylene's IDTs at 20 bar in comparison to the other examined chemical mechanisms. 41

Figure S37. Performance of NUIGMech1.0 for predicting ethane + ethylene's IDTs at 40 bar in comparison to the other examined chemical mechanisms.

Figure S38. Flux analysis of the ten prominent reactions at $1200 \mathrm{~K}$ in Fig. 5(a) for the methane + ethylene blends at different methane/ethylene combinations; Black numbers: 50/50, Red numbers: 70/30, and Green numbers: 90/10.

Figure S39. Flux analysis of the ten prominent reactions at $1200 \mathrm{~K}$ in Fig. 5(a) for the ethane + ethylene blends at different ethane/ethylene combinations; Black numbers: 50/50, Red numbers: 70/30, and Green numbers: 90/10.

Figure S40. Flux analysis of the ten prominent reactions at $1200 \mathrm{~K}$ in Fig. 5(c) for the methane + ethylene blends at different equivalence ratios; Black numbers: 0.5, Red numbers: 1.0, and Green numbers: 2.0.

Figure S41. Comparing the rates related to $\dot{\mathrm{H}}-$ abstraction reactions from fuel by $\dot{\mathrm{H}}$ atom or $\dot{\mathrm{OH}}$ radical and also two important reactions for production of vinyloxy radical. .46 Figure S42. Flux analysis of the ten prominent reactions at $1200 \mathrm{~K}$ in Fig. 5(c) for the ethane + ethylene blends at different equivalence ratios; Black numbers: 0.5, Red numbers: 1.0, and Green numbers: 2.0.

Figure S43. Flux analysis of the ten prominent reactions at $1200 \mathrm{~K}$ in Fig. 5(d) for the methane + ethylene blends at different pressures; Black numbers: 1 bar, Red numbers: 20 bar, and Green numbers: 40 bar. 48

Figure S44. Flux analysis of the ten prominent reactions at $1200 \mathrm{~K}$ in Fig. 5(d) for the ethane + ethylene blends at different pressures; Black numbers: 1 bar, Red numbers: 20 bar, and Green numbers: 40 bar. 


\section{Supporting Information}

\section{Design of experiments}

The applied approach for designing the experiments has been already discussed in details by Baigmohammadi et al ${ }^{1}$. As seen in Table S1, there are four factors (e.g. fuel composition; A, dilution level; B, equivalence ratio; C, and pressure; D) and 3 levels for each parameter (e.g. three pressure levels, 1.0, 20.0, and 40.0 bar) $\mathrm{L}_{9}$ orthogonal array could be still employed for designing the required experiments.

Table S1. Applied factors/variables and levels for designing the current experiments using the Taguchi method.

\begin{tabular}{|c|c|c|c|c|}
\hline Levels & Fuel composition (A) & Dilution (B) & Equivalence ratio (C) & Pressure (bar) (D) \\
\hline $\boldsymbol{I}$ & $50 \% \mathrm{C}_{2} \mathrm{H}_{4}+50 \% \mathrm{C}_{2} \mathrm{H}_{6}$ & $75 \%$ & 0.5 & 1.0 \\
\hline $\mathbf{2}$ & $30 \% \mathrm{C}_{2} \mathrm{H}_{4}+70 \% \mathrm{C}_{2} \mathrm{H}_{6}$ & $85 \%$ & 1.0 & 20.0 \\
\hline 3 & $10 \% \mathrm{C}_{2} \mathrm{H}_{4}+90 \% \mathrm{C}_{2} \mathrm{H}_{6}$ & $90 \%$ & 2.0 & 40.0 \\
\hline
\end{tabular}

\section{Applied gases for making the mixtures}

As mentioned in Section 2 of the manuscript, in the current study, the ignition delay time characteristics of methane + ethylene $\left(\mathrm{CH}_{4}+\mathrm{C}_{2} \mathrm{H}_{4}\right)$, methane + ethane $\left(\mathrm{CH}_{4}+\mathrm{C}_{2} \mathrm{H}_{6}\right)$, and ethane + ethylene $\left(\mathrm{C}_{2} \mathrm{H}_{6}+\mathrm{C}_{2} \mathrm{H}_{4}\right)$ have been investigated individually over a wide range of temperature, pressure, ethylene concentration, equivalence ratio, and dilution conditions. For those experiments performed at the combustion chemistry centre $\left(\mathrm{C}^{3}\right)$ of National University of Ireland, the studied alkane/alkene fuels with purity of $99.5 \%$ (Grade: 2.5 ) have been supplied through high pressure bottles which were provided from Air liquide UK. The other applied gases such as oxygen, argon, nitrogen, and helium in the experiments have been provided by BOC Ireland with purities of $\mathrm{O}_{2}(99.99 \%), \mathrm{N}_{2}$ (99.99\%), $\mathrm{Ar}$ (99.99\%), and $\mathrm{He}$ (99.96\%). However, for those experiments performed at the Physico-Chemical Fundamentals of Combustion (PCFC) of RWTH Aachen University, the studied $\mathrm{C}_{2} \mathrm{H}_{4}+\mathrm{C}_{2} \mathrm{H}_{6}$ with purity of $99.95 \%$ (Grade: 3.5) were provided by Westfalen AG. Also, the other applied gases such as oxygen, argon, and nitrogen, in the experiments have been provided by Westfalen AG and Praxair with purities of $\mathrm{O}_{2}\left((\geq 99.995 \%), \mathrm{N}_{2}((\geq 99.95 \%)\right.$, and $\mathrm{Ar}(\geq 99.996 \%)$.

\section{Low-pressure shock tube}

As known, shock-tube is a robust facility for getting the ignition delay time data under low and high pressures and high temperature $(\geq 1000 \mathrm{~K})$ regime and IDTs $\leq 2 \mathrm{~ms}$. Thus, the NUIG-LPST has been used for getting the IDT data under 1 bar operating condition. The applied NUIG-LPST has been previously documented and explained in details ${ }^{2,3}$. Here, only general information of the facility is presented in Table S2. In the current study, helium was used as the primary driver gas for doing the 


\section{Supporting Information}

experiments unless there was a need to reduce the incident shock velocity through adding nitrogen to helium for the tailored cases.

Table S2. Specifications of the applied low-pressure shock tube.

\begin{tabular}{|c|c|c|}
\hline Total length & \multicolumn{2}{|c|}{$6.33 \mathrm{~m}$} \\
\hline Section & Length $(\mathrm{m})$ & Diameter $(\mathrm{mm})$ \\
\hline Driver & 0.53 & 520 \\
\hline Driven & 5.8 & 102.4 \\
\hline Material & \multicolumn{2}{|c|}{ Stainless steel } \\
\hline Controlling system & \multicolumn{2}{|c|}{ Sharp edges arrow } \\
\hline Diaphragm's material & \multicolumn{2}{|c|}{ Polycarbonate/Polyester } \\
\hline Diaphragm's thickness & \multicolumn{2}{|c|}{$105-120 \mu \mathrm{m}$ (nominal) } \\
\hline
\end{tabular}

Further, as presented in Table S3, the incident shock velocity has been measured using five piezoelectric pressure transducers located on the driven section of the LPST and then the shock velocity at the end-wall was extrapolated through a fitted line to the collected shock velocities over these pressure transducers. All conditions such as the compressed gas temperature $\left(T_{5}\right)$ and pressure $\left(p_{5}\right)$ behind the reflected shock were calculated using the shock velocity at the end-wall using "Gaseq" software $^{4}$. Also, the ignition delay times of the studied mixtures were measured using photomultiplier (PMT) systems equipped with $\mathrm{CH}^{*}$ filter (CWL: $430 \mathrm{~nm} \pm 10$ FWHM; Thorlabs) installed on the side wall of the shock tube's endcap due to very weak pressure signals. Also, it is demonstrated in Figure $\mathrm{S} 1$ that the ignition delay time is defined as a maximum gradient in pressure $\left(\left.\frac{d P}{d t}\right|_{\max }\right)$ or $\mathrm{CH}^{*}\left(\left.\frac{d C H^{*}}{d t}\right|_{\max }\right)$ behind the reflected shock. Further, for increasing the accuracy of experiments and reducing the scattered points, all measured pressures behind the reflected shocks have been forced to be restricted to \pm 0.05 bar of the target pressure of 1 bar. In this regard, all pressure versus time data including oscilloscope files (software is accessible through https://www.tiepie.com/en/oscilloscope-software) and the experimentalist spreadsheets related to the current studied conditions in NUIG-LPST are provided as Supplementary data files.

Table S3. Number of installed PCB sensors on the driven section of LPST shock tube and their distances from the end-wall.

\begin{tabular}{|c|c|}
\hline Sensors & Distance from the end wall (m) \\
\hline PCB\#1 & 0.03 \\
\hline PCB\#2 & 0.237 \\
\hline PCB\#3 & 0.366 \\
\hline PCB\#4 & 0.495 \\
\hline PCB\#5 & 1.89 \\
\hline
\end{tabular}




\section{Supporting Information}

\section{High-pressure shock-tube}

The NUIG-HPST has been used for getting the IDT data for 20 and 40 bar operating conditions. As already mentioned, the applied NUIG-HPST has been previously documented and explained in details ${ }^{5}$ and ,here, only general information of the facility is presented in Table S4. In the current study, helium was used as the primary driver gas for doing the experiments unless there was a need to reduce the incident shock velocity through adding nitrogen to helium for the tailored cases.

Table S4. Specifications of the applied high-pressure shock tube.

\begin{tabular}{|c|c|c|}
\hline Total length & \multicolumn{2}{|c|}{$9.1 \mathrm{~m}$} \\
\hline Section & Length $(\mathrm{m})$ & Diameter (mm) \\
\hline Driver & 3.0 & 63.5 \\
\hline Middle & 0.04 & 63.5 \\
\hline Driven & 5.7 & 63.5 \\
\hline Material & \multicolumn{2}{|c|}{ Stainless-steel (1.4571/316Ti and 1.4462/F51) } \\
\hline Controlling system & \multicolumn{2}{|c|}{ Double-diaphragm type } \\
\hline Diaphragm's material & \multicolumn{2}{|c|}{ Aluminium (1050 H14) } \\
\hline Diaphragm's thickness & \multicolumn{2}{|c|}{$0.8 \sim 2 \mathrm{~mm}$; according to target pressure } \\
\hline Pre-scoring the diaphragms & \multicolumn{2}{|c|}{$0.2 \sim 1.1 \mathrm{~mm}$; according to target pressure and the diaphragms' thickness } \\
\hline
\end{tabular}

Further, as presented in Table S5, the incident shock velocity has been measured using six piezoelectric pressure transducers located on the driven section of the HPST and then the shock velocity at the end-wall was extrapolated through a fitted line to the collected shock velocities over these pressure transducers. All conditions such as the compressed gas temperature $\left(T_{5}\right)$ and pressure $\left(p_{5}\right)$ behind the reflected shock were calculated using the shock velocity at the end-wall through "Gaseq" software ${ }^{4}$. Also, the ignition delay times of the studied normal mixtures (pressure-time profiles) with diluent concentration of $\leq 85 \%$ were recorded using a Kistler 603B transducer mounted on the endwall, while for the mixtures with $90 \%$ dilution, the ignition delay times were measured using photodiode array detector (PDA) or photomultiplier (PMT) systems equipped with $\mathrm{CH}^{*}$ filter (CWL: $430 \mathrm{~nm} \pm 10$ FWHM; Thorlabs) installed on the side wall of the shock tube's endcap due to very weak signals of the Kistler pressure transducer. For increasing the accuracy of experiments and reducing the scattered points, all measured pressures behind the reflected shocks have been forced to be restricted to \pm 0.5 bar of the target pressures (20 and 40 bar). Moreover, all of the experimental results have been divided into two main categories of the acceptable and the affected by facility, so that the affected results have been marked using “囚” symbol. Thus, these data wouldn't be reliable to be applied for evaluating the performance of a chemical mechanism. In this regard, all of the pressure versus time data including oscilloscope files (software is accessible through https://www.tiepie.com/en/oscilloscope-software) and the experimentalist spreadsheets related to the current studied conditions in NUIG-HPST are provided as Supplementary data files. 


\section{Supporting Information}

Table S5. Number of installed PCB sensors on the driven section of the shock-tube and their distances from the end-wall.

\begin{tabular}{|c|c|}
\hline Sensors & Distance from the end wall (m) \\
\hline PCB\#1 & 0.01 \\
\hline PCB\#2 & 0.15 \\
\hline PCB\#3 & 0.29 \\
\hline PCB\#4 & 0.57 \\
\hline PCB\#5 & 0.85 \\
\hline PCB\#6 & 1.165 \\
\hline
\end{tabular}

(a)

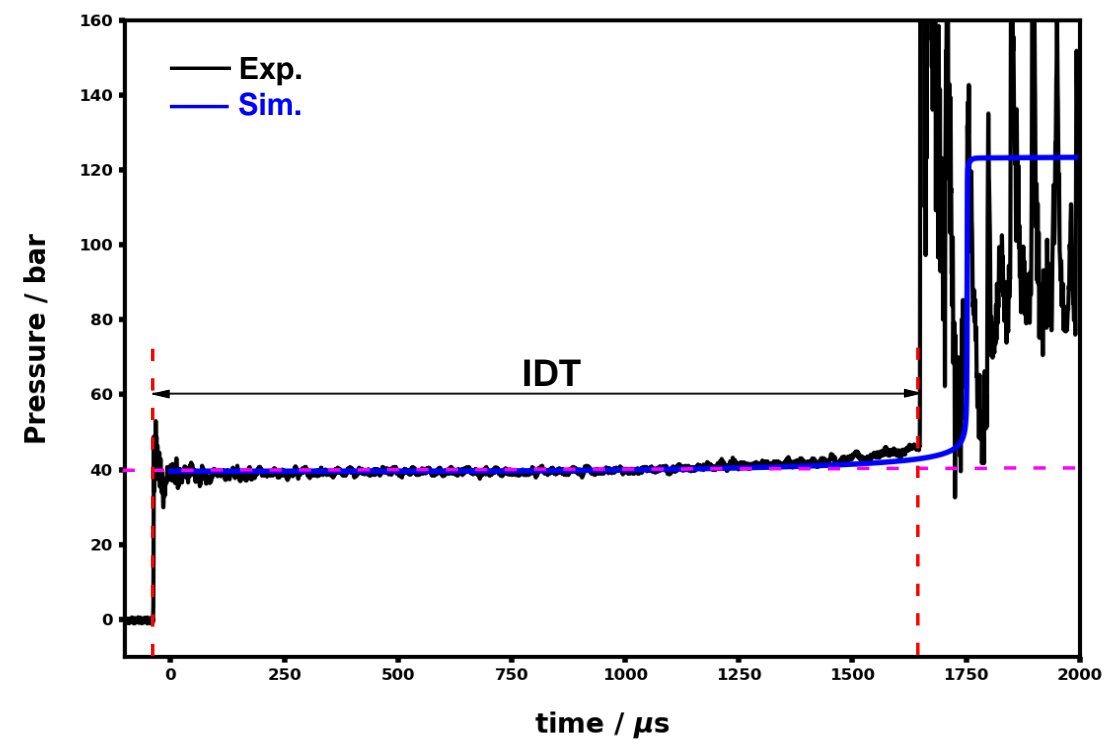

(b)

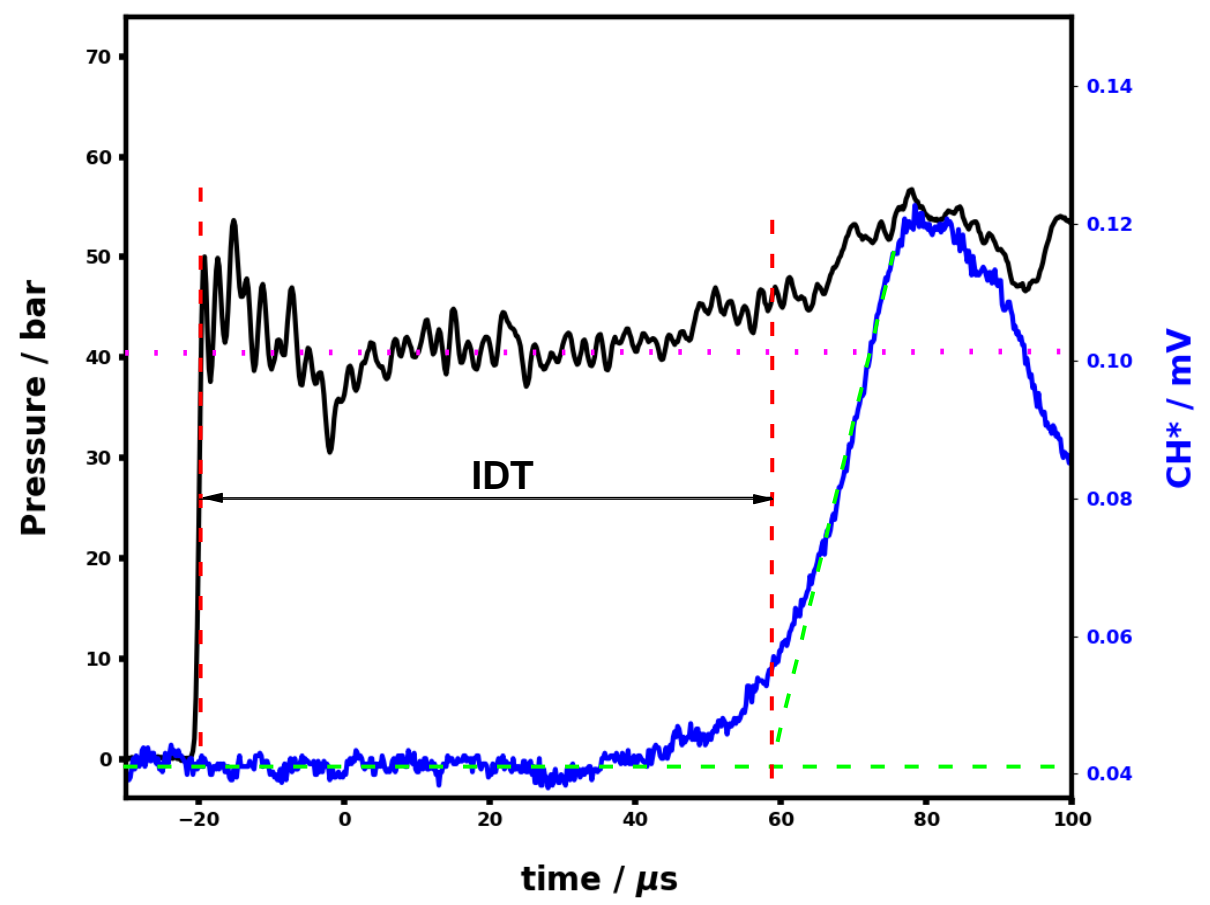

Figure S1. Applied definition for measuring IDT in the NUIG-shock tube: (a) using Kistler pressure trace mounted on the end-wall of the endcap; (b) using PDA- $\mathrm{CH}^{*}$ trace mounted on the side wall of the end-cap. 


\section{Supporting Information}

\section{Rapid compression machine}

The rapid compression machine is a common facility for getting the ignition delay time data under high pressure and low-to-moderate temperature regime ( $<1000 \mathrm{~K})$. In the current study, the experiments have been taken using NUIG- and PCFC-RCMs. According to the previous studies ${ }^{6,7}$, the experimental IDTs have been modelled using the adiabatic core assumption in which the non-adiabatic condition can be compensated by imposing the volume-time profiles of the same non-reactive mixtures to calculations. Thus, general information about each facility have been presented in the following subsections.

\subsection{NUIG-RCM}

The general specifications of NUIG-RCM have been presented in Table S6. The details of the facility has been already documented and explained in details ${ }^{5,6,8-11}$. In this facility, the ignition delay time of the normal studied mixtures (diluent concentration $=75 \%$ ) and the pressure-time histories of their relevant non-reactive mixtures were recorded using a Kistler 6045A transducer mounted on the reaction chamber. However, the ignition delay times of the mixtures with $85 \%$ and $90 \%$ dilution percent and the post-compression pressures of 20 and 40 bar, were reordered using both the Kistler and photomultiplier (PMT) equipped with $\mathrm{CH}^{*}$ filter (CWL: $430 \mathrm{~nm} \pm 10 \mathrm{FWHM}$; Thorlabs) due to vague signal of the Kistler pressure transducer under these conditions. Also, as shown in Figure S2, the ignition delay time is defined as a maximum gradient in pressure $\left(\left.\frac{d P}{d t}\right|_{\text {max }}\right)$ or $\mathrm{CH}^{*}\left(\left.\frac{d C H^{*}}{d t}\right|_{\text {max }}\right)$ after compressing the studied mixtures. Subsequently, the post compression temperatures $\left(T_{\mathrm{C}}\right)$ were calculated by assuming isentropic compression condition using Gaseq software ${ }^{4}$. Similar to the applied procedure in NUIG-HPST, all measured post compression pressures $\left(p_{\mathrm{C}}\right)$ have been forced to be restricted to \pm 0.5 bar of the target pressures due to increasing the accuracy of experiments and also reducing the scattered points. Moreover, unlike the standard operating procedure in NUIG-HPST, all the experimental results have been repeated at least three times and the repeatability of all reported IDTs was $\geq 90 \%$. In this regard, all pressure versus time data including pressure/volume profiles and the experimentalist spreadsheets related to the studied conditions in NUIG-RCM have been provided as the Supplementary files.

Table S6. Specifications of NUIG-RCM.

\begin{tabular}{|c|c|}
\hline Parameter & Value \\
\hline Bore size of the reaction chamber $(\mathrm{m})$ & 0.03820 \\
\hline Volume of the reaction chamber $\left(\mathrm{m}^{3}\right)$ & $3.3191 \times 10^{-5}$ \\
\hline Piston's velocity $\left(\mathrm{U}_{\mathrm{p}}\right)(\mathrm{m} / \mathrm{s})$ & $9.34 \sim 12.94$ \\
\hline Pistons' stroke length $(\mathrm{m})$ & 0.16817 \\
\hline Piston's type & Flat head with the crevice \\
\hline Type & Twin-counter pistons \\
\hline
\end{tabular}


(a)

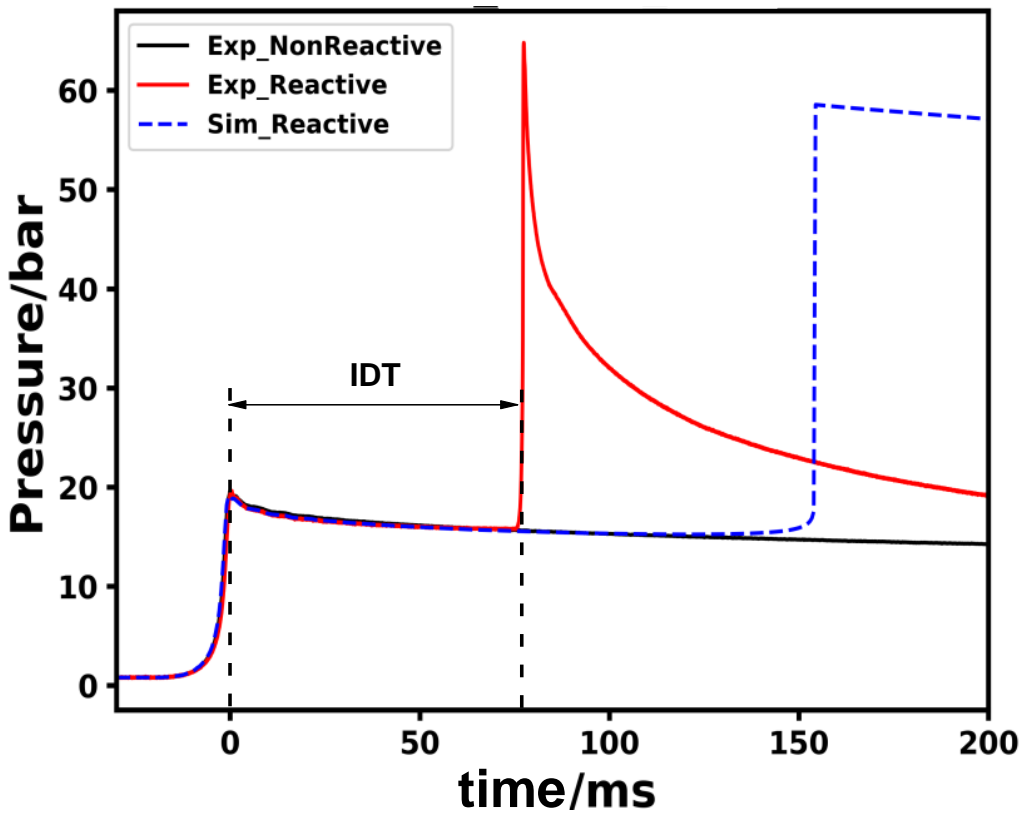

(b)

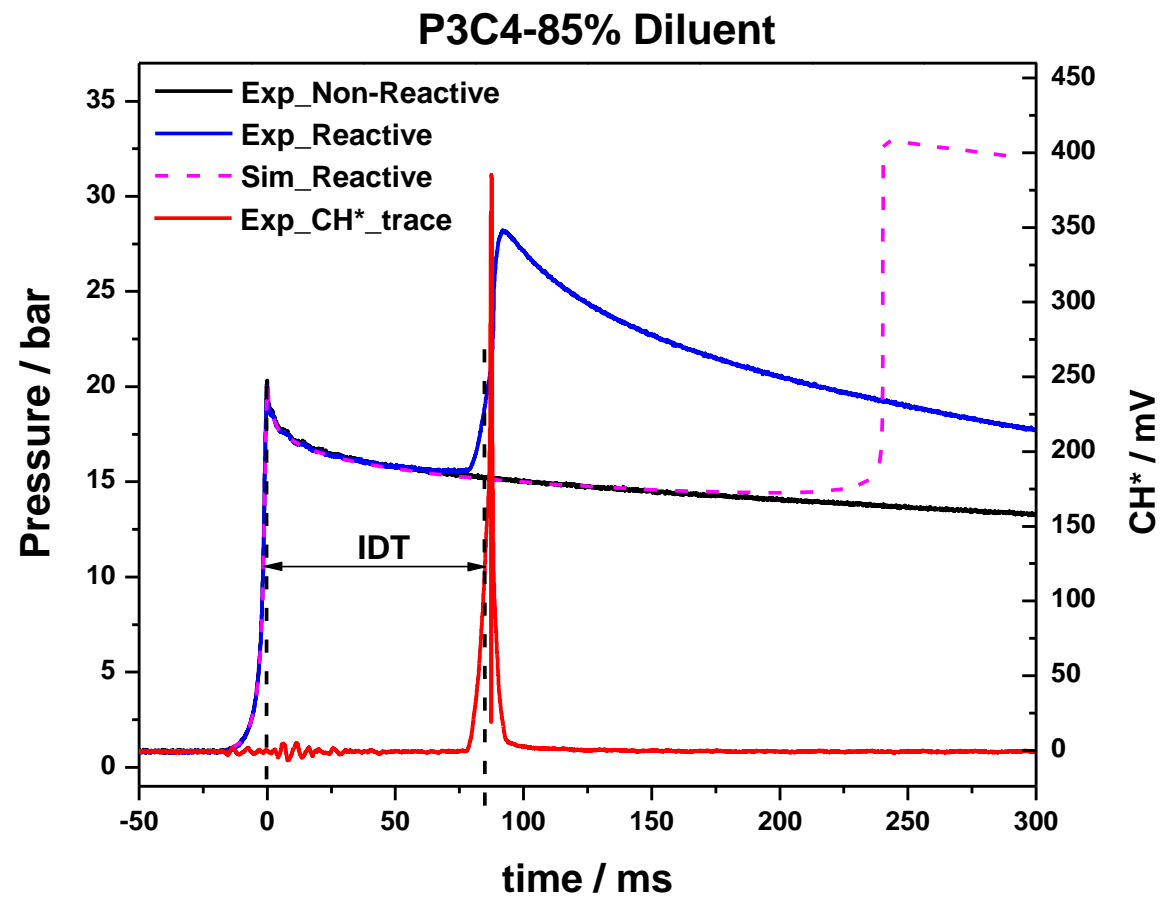

Figure S2. Applied definition for measuring IDT in the NUIG-RCM: (a) using Kistler pressure trace; (b) using both pressure and PMT- $\mathrm{CH}^{*}$ trace mounted on the side wall of the reaction chamber.

\subsection{PCFC-RCM}

The PCFC-RCM is a well-known facility which has been already introduced properly in literature. As presented in Table S7, this facility is constructed from a single-piston mechanism which is driven pneumatically and stopped hydraulically at the end of compression. Similar to the applied piston in NUIG-RCM, the crevice piston design has been applied in the PCFC-RCM. In the facility, the pressure-time profile during the compression and the post-compression processes and the initial temperature in the reaction chamber were monitored and controlled using a Kistler $6125 \mathrm{C}$ pressure 


\section{Supporting Information}

transducer and type ' $\mathrm{T}$ ' thermocouple, respectively. In this regard, the detail information about the construction, measurement procedure, and the applied sensors in the study have been already presented in ${ }^{12}$. As the same process explained in section 5.1, the compressed mixture's temperature $\left(T_{5}\right)$ was calculated using the isentropic compression formulation of Gaseq software ${ }^{4}$. According to the procedure explained by Ramalingam et al. ${ }^{7}$, the reproducibility of evaluated IDTs and also the experimental uncertainty of the compressed mixture's temperature for the measured conditions in the study were within $15 \%$ and $\pm 5 \mathrm{~K}$, respectively. In this regard, the related experimental data to PCFCRCM facility and the volume-time profiles are reported in the Supplementary files.

Table S7. Specifications of PCFC-RCM.

\begin{tabular}{|c|c|}
\hline Parameter & Value \\
\hline Bore size of the reaction chamber $(\mathrm{m})$ & 0.05 \\
\hline Volume of the reaction chamber $\left(\mathrm{m}^{3}\right)$ & $5.06 \times 10^{-4}-5.51 \times 10^{-4}$ \\
\hline Piston's velocity $\left(\mathrm{U}_{\mathrm{p}}\right)(\mathrm{m} / \mathrm{s})$ & 16.67 \\
\hline Pistons' stroke length $(\mathrm{m})$ & 0.25 \\
\hline Piston's type & Flat head with the crevice \\
\hline Type & Single piston \\
\hline
\end{tabular}

\section{Data acquisition system}

As shown in Table S8, in the current study, many sensors have been used in the four applied facilities at $\mathrm{C}^{3}$-NUIG and PCFC-RWTH Aachen University to measure the required parameters. In this regard, all installed sensors in NUIG-L/HPST which had been used for measuring the incident shock velocities and the ignition delay times, were synchronized and connected to two TiePie Handyscope HS4 oscilloscopes ${ }^{13}$. Also, all generated signals from the installed sensors on NUIG-RCM including the Kistler pressure transducer, the position sensors, and the photomultiplier were synchronized and collected using a PicoScope 5443B ${ }^{14}$.

Table S8. Applied sensors and detectors for measuring during the current study (NUIG-HPST/RCM and PCFC$\mathrm{RCM})$.

\begin{tabular}{|c|c|c|c|c|}
\hline Sensor & Company & Model & Accuracy & Resolution \\
\hline Pressure sensor transducer & Kistler & $603 \mathrm{~B}$ & $\leq \pm 1.0 \%$ FSO; linearity & NA \\
\hline Pressure sensor transducer & Kistler & $6045 \mathrm{~A}$ & $\leq \pm 0.4 \% / F S O ;$ linearity & NA \\
\hline Pressure sensor transducer & Kistler & $6125 \mathrm{C}$ & $\leq \pm 0.4 \% / F S O ;$ linearity & NA \\
\hline Piezoelectric pressure sensor & PCB & 113B24 & $\leq \pm 1.0 \% \mathrm{FS} ;$ Non-linearity & $\pm 0.035 \mathrm{KPa}$ \\
\hline Digital Absolut pressure transmitter & Kurt J Lesker & ACG \& HCG & $0.25 \%$ of FS & \pm 0.01 Torr \\
\hline Digital Absolut pressure transmitter & Edwards & 600 Barocel & $0.15 \%$ of reading & \pm 0.01 of $\mathrm{FS}$ \\
\hline Digital Absolut pressure transmitter & MKS & Baratron 121AA-0100D & $0.5 \%$ of reading & \pm 0.01 Torr \\
\hline Digital Absolut pressure transmitter & MKS & Baratron 121AA-01000D & $0.5 \%$ of reading & \pm 0.1 Torr \\
\hline Digital Absolut pressure transmitter & MKS & Baratron 121AA-05000B & $0.5 \%$ of reading & \pm 0.5 Torr \\
\hline Analog vacuum pressure gauge & Edwards & Pirani-PRE10K & NA & \pm 2 of reading scale \\
\hline
\end{tabular}




\section{Supporting Information}

\begin{tabular}{|c|c|c|c|c|}
\hline Thermocouples and Controller & Radionics & T-type & $\pm 1.0^{\circ} \mathrm{C}$ & $\pm 0.1^{\circ} \mathrm{C}$ \\
\hline Photodetector & Thorlabs & PDA36A/PDA55 & NA & NA \\
\hline Photomultiplier & EMI Electronics & $9924 \mathrm{P}$ & NA & NA \\
\hline
\end{tabular}

\section{Uncertainty analysis}

For getting a detailed understanding about the uncertainty of the experimental tests of the current study, the following subsections have been presented. In fact, these subsections try to analytically explain the effect of some important factors including pressure, temperature, and equivalence ratio on the total uncertainty of the experimental results. It seems that the output of the section could provide a good clue for better analysing and evaluating the quality of the experimental data.

\subsection{Equivalence ratio}

In the following lines, it is tried to somehow evaluate probable uncertainties which may be included in equivalence ratios of the applied mixtures of the current study.

Making a mixture:

Fuel: $F=P_{F}=\sum_{i=1}^{n} P_{i} \rightarrow \sigma_{F}=\sqrt{\sum_{i=1}^{n} \sigma_{i}^{2}}$

where, pi and $\sigma_{\mathrm{i}}$ are absolute pressure of $\mathrm{i}$-th component in the fuel mixture and uncertainty of each absolute pressure of $\mathrm{i}$-th component in the fuel mixture, respectively. Because, in the current study, binary-fuel mixtures have been studied, thus: Fuel: $\mathrm{F}=\left(p_{\mathrm{F} 1} \pm \sigma_{\mathrm{F} 1}\right)+\left(p_{F 2} \pm \sigma_{\mathrm{F} 2}\right)$ and Oxygen: $\mathrm{O}=p_{O 2} \pm \sigma_{\mathrm{O} 2}$.

Equivalence ratio: $\varphi=\frac{\left(\frac{F}{o}\right)_{\text {real }}}{\left(\frac{F}{\partial}\right)_{\text {stoi }}} \rightarrow\left(\frac{O}{F}\right)_{\text {Stoi }}=\operatorname{Cte} \rightarrow \varphi=\operatorname{Cte}\left(\frac{F_{1}+F_{2}}{O}\right)_{\text {real }} \rightarrow \sigma_{\varphi}=\left(\frac{\partial \varphi}{\partial F_{1}}\right) \sigma_{F_{1}}+\left(\frac{\partial \varphi}{\partial F_{2}}\right) \sigma_{F_{2}}+\left(\frac{\partial \varphi}{\partial O}\right) \sigma_{O}$

$$
\begin{aligned}
\varphi & =\operatorname{Cte}\left(\frac{\sum_{i=1}^{n} p_{F i}}{p_{O_{2}}}\right)_{\text {real }} \rightarrow \frac{\partial \varphi}{\partial p_{F_{n}}}=\frac{1}{o} \rightarrow \frac{\partial \varphi}{\partial p_{O_{2}}}=-\frac{\sum_{i=1}^{n} p_{F_{i}}}{\left(p_{O_{2}}\right)^{2}} \\
\sigma_{\varphi} & =\frac{\partial \varphi}{\partial p_{F_{1}}} \cdot \sigma_{p_{F_{1}}}+\frac{\partial \varphi}{\partial p_{F_{2}}} \cdot \sigma_{p_{F_{2}}}+\frac{\partial \varphi}{\partial p_{F_{3}}} \cdot \sigma_{p_{F_{3}}}+\cdots+\frac{\partial \varphi}{\partial p_{F_{n}}} \cdot \sigma_{p_{F_{n}}}+\left(-\frac{\sum_{i=1}^{n} p_{F_{i}}}{\left(p_{O_{2}}\right)^{2}}\right) \sigma_{p_{O_{2}}}
\end{aligned}
$$

If we assume that there is no correlation between measurements of $\sigma_{i} \sigma_{j}=0$

$$
\begin{aligned}
& \sigma_{\varphi}{ }^{2}=\left(\frac{\partial \varphi}{\partial p_{F_{1}}} \cdot \sigma_{p_{F_{1}}}\right)^{2}+\left(\frac{\partial \varphi}{\partial p_{F_{2}}} \cdot \sigma_{p_{F_{2}}}\right)^{2}+\left(\frac{\partial \varphi}{\partial p_{F_{3}}} \cdot \sigma_{p_{F_{3}}}\right)^{2}+\cdots+\left(\frac{\partial \varphi}{\partial p_{F_{n}}} \cdot \sigma_{p_{F_{n}}}\right)^{2}+\left(\left(-\frac{\sum_{i=1}^{n} p_{F_{i}}}{\left(p_{O_{2}}\right)^{2}}\right)_{p_{O_{2}}}\right)^{2} \\
& \sigma_{\varphi}=\sqrt{\left(\frac{1}{p_{O_{2}}} \cdot \sigma_{p_{F_{1}}}\right)^{2}+\left(\frac{1}{p_{O_{2}}} \cdot \sigma_{p_{F_{2}}}\right)^{2}+\left(\frac{1}{p_{O_{2}}} \cdot \sigma_{p_{F_{3}}}\right)^{2}+\cdots+\left(\frac{1}{p_{O_{2}}} \cdot \sigma_{p_{F_{n}}}\right)^{2}+\left(\left(-\frac{\sum_{i=1}^{n} p_{F_{i}}}{\left(p_{O_{2}}\right)^{2}}\right)_{{p_{O_{2}}}}\right)^{2}} \\
& \sigma_{\varphi}=\sqrt{\left(\frac{\sum_{i=1}^{n} \sigma_{F_{i}}{ }^{2}}{\left(p_{O_{2}}\right)^{2}}\right)+\left(\left(-\frac{\sum_{i=1}^{n} p_{F_{i}}}{\left(p_{O_{2}}\right)^{2}}\right) \sigma_{p_{O_{2}}}\right)^{2}}=\sqrt{\left(\frac{\sigma_{F_{1}}}{p_{o_{2}}}\right)^{2}+\left(\frac{\sigma_{F_{2}}}{p_{o_{2}}}\right)^{2}+\left(\left(-\frac{p_{F}}{p_{O_{2}}}\right)^{2} \sigma_{p_{O_{2}}}\right)^{2}}=\frac{c t e}{\left(p_{o_{2}}\right)^{2}} \sqrt{\left(p_{O_{2}}\right)^{2} \sigma_{F_{1}}^{2}+\left(p_{o_{2}}\right)^{2} \sigma_{F_{2}}^{2}+p_{F}^{2} \sigma_{p_{O_{2}}}{ }^{2}}
\end{aligned}
$$




\section{Supporting Information}

Based on the above analysis, the average uncertainty of the equivalence ratios is $\overline{\sigma_{\varphi}}=$ $\pm 5 \times 10^{-3}$.

\subsection{Diluent concentration}

For determining the uncertainty of diluent concentration in the studied mixtures the following formulations are presented:

$$
\begin{aligned}
& {[D]=\frac{p_{i}}{R T_{i}}} \\
& \sigma_{[D]}=\frac{\partial[D]}{\partial p_{i}} \sigma_{p_{i}} \\
& \frac{\partial[D]}{\partial p_{i}}=\frac{1}{R T_{i}}
\end{aligned}
$$

Because, in the study, all mixtures have been prepared under $303 \mathrm{~K}$, so the Eq. (6) would be as follows:

$$
\frac{\partial[D]}{\partial P_{i}}=3.96961 \times 10^{-4}
$$

Therefore, the worst uncertainty in diluent concentration in the studied mixtures is related to cases with $90 \%$ diluent in a mixture with total pressure of 4000 Torr which yields $\sigma_{[D]}=$ $\pm 1.05848 \frac{\mathrm{mol}}{\mathrm{m}^{3}}= \pm 1.05848 \times 10^{-5} \frac{\mathrm{mol}}{10^{5} \cdot \mathrm{m}^{3}} \approx \pm 0.56 \%[D]$

For calculating the uncertainty in concentration of each species under the compressed conditions, the following formulations are presented:

$$
\begin{aligned}
& {[D]=\frac{p_{c,[D]}}{R T_{c}}} \\
& \sigma_{[D]}=\sqrt{\left(\frac{\partial[D]}{\partial p_{c,[D]}} \sigma_{\left.p_{c,[D]}\right)^{2}+\left(\frac{\partial[D]}{\partial T_{c}} \sigma_{T_{C}}\right)^{2}}\right.} \\
& \sigma_{[D]}=\sqrt{\left(\frac{1}{R T_{c}} \sigma_{p_{c,[D]}}\right)^{2}+\left(-\frac{p_{c,[D]}}{R T_{c}^{2}} \sigma_{T_{c}}\right)^{2}}=\frac{1}{8.314 \times T_{c}^{2}} \sqrt{\left(T_{c} \sigma_{p_{c,[D]}}\right)^{2}+\left(p_{c,[D]} \sigma_{T_{c}}\right)^{2}}
\end{aligned}
$$

\subsection{IDTs in Shock tube}

If the following equations, for determining total uncertainty of the measured ignition delay times in NUIG-L/HPST, it is assumed:

$$
p_{c}=p\left(p_{1}, V_{S}, \varphi, T_{1}\right) ; T_{c}=T\left(T_{1}, V_{S}, \varphi\right)
$$




\section{Supporting Information}

As shown by Petersen et al. ${ }^{15}$, one could assume that:

$$
\begin{aligned}
& T_{C}=\frac{T_{1}\left[2\left(\gamma_{1}-1\right) M^{2}+\left(3-\gamma_{1}\right)\right]\left[\left(3 \gamma_{1}-1\right) M^{2}-2\left(\gamma_{1}-1\right)\right]}{\left(\gamma_{1}+1\right)^{2} M^{2}} ; M=\frac{V_{S}}{\sqrt{\gamma_{1} R T_{1}}} ; V_{S}=\frac{\Delta z}{\Delta t} \\
& \sigma_{V_{S}}=\sqrt{\left(\frac{\partial V_{S}}{\partial(\Delta z)} \sigma_{\Delta z}\right)^{2}+\left(\frac{\partial V_{S}}{\partial(\Delta t)} \sigma_{\Delta t}\right)^{2}}=\sqrt{\left(\frac{1}{\Delta t} \sigma_{\Delta z}\right)^{2}+\left(-\frac{\Delta z}{(\Delta t)^{2}} \sigma_{\Delta t}\right)^{2}} \\
& \sigma_{T_{C}}=\sigma_{T}=\frac{\partial T_{c}}{\partial M} \sigma_{M}=\left(T_{1}\left[\left(\frac{4\left(3 \gamma_{1}^{2}-4 \gamma_{1}+1\right)}{\left(\gamma_{1}+1\right)^{2}}\right) M+\left(\frac{4\left(\gamma_{1}-1\right)\left(3-\gamma_{1}\right)}{\left(\gamma_{1}+1\right)^{2}}\right) M^{-3}\right]\right) \frac{\sigma_{V_{S}}}{\sqrt{\gamma_{1} R T_{1}}} \\
& p_{C}=\frac{P_{1}\left[2 \gamma_{1} M^{2}-\left(\gamma_{1}-1\right)\right]\left[\left(3 \gamma_{1}-1\right) M^{2}-2\left(\gamma_{1}-1\right)\right]}{2\left(\gamma_{1}+1\right)+M^{2}\left(\gamma_{1}^{2}-1\right)} ; \sigma_{p_{c}}=\sigma_{p}=\frac{\partial p_{c}}{\partial M} \sigma_{M}= \\
& \left(p_{1}\left[\frac{20 M^{5} \gamma^{4}-4 M^{5} \gamma^{3}+48 M^{3} \gamma^{3}+32 M^{3} \gamma^{2}-12 M^{5} \gamma^{2}+4 M^{5} \gamma-16 M^{3} \gamma-20 M \gamma^{3}+4 M \gamma^{2}+}{\left(M^{2} \gamma^{2}-M^{2}+2 \gamma+2\right)^{2}}\right]\right) \frac{\sigma_{V_{S}}}{\sqrt{\gamma_{1} R T_{1}}}
\end{aligned}
$$

Here, it was supposed that the effect of changing in equivalence ratio on $\gamma$ is negligible. Here, it is supposed that the maximum $\sigma_{\Delta t}$ which is related to TiePie Handyscope HS4 Oscilloscope is $\pm 1 \mu \mathrm{s}$, and, $\sigma_{\Delta z}$ is $\pm 0.001 \mathrm{~m}$. Now, if it could be assumed the defined ignition delay time (IDT) could be correlated as follows, then:

$$
\begin{aligned}
& \tau_{I D T} \cong A \cdot \exp \left(\frac{B}{T}\right) p^{m} \varphi^{n}[D]^{q} \rightarrow \partial \tau=\frac{\partial \tau}{\partial T} \cdot \partial T+\frac{\partial \tau}{\partial p} \cdot \partial p+\frac{\partial \tau}{\partial \varphi} \cdot \partial \varphi+\frac{\partial \tau}{\partial[D]} \cdot \partial[D] \rightarrow\left(\sigma_{\tau}\right)^{2}=\left(\frac{\partial \tau}{\partial T} \cdot \partial T\right)^{2}+\left(\frac{\partial \tau}{\partial p} \cdot\right. \\
& \partial p)^{2}+\left(\frac{\partial \tau}{\partial \varphi} \cdot \partial \varphi\right)^{2}+\left(\frac{\partial \tau}{\partial[D]} \cdot \partial[D]\right)^{2}+2\left(\frac{\partial \tau}{\partial T} \cdot \frac{\partial \tau}{\partial p} \cdot \partial T \partial p\right)+2\left(\frac{\partial \tau}{\partial T} \cdot \frac{\partial \tau}{\partial \varphi} \cdot \partial T \partial \varphi\right)+2\left(\frac{\partial \tau}{\partial \varphi} \cdot \frac{\partial \tau}{\partial p} \cdot \partial \varphi \partial p\right)+2\left(\frac{\partial \tau}{\partial T}\right. \\
& \left.\frac{\partial \tau}{\partial[D]} \cdot \partial T \partial[D]\right)+2\left(\frac{\partial \tau}{\partial p} \cdot \frac{\partial \tau}{\partial[D]} \cdot \partial p \partial[D]\right)+2\left(\frac{\partial \tau}{\partial \varphi} \cdot \frac{\partial \tau}{\partial[D]} \cdot \partial \varphi \partial[D]\right)
\end{aligned}
$$

Now, one assumes that there is no correlation between measurements of $(p, T$, and $\varphi$ ), so the above equation would be followed by:

$$
\begin{aligned}
& \left(\sigma_{\tau, i}\right)^{2}=\left(\frac{\partial \tau}{\partial T} \cdot \partial T\right)^{2}+\left(\frac{\partial \tau}{\partial p} \cdot \partial p\right)^{2}+\left(\frac{\partial \tau}{\partial \varphi} \cdot \partial \varphi\right)^{2}+\left(\frac{\partial \tau}{\partial[D]} \cdot \partial[D]\right)^{2}+2(\underbrace{\frac{\partial \tau}{\partial T} \cdot \frac{\partial \tau}{\partial p} \cdot \partial T \partial p}_{=0})+2 \underbrace{\left.\frac{\partial \tau}{\partial T} \cdot \frac{\partial \tau}{\partial \varphi} \cdot \partial T \partial \varphi\right)}_{=0}+2(\underbrace{\frac{\partial \tau}{\partial \varphi} \cdot \frac{\partial \tau}{\partial p} \cdot \partial \varphi \partial p}_{=0})+ \\
& 2(\underbrace{\frac{\partial \tau}{\partial T} \cdot \frac{\partial \tau}{\partial[D]} \cdot \partial T \partial[D]}_{\neq 0})+2(\underbrace{\frac{\partial \tau}{\partial p} \cdot \frac{\partial \tau}{\partial[D]} \cdot \partial p \partial[D]}_{\neq 0})+2 \underbrace{\left(\frac{\partial \tau}{\partial \varphi} \cdot \frac{\partial \tau}{\partial[D]} \cdot \partial \varphi \partial[D]\right)}_{=0}
\end{aligned}
$$

One could re-write the above equation as follows:

$$
\begin{aligned}
& \left(\sigma_{\tau, i}\right)^{2}=\left(\frac{\partial \tau}{\partial T} \cdot \sigma_{T}\right)^{2}+\left(\frac{\partial \tau}{\partial p} \cdot \sigma_{p}\right)^{2}+\left(\frac{\partial \tau}{\partial \varphi} \cdot \sigma_{\varphi}\right)^{2}+\left(\frac{\partial \tau}{\partial[D]} \cdot \sigma_{[D]}\right)^{2}+2\left(\frac{\partial \tau}{\partial T} \cdot \frac{\partial \tau}{\partial[D]} \cdot \sigma_{T} \sigma_{[D]}\right)+2\left(\frac{\partial \tau}{\partial p} \cdot \frac{\partial \tau}{\partial[D]} \cdot \sigma_{p} \sigma_{[D]}\right) \\
& \frac{\partial \tau}{\partial T}=A \cdot\left(-\frac{B}{T^{2}} \cdot \exp \left(\frac{B}{T}\right) p^{m} \varphi^{n}[D]^{q}\right) \\
& \frac{\partial \tau}{\partial P}=A \cdot\left(m \cdot \exp \left(\frac{B}{T}\right) p^{m-1} \varphi^{n}[D]^{q}\right) \\
& \frac{\partial \tau}{\partial \varphi}=A \cdot\left(n \cdot \exp \left(\frac{B}{T}\right) p^{m} \varphi^{n-1}[D]^{q}\right)
\end{aligned}
$$




\section{Supporting Information}

$$
\begin{aligned}
& \frac{\partial \tau}{\partial[D]}=A \cdot\left(q \cdot \exp \left(\frac{B}{T}\right) p^{m} \varphi^{n}[D]^{q-1}\right) \\
& \left(\sigma_{\tau, i}\right)^{2}=A^{2} \cdot\left(\left(-\frac{B}{T^{2}} \cdot \exp \left(\frac{B}{T}\right) p^{m} \varphi^{n}[D]^{q}\right) \cdot \sigma_{T}\right)^{2}+A^{2} \cdot\left(\left(m \cdot \exp \left(\frac{B}{T}\right) p^{m-1} \varphi^{n}[D]^{q}\right) \cdot \sigma_{p}\right)^{2}+A^{2} \cdot((n \cdot \\
& \left.\left.\exp \left(\frac{B}{T}\right) p^{m} \varphi^{n-1}[D]^{q}\right) \cdot \sigma_{\varphi}\right)^{2}+A^{2} \cdot\left(\left(q \cdot \exp \left(\frac{B}{T}\right) p^{m} \varphi^{n}[D]^{q-1}\right) \cdot \sigma_{[D]}\right)^{2}-2 A^{2}\left(\frac{B q}{T^{2}} .\right. \\
& \left.\exp \left(\frac{2 B}{T}\right) p^{2 m} \varphi^{2 n}[D]^{2 q-1}\right) \cdot \rho_{T[D]} \sigma_{T} \sigma_{[D]}+2 A^{2}\left(q m \cdot \exp \left(\frac{2 B}{T}\right) p^{2 m-1} \varphi^{2 n}[D]^{2 q-1}\right) \cdot \rho_{p[D]} \sigma_{p} \sigma_{[D]}
\end{aligned}
$$

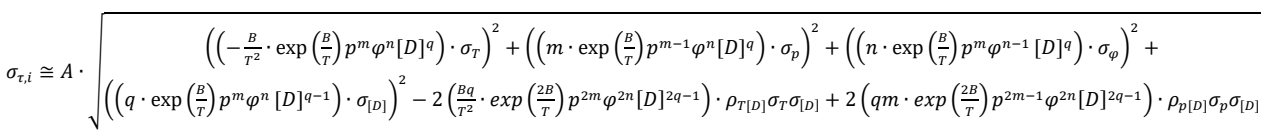

$$
\begin{aligned}
& \rho_{i j} \sigma_{i} \sigma_{j}=\sigma_{i j}=\sum_{i j} f(i, j)\left(x_{i}-\bar{x}_{l}\right)\left(x_{j}-\bar{x}_{J}\right)
\end{aligned}
$$

The uncertainty of the measured ignition delay time in shock tube could be acceptably estimated using the above equation. As seen in the above expression, the uncertainty parameter is changing by changing in the compressed temperature and pressure, and equivalence ratio, so that it is not a constant parameter during the experimental tests. Thus, it should be calculated specifically for each case. Therefore, regarding Eq. (22) and Table S9, specific uncertainty for each fuel according to its specific temperature, pressure, and equivalence ratio could be estimated.

Table S9. Correlation variables of the studied experimental datasets for different fuels in shock tubes.

\begin{tabular}{|c|c|c|c|c|c|c|c|c|}
\hline \multicolumn{7}{|c|}{$\tau_{I D T}=10^{A} \cdot \exp \left(\frac{B}{T}\right) P^{m} \varphi^{n}[D]^{q}$} \\
\hline \multirow{3}{*}{ Fuel } & $\mathrm{A}$ & $\mathrm{B}$ & $\mathrm{m}$ & $\mathrm{n}$ & $\mathrm{q}$ & $\mathrm{R}^{2}$ & Adj R $^{2}$ \\
\hline \multirow{3}{*}{$\mathrm{CH}_{4}+\mathrm{C}_{2} \mathrm{H}_{4}$} & $50 \%+50 \%$ & -8.189 & 14359.44 & -0.268 & 0.293 & 0.0 & 0.993 & 0.993 \\
\cline { 2 - 10 } & $70 \%+30 \%$ & -13.96 & -552.43 & -13.16 & 1.371 & 12.77 & 0.996 & 0.995 \\
\cline { 2 - 10 } & $90 \%+10 \%$ & -15.02 & -5834.91 & -16.69 & 1.625 & 16.36 & 0.997 & 0.997 \\
\hline \multirow{3}{*}{$\mathrm{C}_{2} \mathrm{H}_{6}+\mathrm{C}_{2} \mathrm{H}_{4}$} & $50 \%+50 \%$ & -12.14 & 7982.58 & -7.49 & -0.177 & 6.88 & 0.971 & 0.968 \\
\cline { 2 - 10 } & $70 \%+30 \%$ & -20.50 & -11369.34 & -21.85 & 3.283 & 22.48 & 0.992 & 0.992 \\
\cline { 2 - 9 } & $90 \%+10 \%$ & -15.27 & 1437.05 & -12.64 & 0.770 & 12.48 & 0.999 & 0.999 \\
\hline
\end{tabular}

\subsection{Rapid compression machine}

As shown in the previous section, the uncertainty of each experimental point is changing by varying temperature, pressure, and mixture composition, so that it is not identical during IDT measurement experimental tests. Therefore, for doing the uncertainty analysis for the studied RCM regimes, the same procedure performed for shock-tube is followed and relevant correlations between parameters and IDTs 


\section{Supporting Information}

have been evaluated as shown in Table S10. As already mentioned by Weber et al ${ }^{16}$, using Monte Carlo analysis or independent parameters methodology doesn't led to significant change in the calculated uncertainties. Therefore, like the performed uncertainty analysis for NUIG-HPST, it is supposed that there is no correlation between $p_{\mathrm{C}}, T_{\mathrm{C}}$ and $\varphi$ which can affect measured ignition delay time in the rapid compression machine. However, the correlation between $[\mathrm{D}]$ and $p_{\mathrm{C}}, T_{\mathrm{C}}$ is taken in to account according to Eq. (23). In this regard, the effect of temperature on the measured ignition delay time has been correlated through fitting an exponential equation to the experimental IDT data, and then the individual effect of pressure on the measured ignition delay time has been estimated using the applied approach by Weber et al ${ }^{16}$. Also, the effect of each individual parameter such as equivalence ratio (0.5-2.0) and dilution (75\%-90\%) on the simulated ignition delay times has been correlated using fitted equations to the experimentally measured ignition delay times. Therefore, the following formulations could be proposed to estimate available uncertainties in the measured independent parameters and consequently the measured ignition delay times:

$\frac{\partial T_{\mathrm{C}}}{\partial P_{\mathrm{C}}}=\frac{W\left(\frac{b}{a} \exp \left[\frac{b T_{0}}{a}\right] T_{0}\left[\frac{P_{\mathrm{C}}}{P_{0}}\right]^{\frac{1}{a}}\right)}{b P_{\mathrm{C}}\left(W\left(\frac{b}{a} \exp \left[\frac{b T_{0}}{a}\right] T_{0}\left[\frac{P_{\mathrm{C}}}{P_{0}}\right]^{\frac{1}{a}}\right)+1\right)}$

where, $\mathrm{W}, \mathrm{T}_{0}$, and $\mathrm{P}_{0}$ are Lambert's $\mathrm{W}$ function, initial temperature, and initial pressure in the reaction chamber, respectively. In Eq. (24), "a", "b", and $\frac{\partial T_{C}}{\partial P_{C}}$ were calculated using a Python code developed by Weber et al ${ }^{16}$.

$\frac{\partial \tau_{I D T}}{\partial P_{\mathrm{C}}}=\frac{\partial \tau_{I D T}}{\partial T_{\mathrm{C}}} \cdot \frac{\partial T_{\mathrm{C}}}{\partial P_{\mathrm{C}}}=\frac{\partial \tau_{I D T}}{\partial T_{\mathrm{C}}}($ from Table S10) $) \frac{W\left(\frac{b}{a} \exp \left[\frac{b T_{0}}{a}\right] T_{0}\left[\frac{P_{\mathrm{C}}}{P_{0}}\right]^{\frac{1}{a}}\right)}{b P_{\mathrm{C}}\left(W\left(\frac{b}{a} \exp \left[\frac{b T_{0}}{a}\right] T_{0}\left[\frac{P_{\mathrm{C}}}{P_{0}}\right]^{\frac{1}{a}}\right)+1\right)}$

$\left(\sigma_{\tau, i}\right)^{2}=\left(\frac{\partial \tau}{\partial T} \cdot \sigma_{T}\right)^{2}+\left(\frac{\partial \tau}{\partial p} \cdot \sigma_{p}\right)^{2}+\left(\frac{\partial \tau}{\partial \varphi} \cdot \sigma_{\varphi}\right)^{2}+\left(\frac{\partial \tau}{\partial[D]} \cdot \sigma_{[D]}\right)^{2}+2\left(\frac{\partial \tau}{\partial T} \cdot \frac{\partial \tau}{\partial[D]} \cdot \sigma_{T} \sigma_{[D]}\right)+2\left(\frac{\partial \tau}{\partial p} \cdot \frac{\partial \tau}{\partial[D]}\right.$. $\left.\sigma_{p} \sigma_{[D]}\right)$

$\tau_{I D T}=f\left(T_{\mathrm{C}}, p_{\mathrm{C}}, \varphi,[D]\right) \rightarrow \sigma_{\tau_{I D T}}=$

$\sqrt{\left(\frac{\partial \tau_{I D T}}{\partial T_{\mathrm{C}}} \cdot \sigma_{T_{\mathrm{C}}}\right)^{2}+\left(\frac{\partial \tau_{I D T}}{\partial p_{\mathrm{C}}} \cdot \sigma_{p_{\mathrm{C}}}\right)^{2}+\left(\frac{\partial \tau_{I D T}}{\partial \varphi} \cdot \sigma_{\varphi}\right)^{2}+\left(\frac{\partial \tau_{I D T}}{\partial[D]} \cdot \sigma_{[D]}\right)^{2}+2\left(\frac{\partial \tau_{I D T}}{\partial T_{\mathrm{C}}} \cdot \frac{\partial \tau_{I D T}}{\partial[D]} \cdot \sigma_{T_{\mathrm{C}}} \sigma_{[D]}\right)+2\left(\frac{\partial \tau_{I D T}}{\partial p_{\mathrm{C}}} \cdot \frac{\partial \tau_{I D T}}{\partial[D]} \cdot \sigma_{p_{\mathrm{C}}} \sigma_{[D]}\right)}$

By substituting correlations from Table S10 and Eqs. (23) and (25) into Eq. (27), the uncertainty of the measured ignition delay times in RCM regime would be calculated based on a Python code developed by Weber et al ${ }^{16}$.

Table S10. Correlation variables of the studied experimental datasets for different fuels in RCMs. 


\section{Supporting Information}

\begin{tabular}{|c|c|c|c|c|c|c|c|}
\hline \multicolumn{7}{|c|}{$\tau_{I D T}=10^{A} \cdot \exp \left(\frac{B}{T}\right) \varphi^{n}[D]^{q}$} \\
\hline \multirow{3}{*}{ Fuel } & A & B & n & q & $\mathrm{R}^{2}$ & Adj $\mathrm{R}^{2}$ \\
\hline \multirow{3}{*}{$\mathrm{CH}_{4}+\mathrm{C}_{2} \mathrm{H}_{4}$} & $50 \%+50 \%$ & -33.82 & 16398.20 & -14.03 & 10.79 & 0.995 & 0.994 \\
\cline { 2 - 8 } & $70 \%+30 \%$ & -5.88 & 31697.98 & -3.11 & -4.22 & 0.996 & 0.996 \\
\cline { 2 - 9 } & $90 \%+10 \%$ & 204.42 & 126728.67 & -63.23 & -107.3 & 0.997 & 0.997 \\
\hline \multirow{3}{*}{$\mathrm{C}_{2} \mathrm{H}_{6}+\mathrm{C}_{2} \mathrm{H}_{4}$} & $70 \%+50 \%$ & 14.92 & 42743.02 & 15.25 & -15.40 & 0.998 & 0.998 \\
\cline { 2 - 8 } & $70 \%+30 \%$ & -118.99 & -8476.95 & -20.06 & 49.20 & 0.991 & 0.990 \\
\cline { 2 - 8 } & $90 \%+10 \%$ & 186.68 & 131240.51 & -60.44 & -101.1 & 0.975 & 0.971 \\
\hline
\end{tabular}

\section{Pressure profiles of the applied rapid compression machines (RCMs)}

The reactive and non-reactive pressure profiles of the applied rapid compression machines including NUIG-RCM and PCFC-RCM for the studied cases alongside the simulation profiles are shown in the following figures. Here, it should be noted that all the simulations were performed using NUIGMech0.9 mechanism, otherwise, it is mentioned in caption or legend of figures.

$\mathrm{P5C2} @ 65^{\circ} \mathrm{C}$

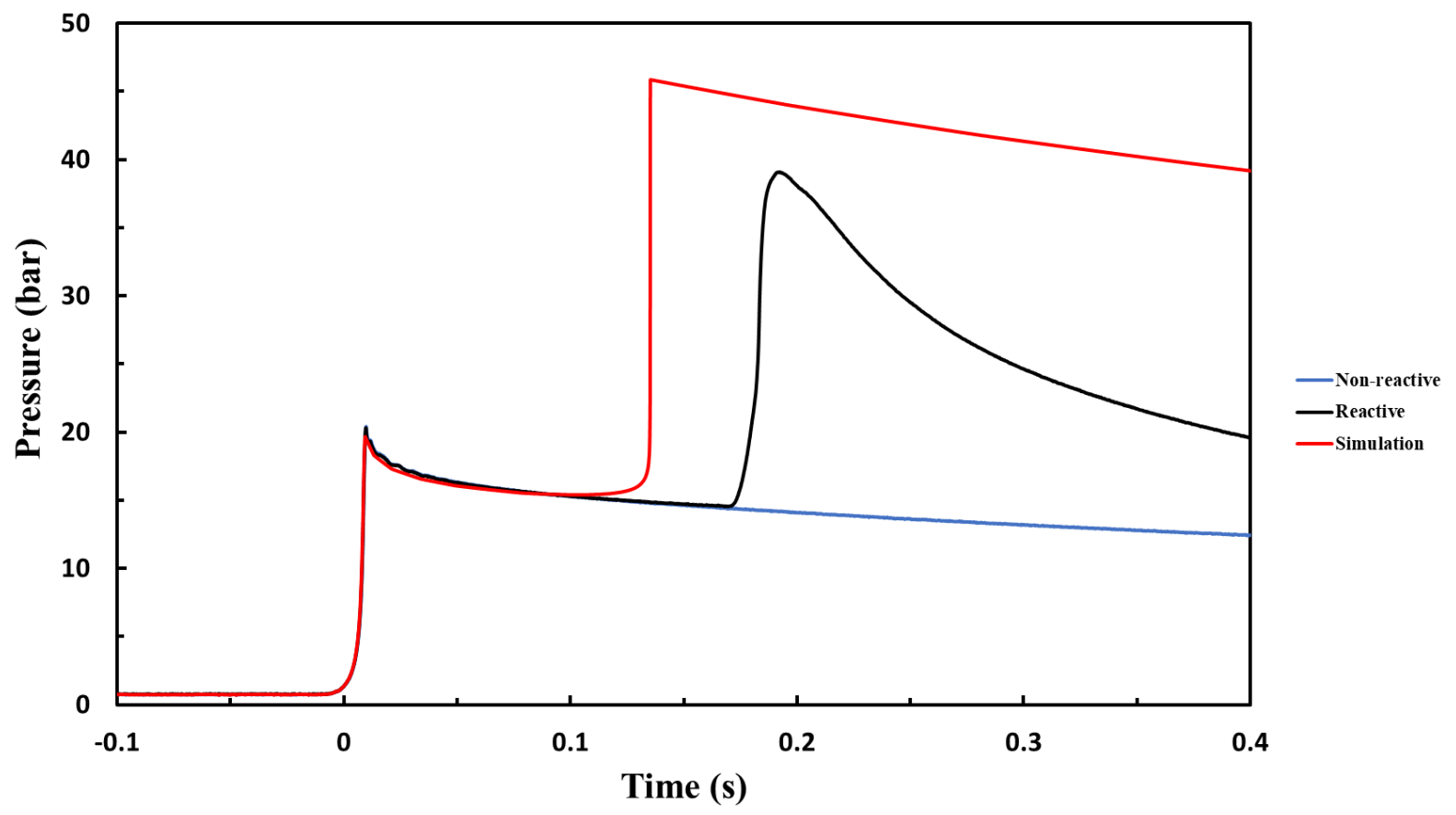

Figure S3. Pressure history of tested reactive and non-reactive mixtures of $\mathrm{P} 5 \mathrm{C} 2$ case alongside the simulation's profile for initial temperature of $338 \mathrm{~K}$. 


\section{Supporting Information}

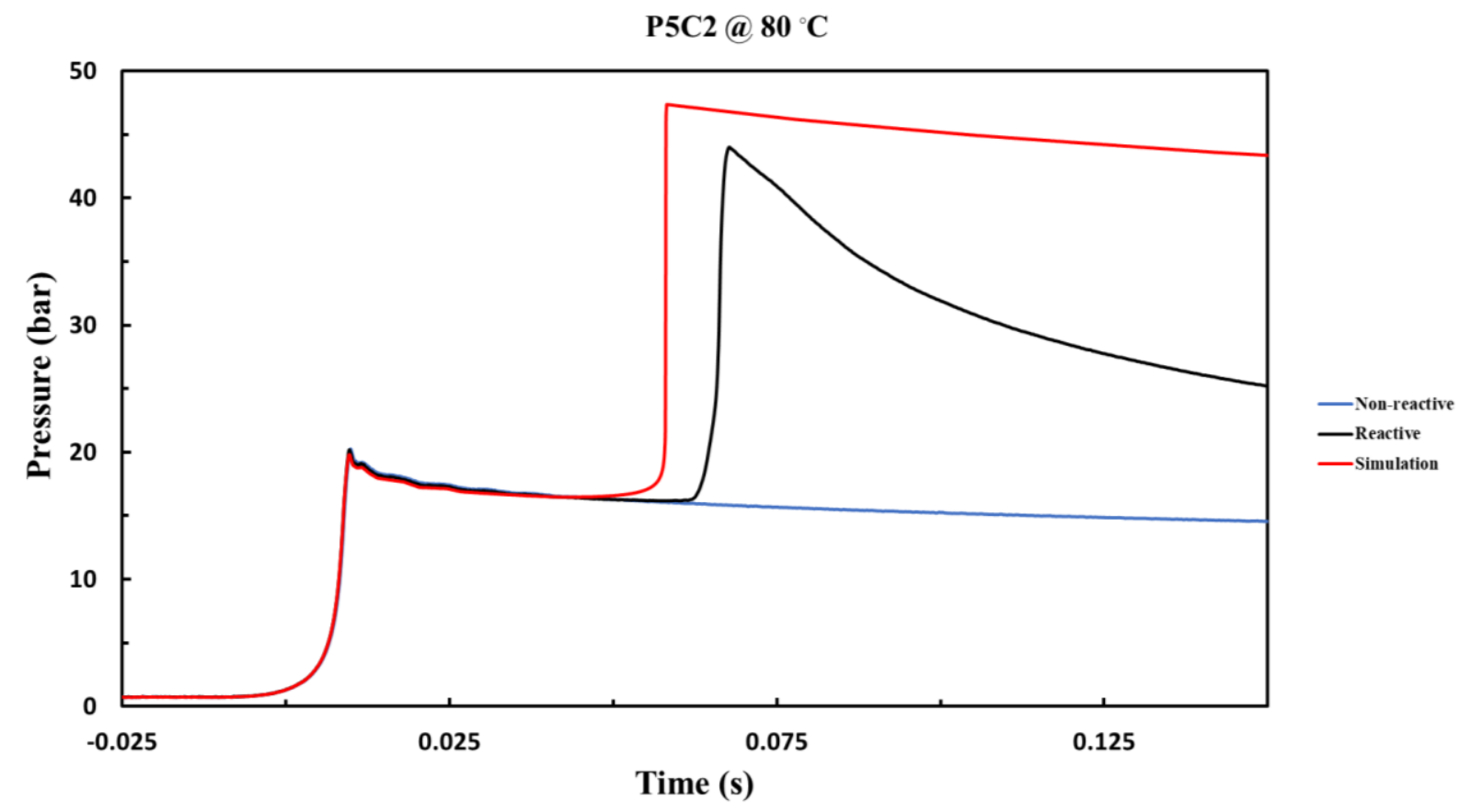

Figure S4. Pressure history of tested reactive and non-reactive mixtures of P5C2 case alongside the simulation's profile for initial temperature of $353 \mathrm{~K}$.

P5C2 @ $95{ }^{\circ} \mathrm{C}$

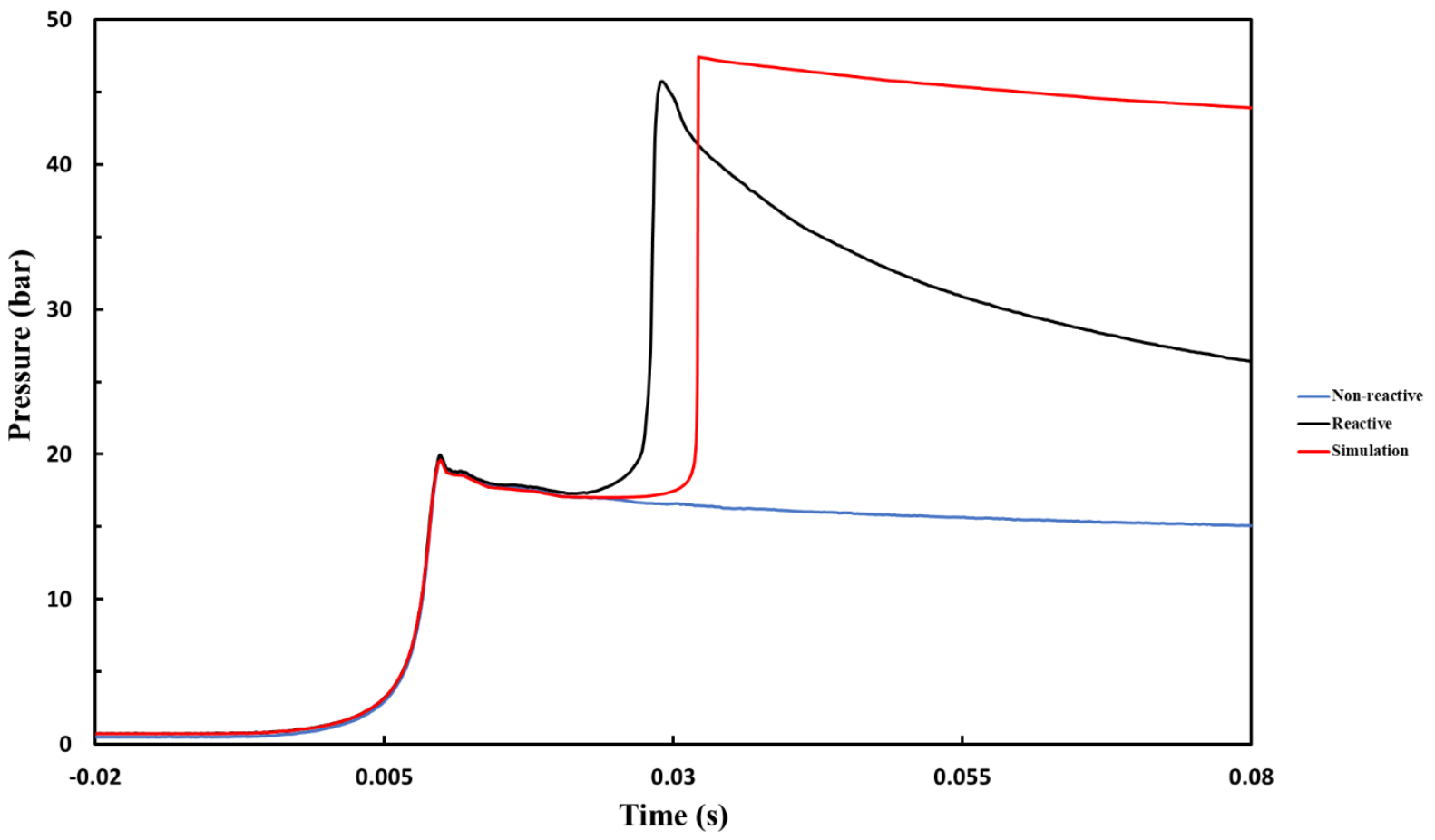

Figure S5. Pressure history of tested reactive and non-reactive mixtures of P5C2 case alongside the simulation's profile for initial temperature of $368 \mathrm{~K}$. 


\section{Supporting Information}

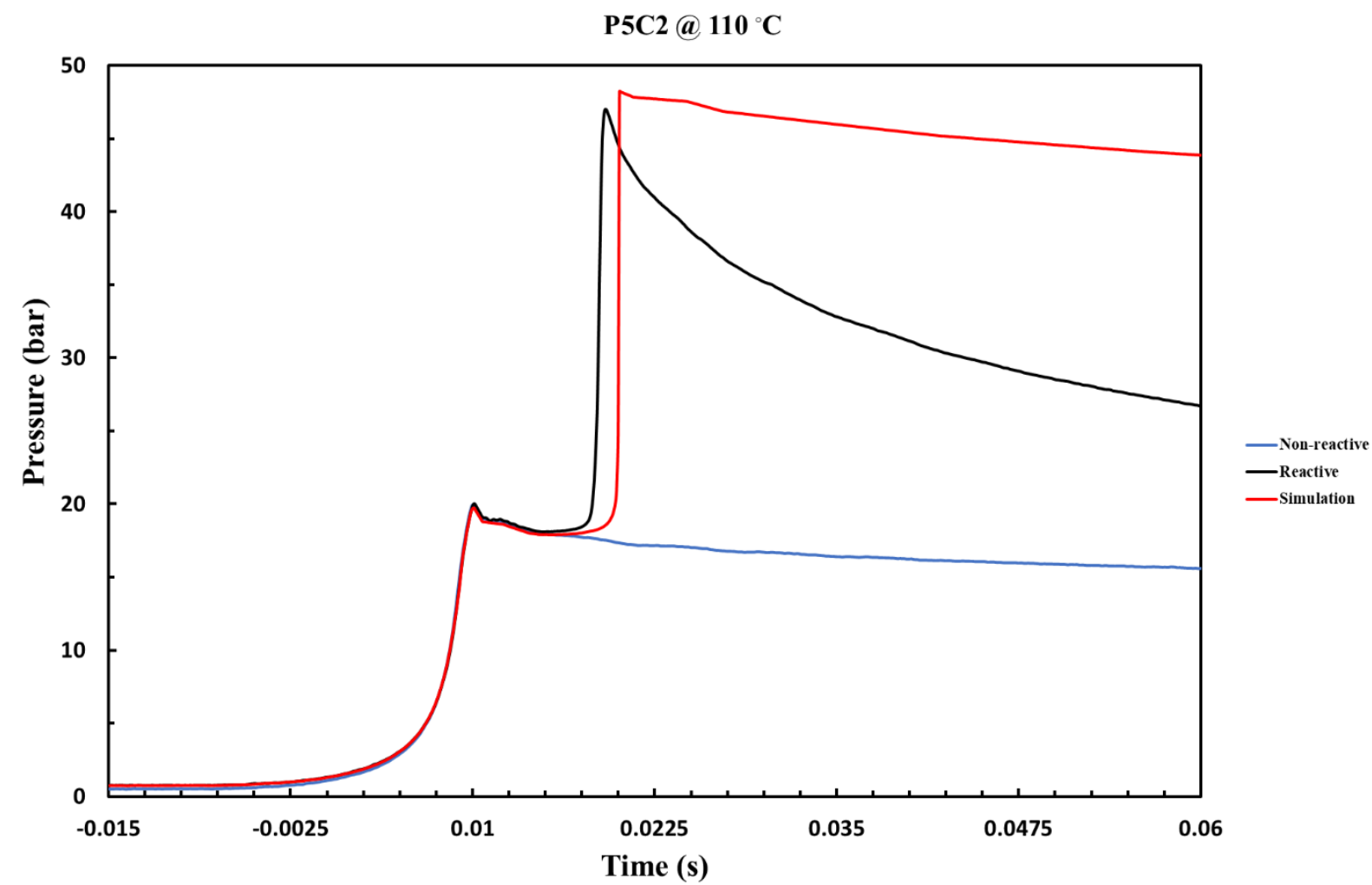

Figure S6. Pressure history of tested reactive and non-reactive mixtures of $\mathrm{P} 5 \mathrm{C} 2$ case alongside the simulation's profile for initial temperature of $383 \mathrm{~K}$.

P5C6@ $95{ }^{\circ} \mathrm{C}$

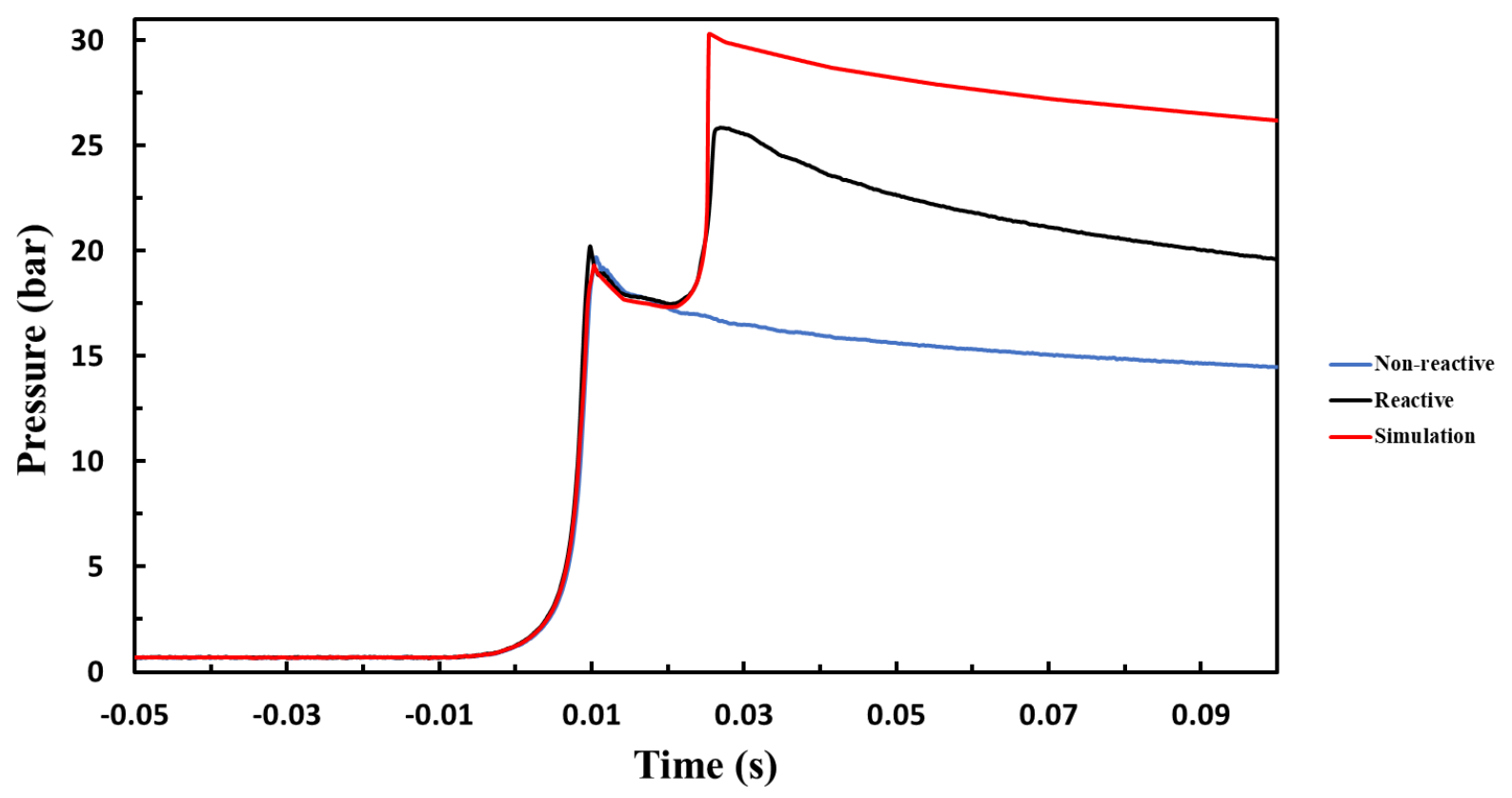

Figure S7. Pressure history of tested reactive and non-reactive mixtures of P5C6 case alongside the simulation's profile for initial temperature of $368 \mathrm{~K}$. 


\section{Supporting Information}

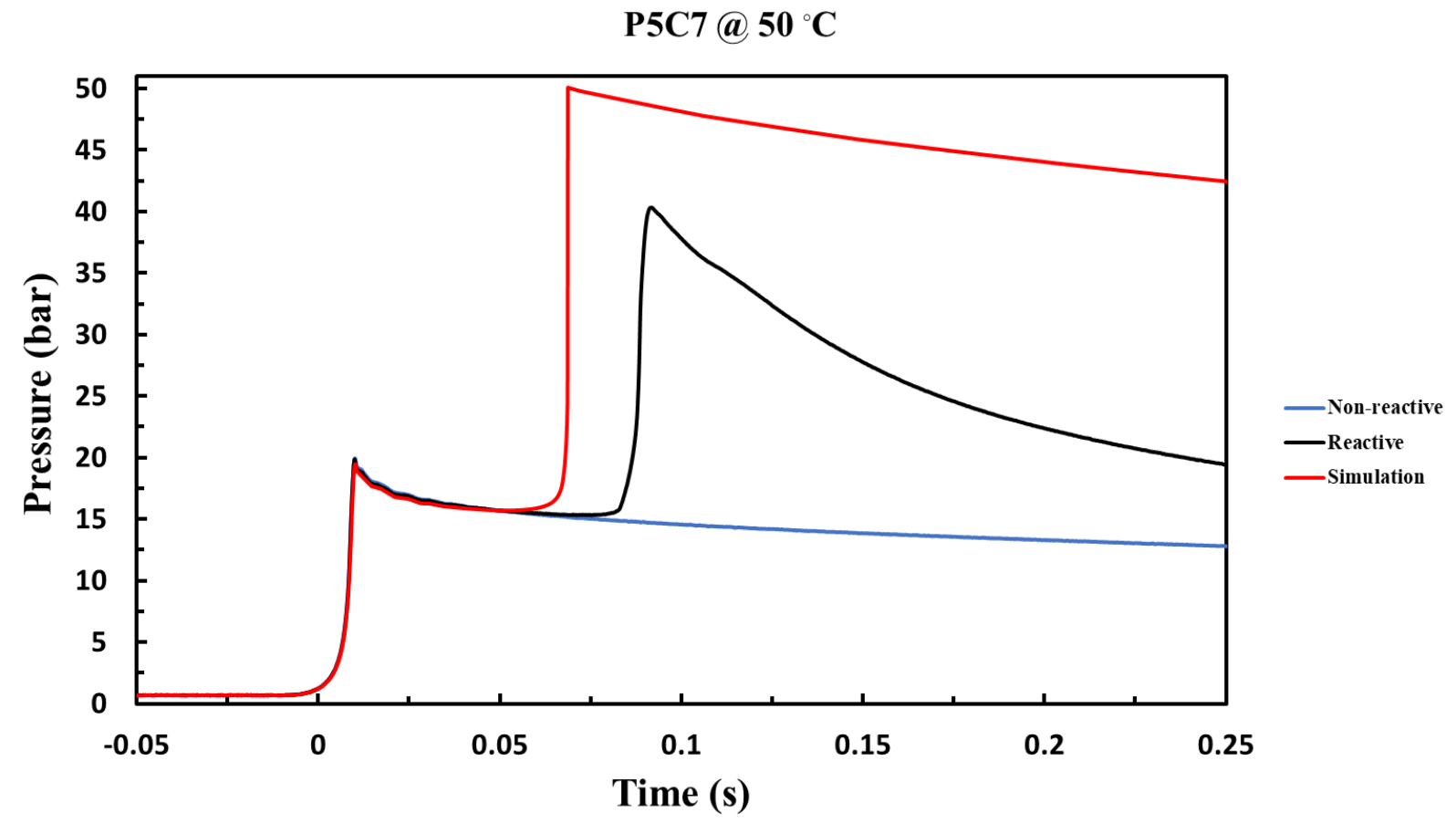

Figure S8. Pressure history of tested reactive and non-reactive mixtures of P5C7 case alongside the simulation's profile for initial temperature of $323 \mathrm{~K}$.

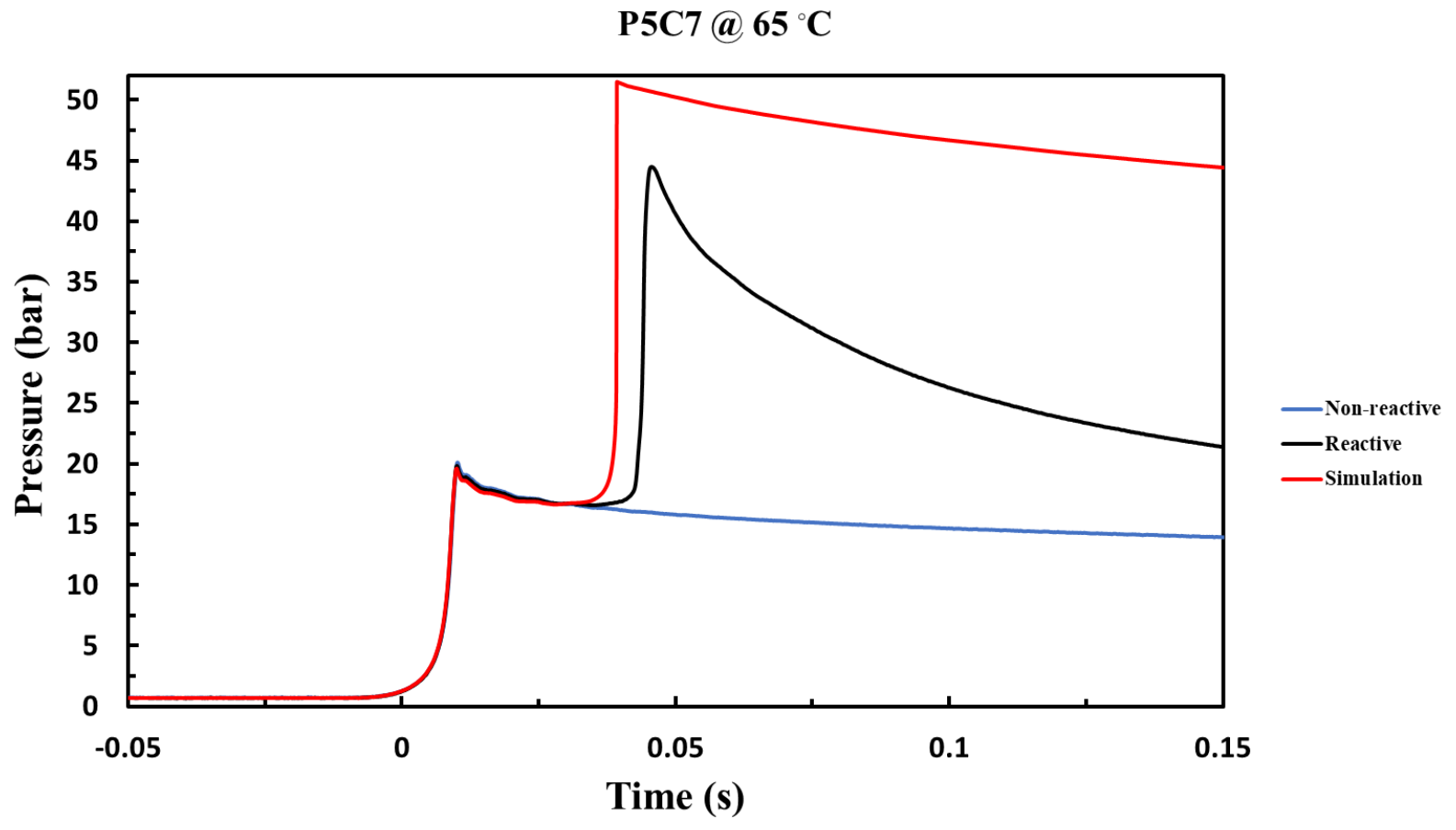

Figure S9. Pressure history of tested reactive and non-reactive mixtures of $\mathrm{P} 5 \mathrm{C} 7$ case alongside the simulation's profile for initial temperature of $338 \mathrm{~K}$. 


\section{Supporting Information}

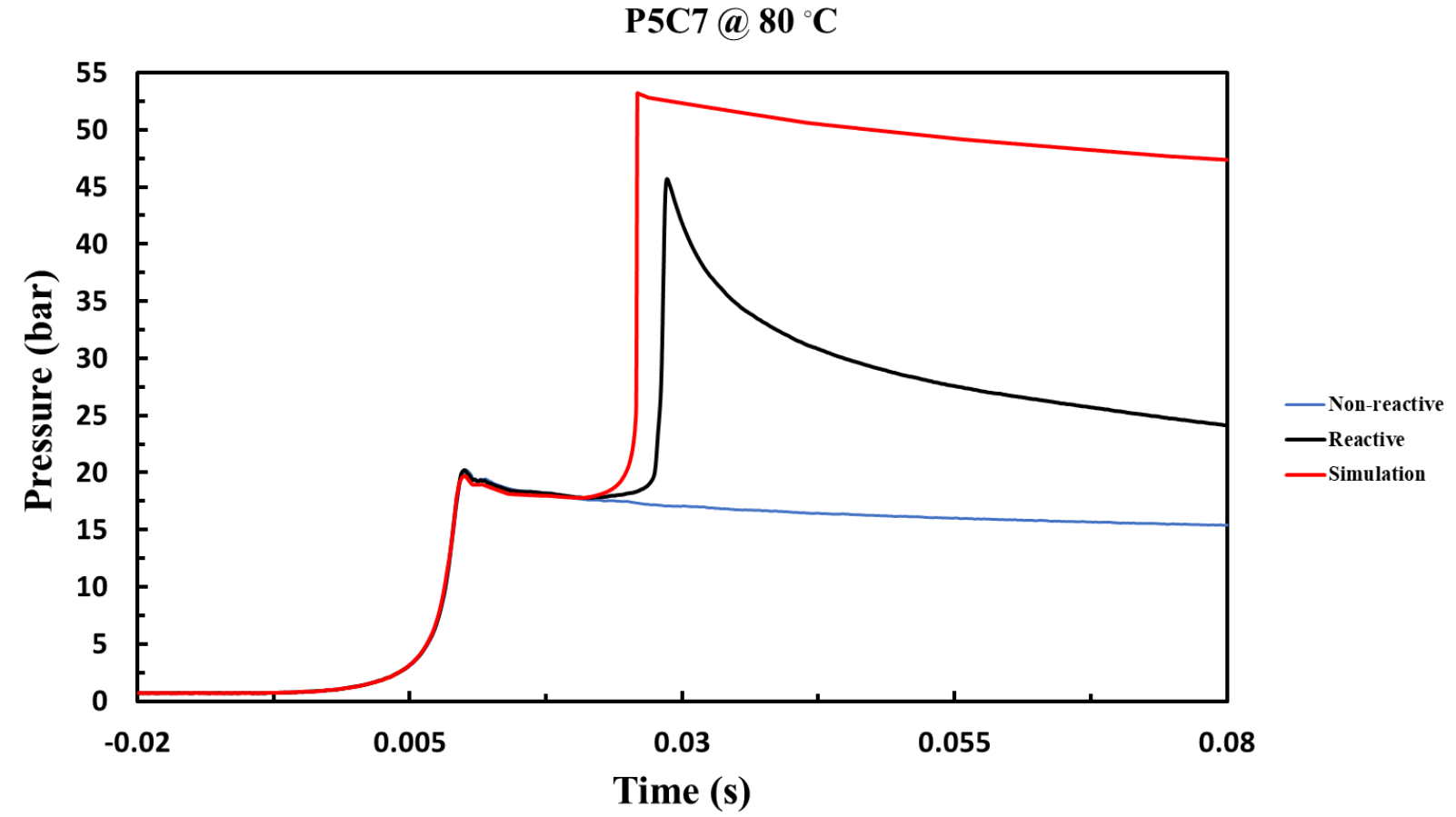

Figure S10. Pressure history of tested reactive and non-reactive mixtures of $\mathrm{P} 5 \mathrm{C} 7$ case alongside the simulation's profile for initial temperature of $353 \mathrm{~K}$.

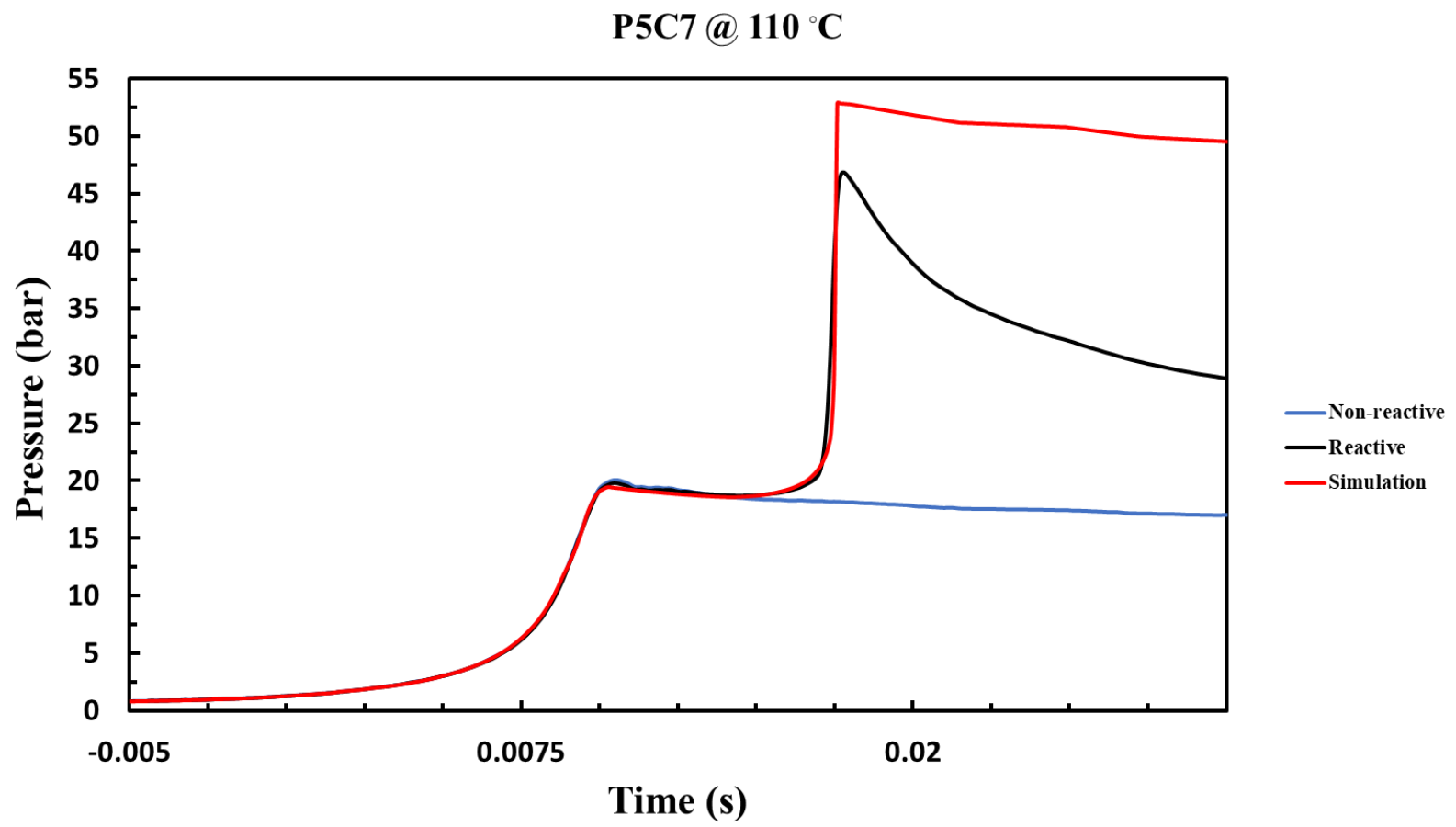

Figure S11. Pressure history of tested reactive and non-reactive mixtures of $\mathrm{P} 5 \mathrm{C} 7$ case alongside the simulation's profile for initial temperature of $383 \mathrm{~K}$. 


\section{Supporting Information}

P8C2@65 ${ }^{\circ} \mathrm{C}$

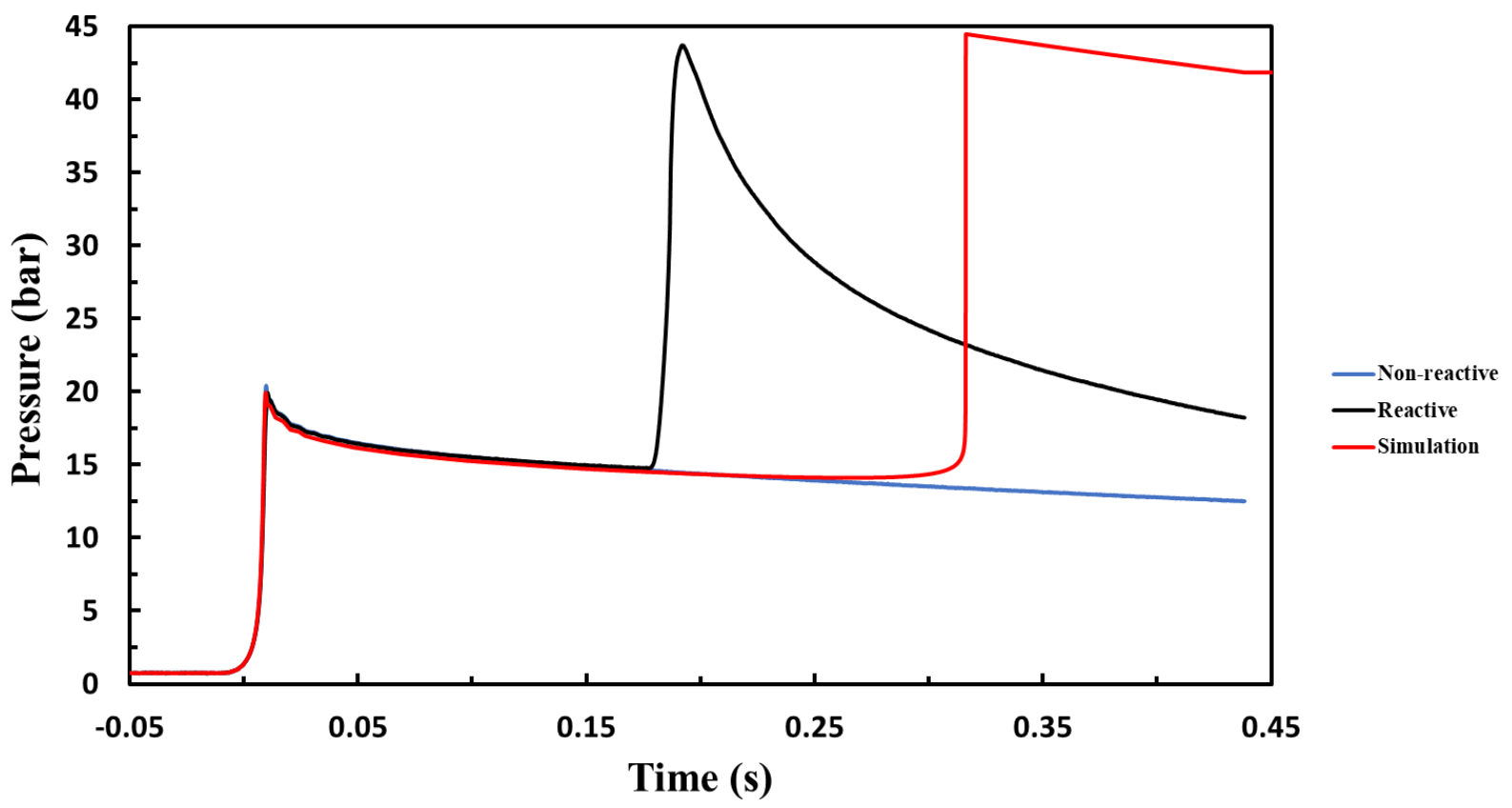

Figure S12. Pressure history of tested reactive and non-reactive mixtures of P8C2 case alongside the simulation's profile for initial temperature of $338 \mathrm{~K}$.

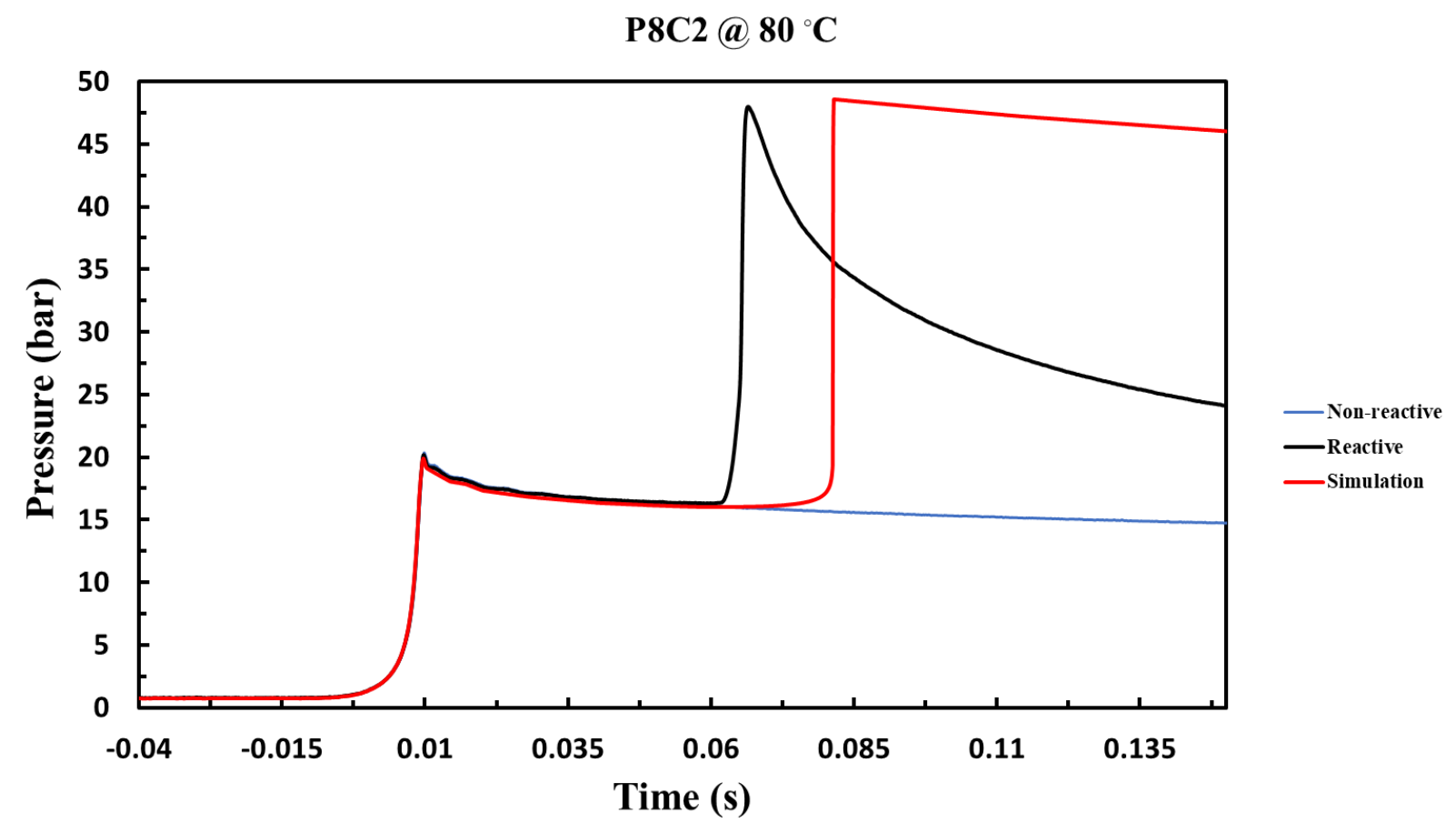

Figure S13. Pressure history of tested reactive and non-reactive mixtures of $\mathrm{P} 8 \mathrm{C} 2$ case alongside the simulation's profile for initial temperature of $353 \mathrm{~K}$. 


\section{Supporting Information}

P8C2@ $95{ }^{\circ} \mathrm{C}$

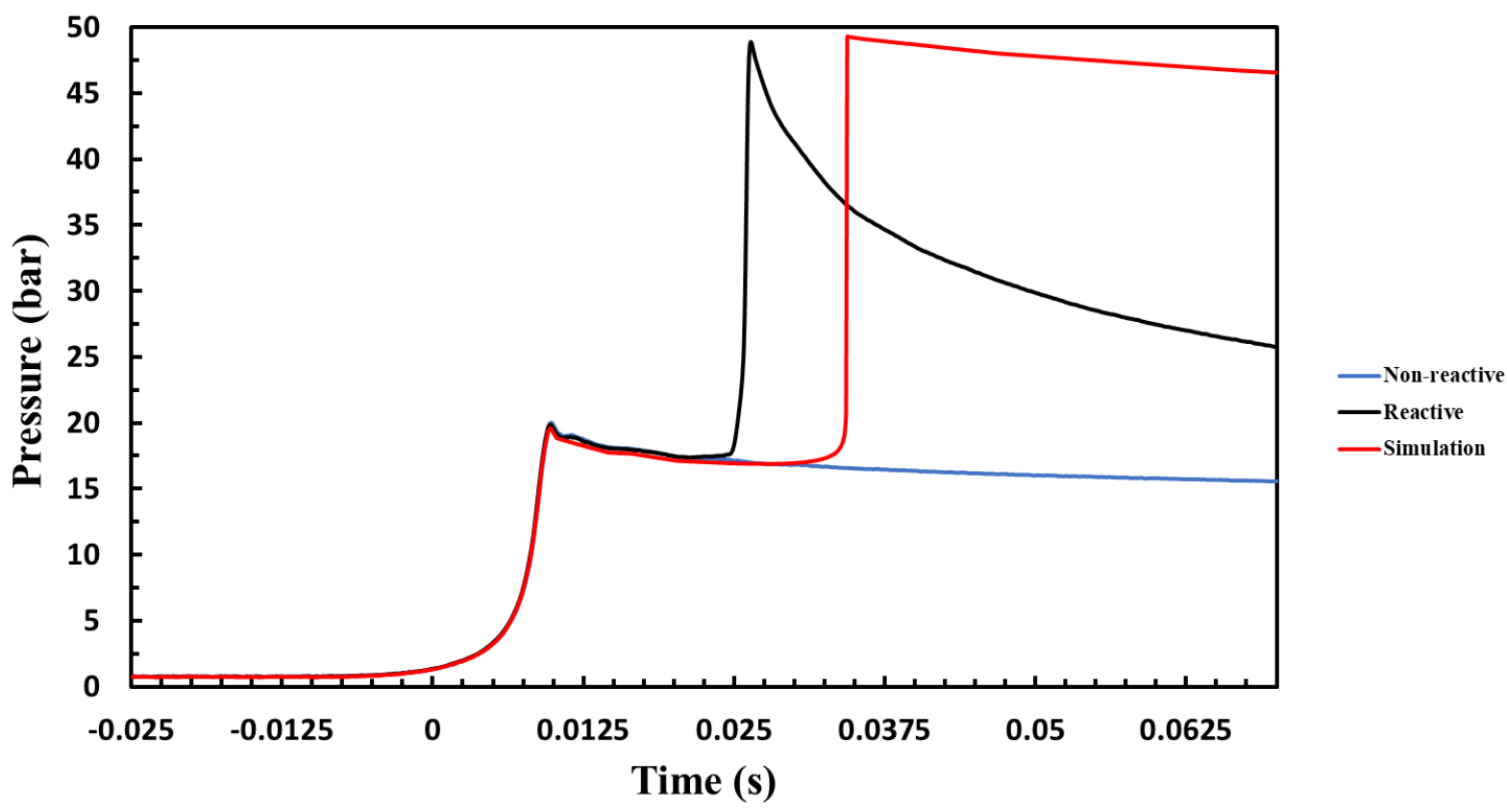

Figure S14. Pressure history of tested reactive and non-reactive mixtures of P8C2 case alongside the simulation's profile for initial temperature of $368 \mathrm{~K}$.

P8C2@ 105 C

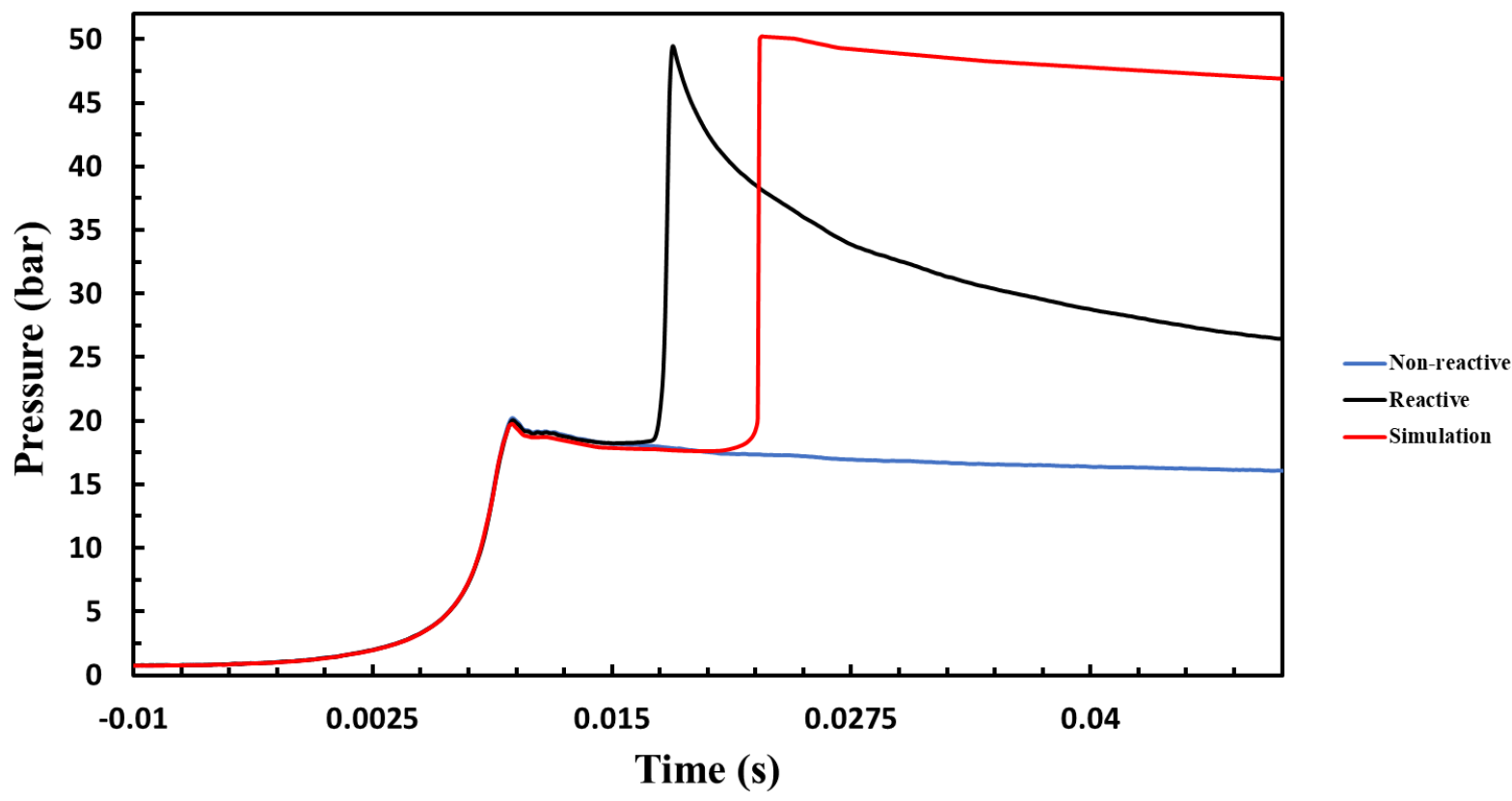

Figure S15. Pressure history of tested reactive and non-reactive mixtures of P8C2 case alongside the simulation's profile for initial temperature of $378 \mathrm{~K}$. 


\section{Supporting Information}

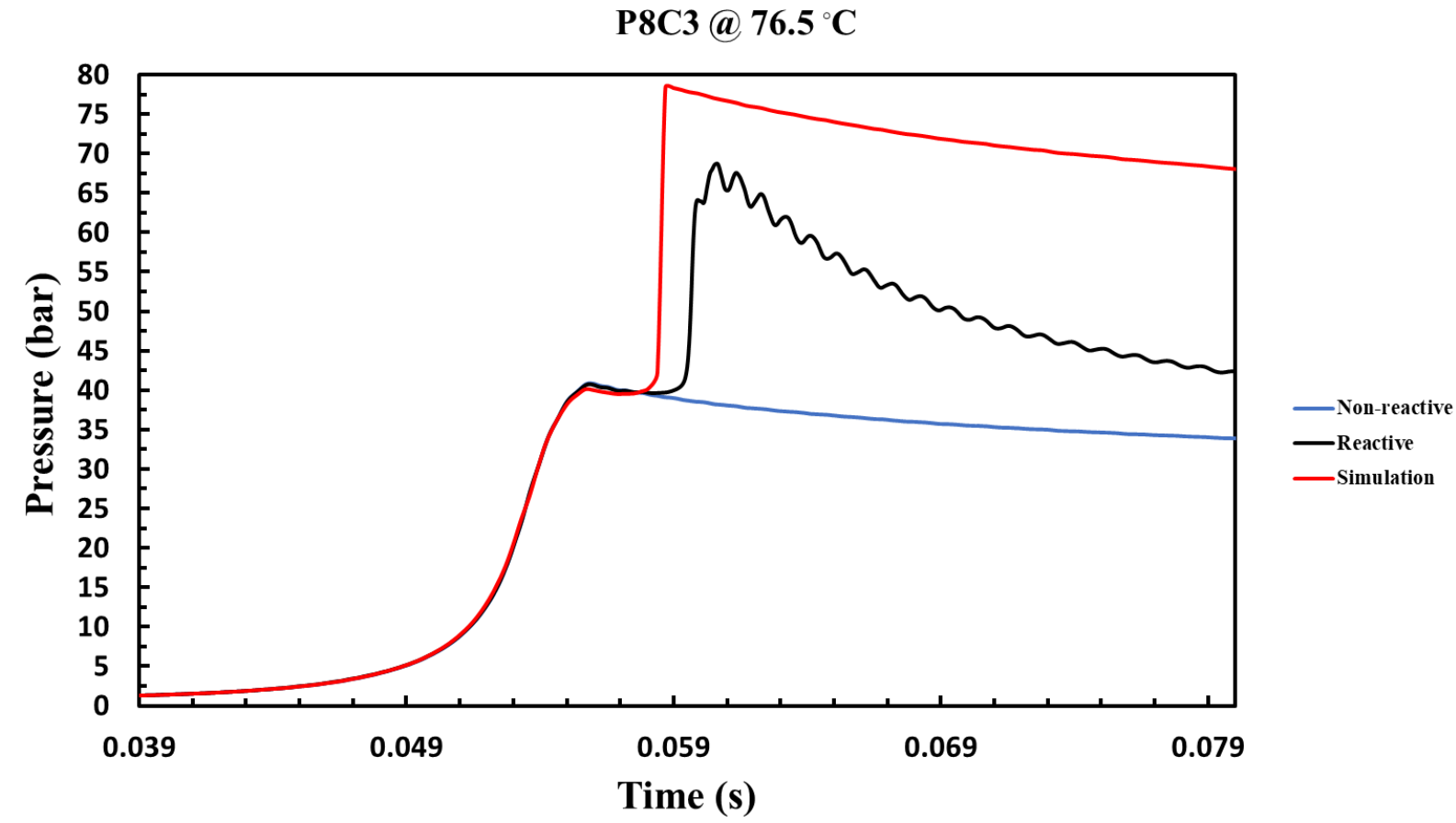

Figure S16. Pressure history of tested reactive and non-reactive mixtures of P8C 3 case alongside the simulation's profile for initial temperature of $349.5 \mathrm{~K}$.

$\operatorname{P8C3} @ 76.48{ }^{\circ} \mathrm{C}$

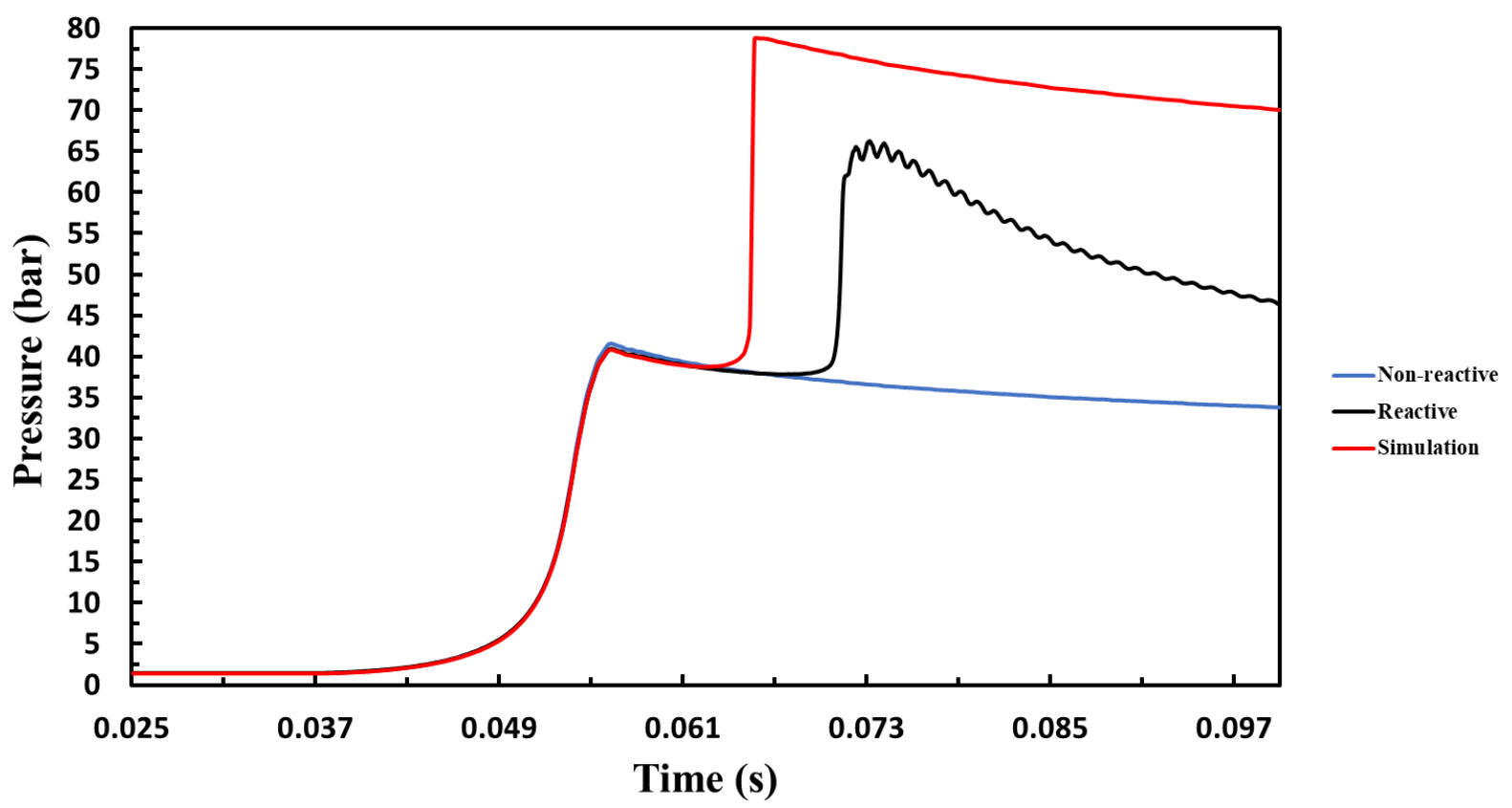

Figure S17. Pressure history of tested reactive and non-reactive mixtures of P8C3 case alongside the simulation's profile for initial temperature of $349.6 \mathrm{~K}$. 


\section{Supporting Information}

P8C4@ $7^{\circ} .67^{\circ} \mathrm{C}$

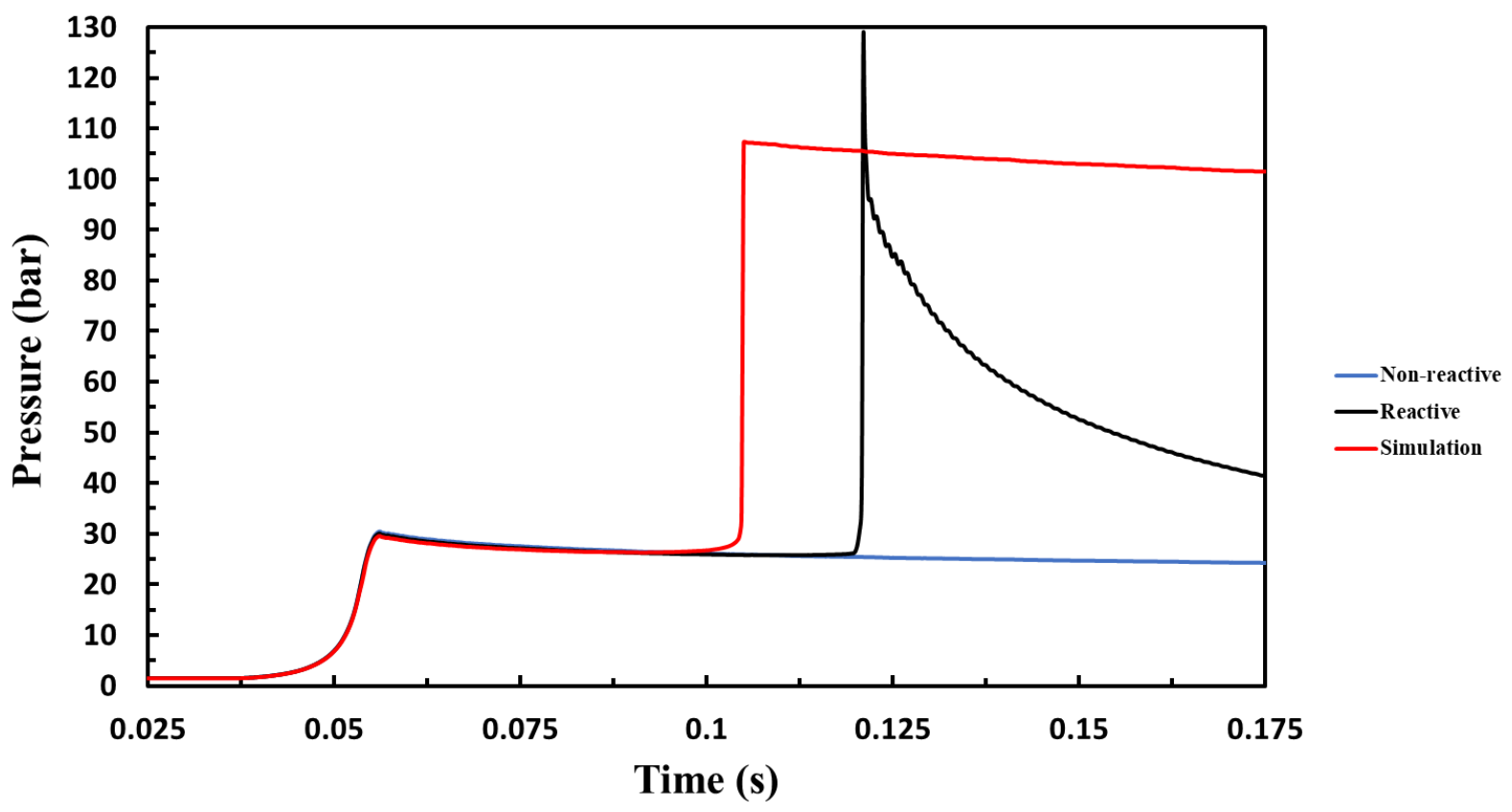

Figure S18. Pressure history of tested reactive and non-reactive mixtures of P8C4 case alongside the simulation's profile for initial temperature of $349.8 \mathrm{~K}$.

P8C4@ $76.55{ }^{\circ} \mathrm{C}$

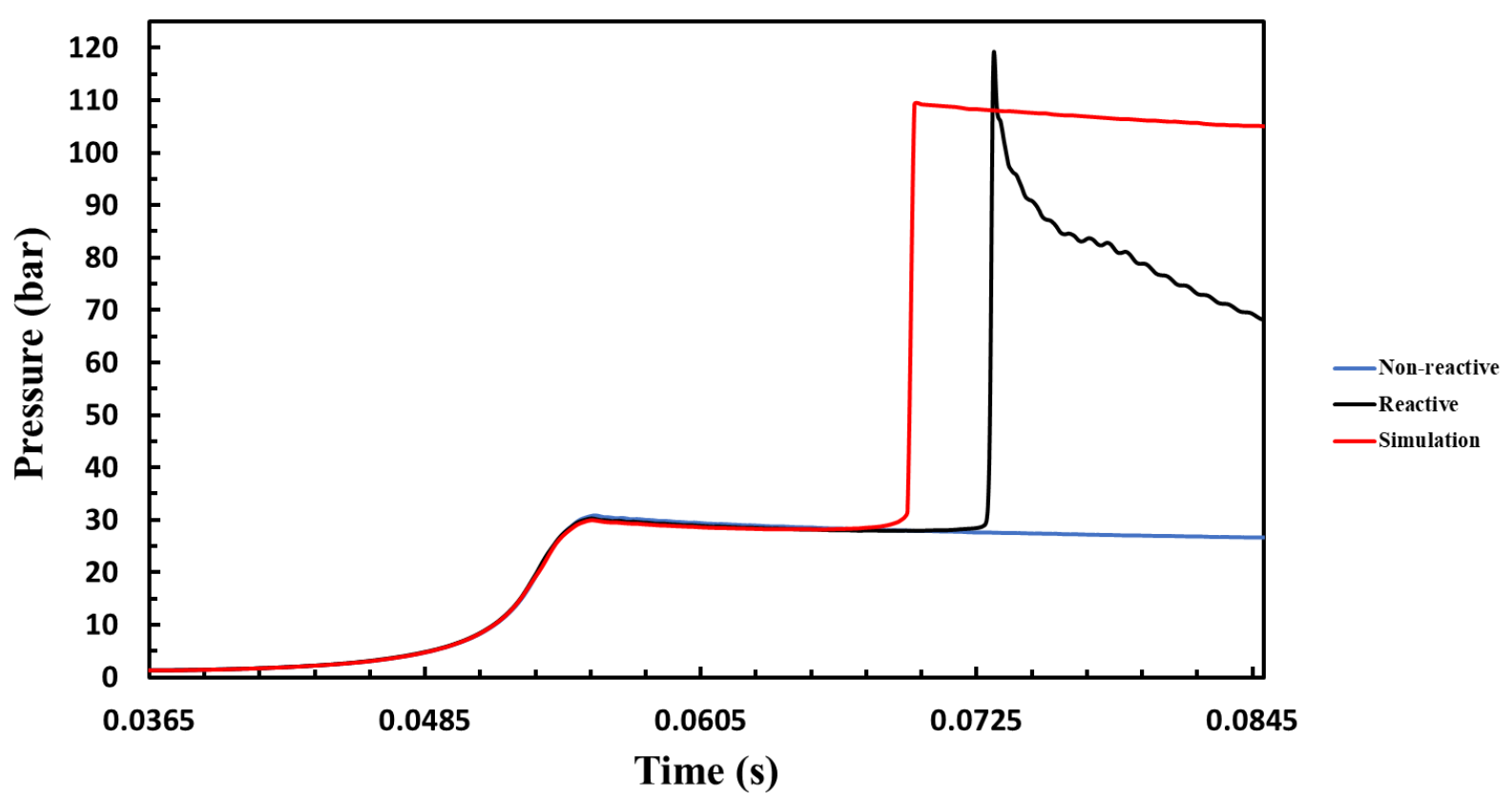

Figure S19. Pressure history of tested reactive and non-reactive mixtures of $\mathrm{P} 8 \mathrm{C} 4$ case alongside the simulation's profile for initial temperature of $349.7 \mathrm{~K}$. 


\section{Supporting Information}

P8C4@ $76.44{ }^{\circ} \mathrm{C}$

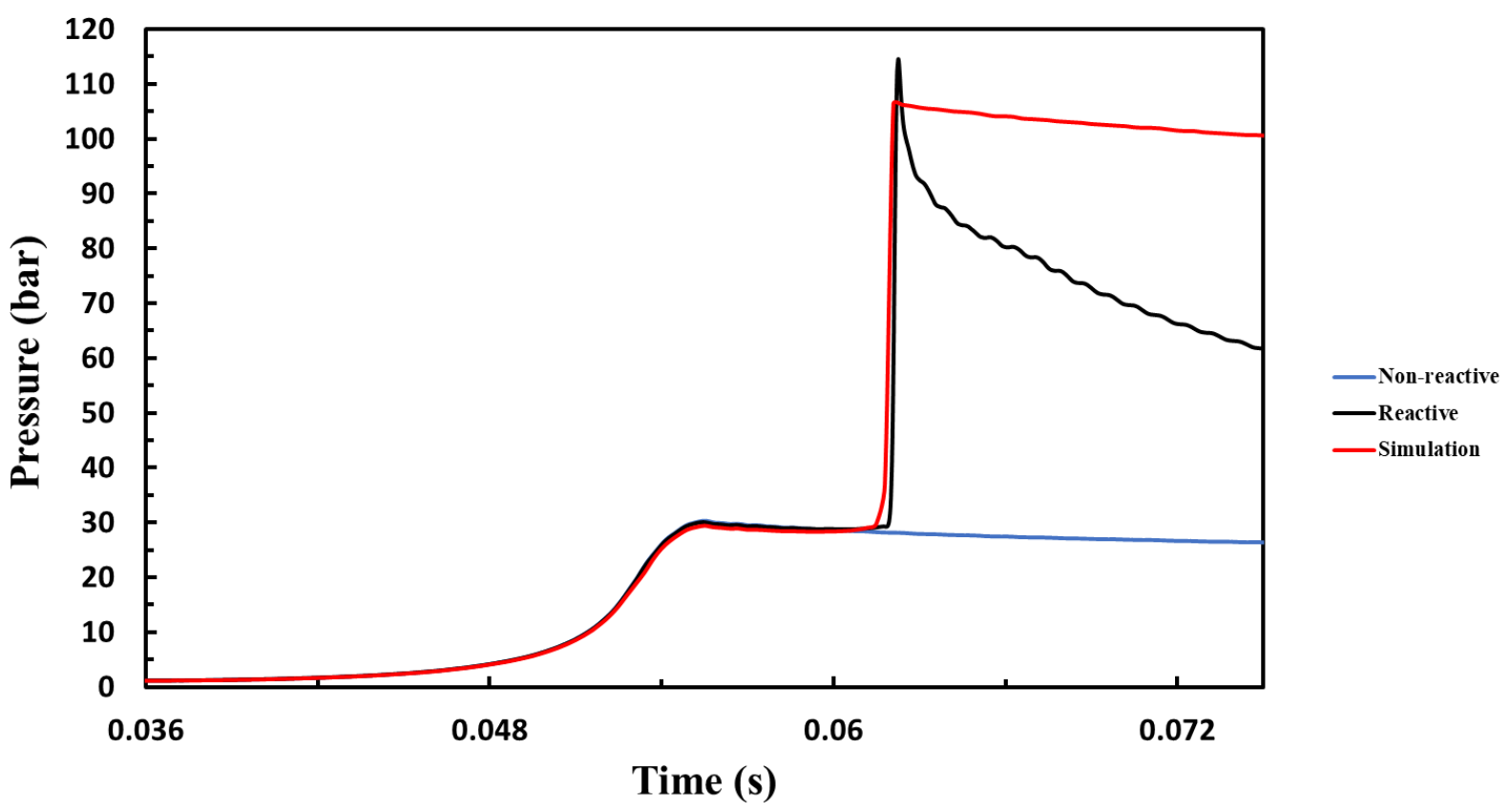

Figure S20. Pressure history of tested reactive and non-reactive mixtures of P8C4 case alongside the simulation's profile for initial temperature of $349.6 \mathrm{~K}$.

P8C7@ $65{ }^{\circ} \mathrm{C}$

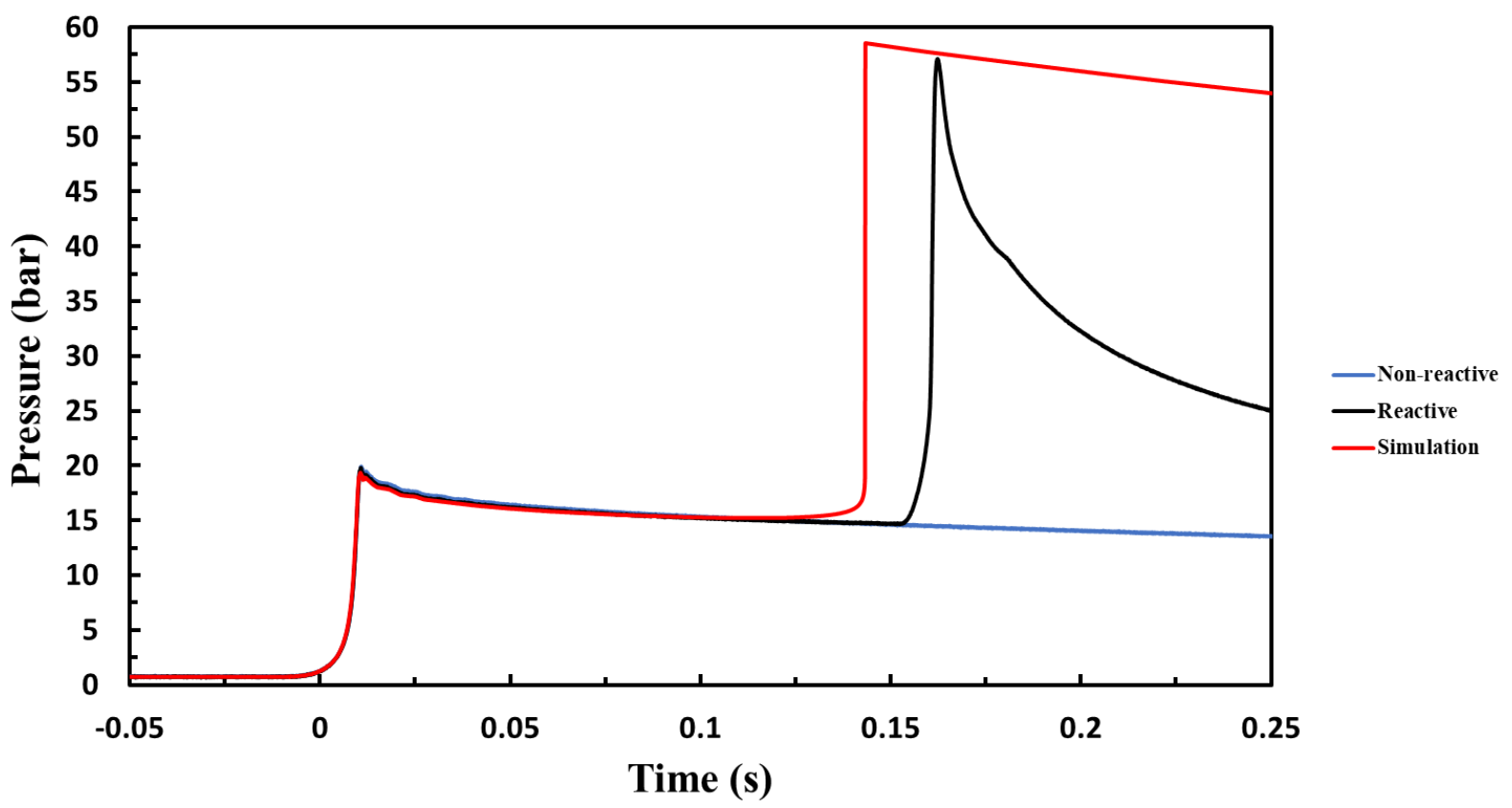

Figure S21. Pressure history of tested reactive and non-reactive mixtures of P8C7 case alongside the simulation's profile for initial temperature of $338 \mathrm{~K}$. 
P8C7@ $80{ }^{\circ} \mathrm{C}$

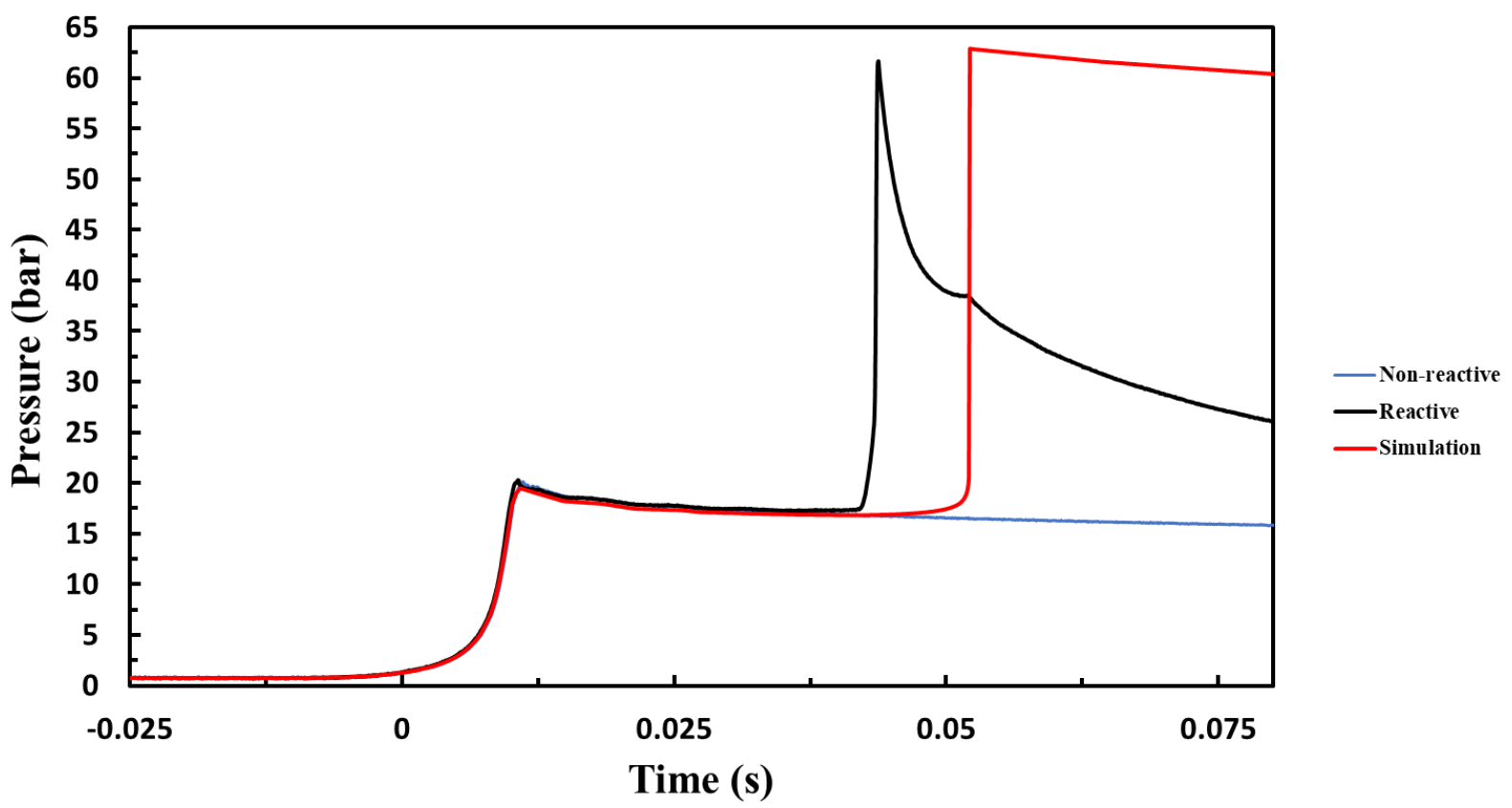

Figure S22. Pressure history of tested reactive and non-reactive mixtures of P8C7 case alongside the simulation's profile for initial temperature of $353 \mathrm{~K}$.

P8C7@95 ${ }^{\circ} \mathrm{C}$

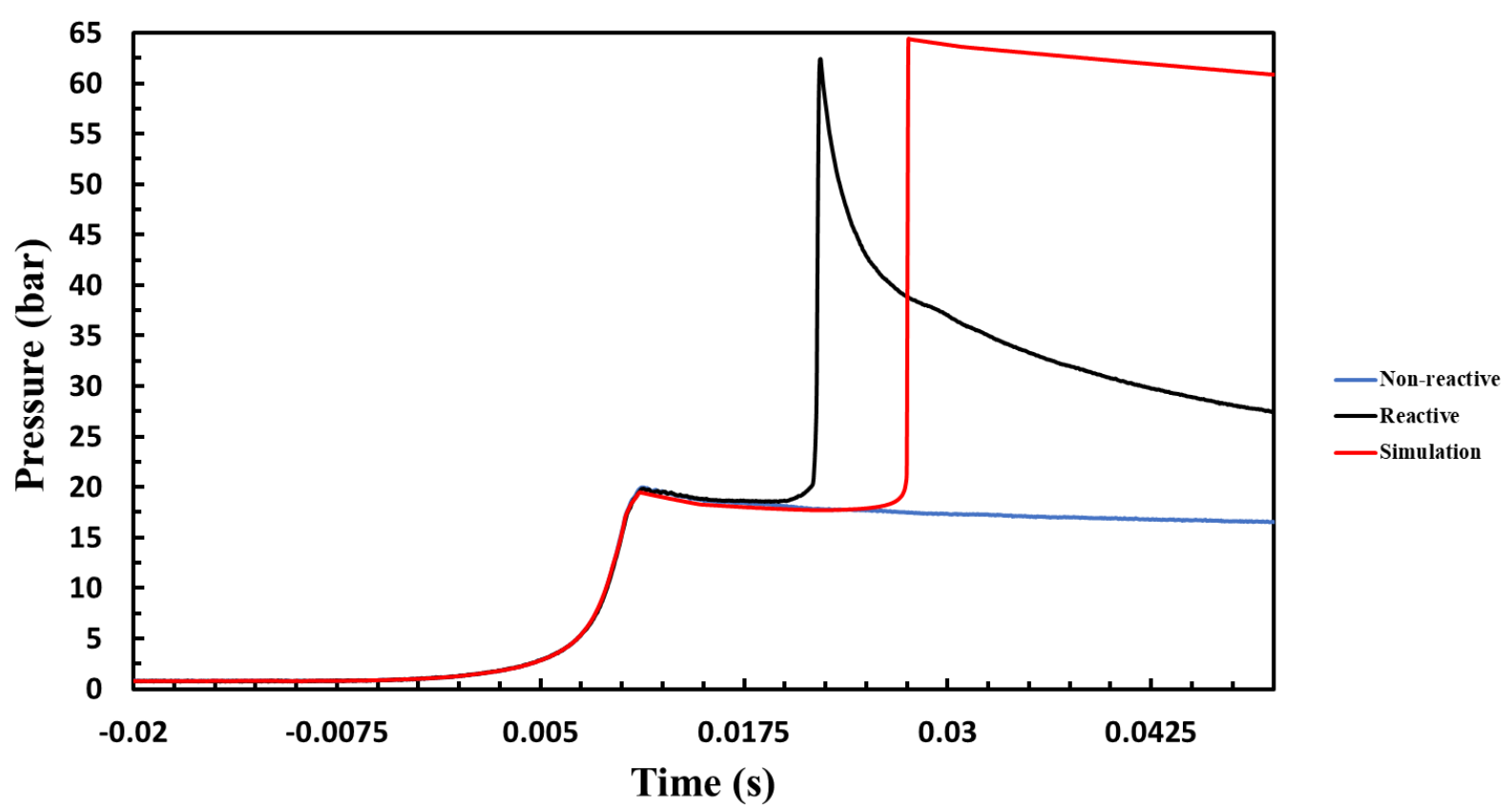

Figure S23. Pressure history of tested reactive and non-reactive mixtures of $\mathrm{P} 8 \mathrm{C} 7$ case alongside the simulation's profile for initial temperature of $368 \mathrm{~K}$. 


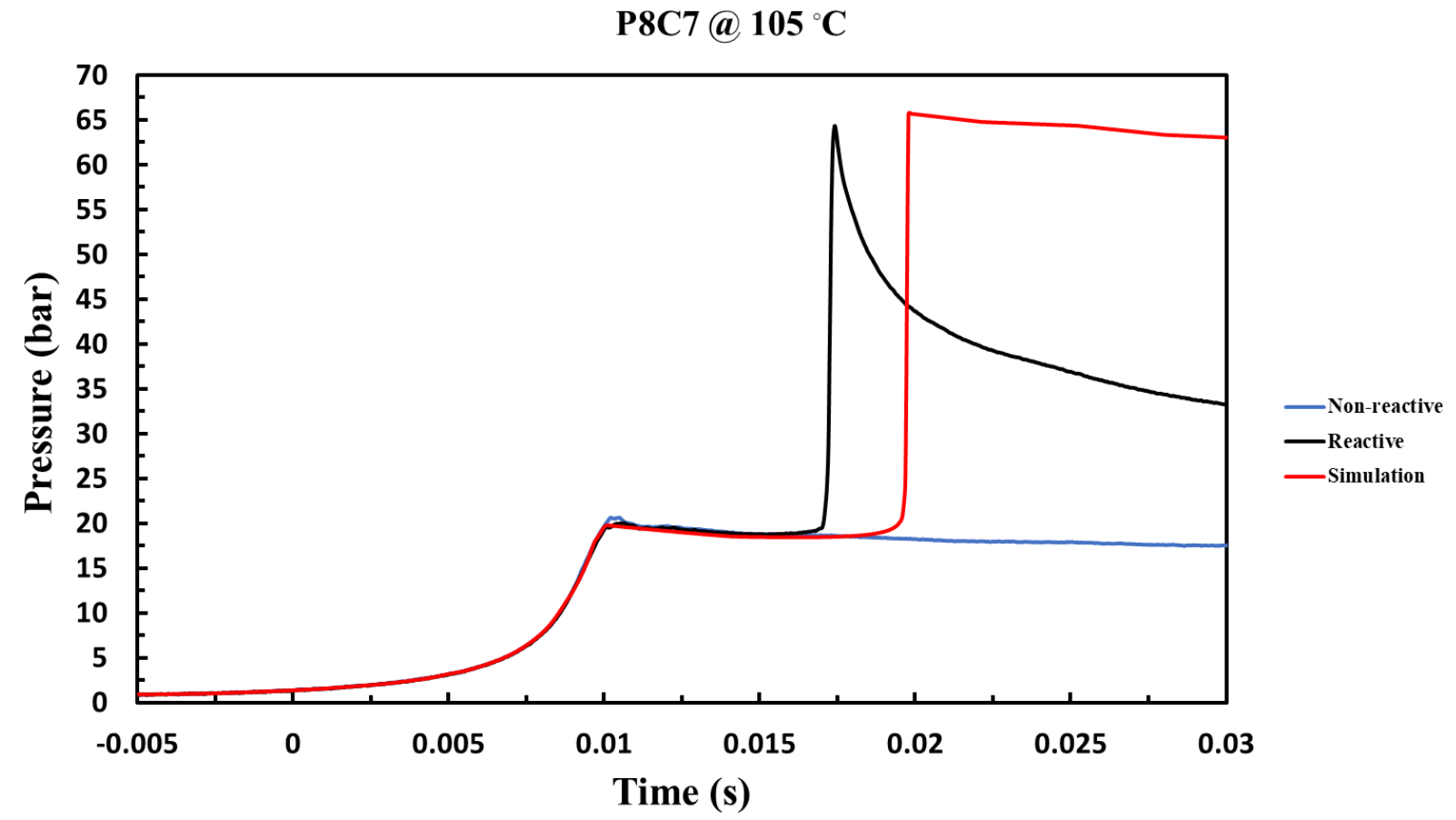

Figure S24. Pressure history of tested reactive and non-reactive mixtures of P8C7 case alongside the simulation's profile for initial temperature of $378 \mathrm{~K}$.

P8C8@ $73.35{ }^{\circ} \mathrm{C}$

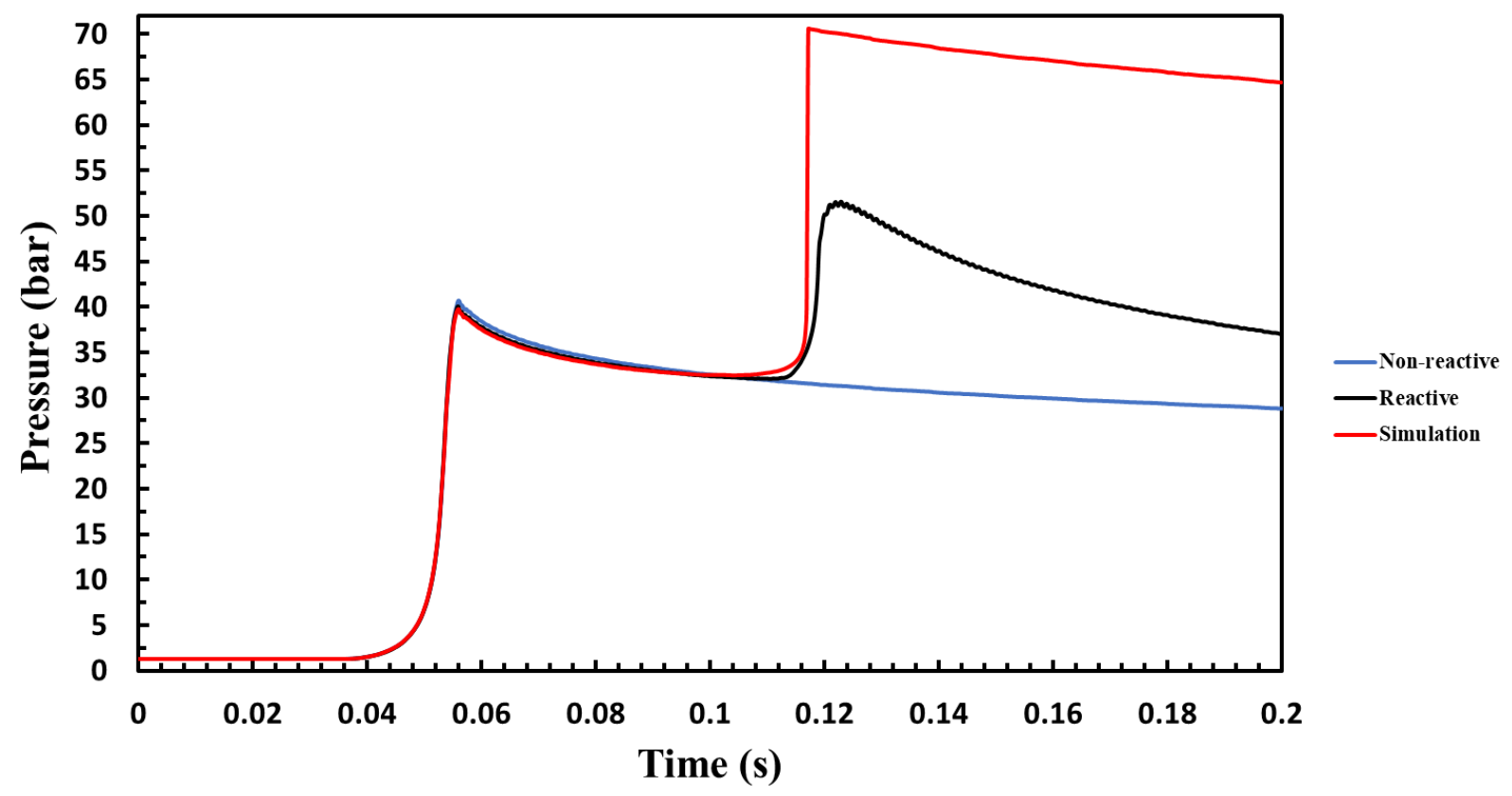

Figure S25. Pressure history of tested reactive and non-reactive mixtures of P8C8 case alongside the simulation's profile for initial temperature of $346.5 \mathrm{~K}$.

9 Comparing the performances of NUIGMech1.0 versus other available mechanisms

In this regard, the performances of chemical mechanisms presented in have been evaluated and compared over a wide range of conditions studied in the article. 


\section{Supporting Information}

Table S11. Applied chemical mechanisms.

\begin{tabular}{|c|c|c|c|c|}
\hline No & Mechanism & Number of reactions & Number of species & Comments \\
\hline 1 & AramcoMech 3.0 & 3037 & 581 & Released at $2018 ;{ }^{17}$ \\
\hline 2 & AramcoMech 2.0 & 2716 & 493 & Released at $2016 ;{ }^{10,18-23}$ \\
\hline 3 & AramcoMech 1.3 & 1542 & 253 & Released at $2013 ;{ }^{10}$ \\
\hline 4 & DTU-C 3 & 142 & 1308 & Released at $2019 ;{ }^{24}$ \\
\hline 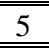 & CRECK & 1941 & 114 & Released at $2020 ;{ }^{25}$ \\
\hline 6 & UCSD & 268 & 57 & Released at $2016 ;{ }^{26}$ \\
\hline 7 & GRI 3.0 & 325 & 53 & Released at $2000 ;{ }^{27}$ \\
\hline 8 & $\begin{array}{l}\text { JetSurF } 2.0 \\
\end{array}$ & 348 & 2163 & Released at $2010 ;{ }^{28}$ \\
\hline 9 & FFCM-1 & 291 & 38 & $\begin{array}{l}\mathrm{C}_{1}-\mathrm{C}_{2} ; \text { Low temperature reactions are not included; } \\
\text { released at } 2016 ;{ }^{29}\end{array}$ \\
\hline
\end{tabular}
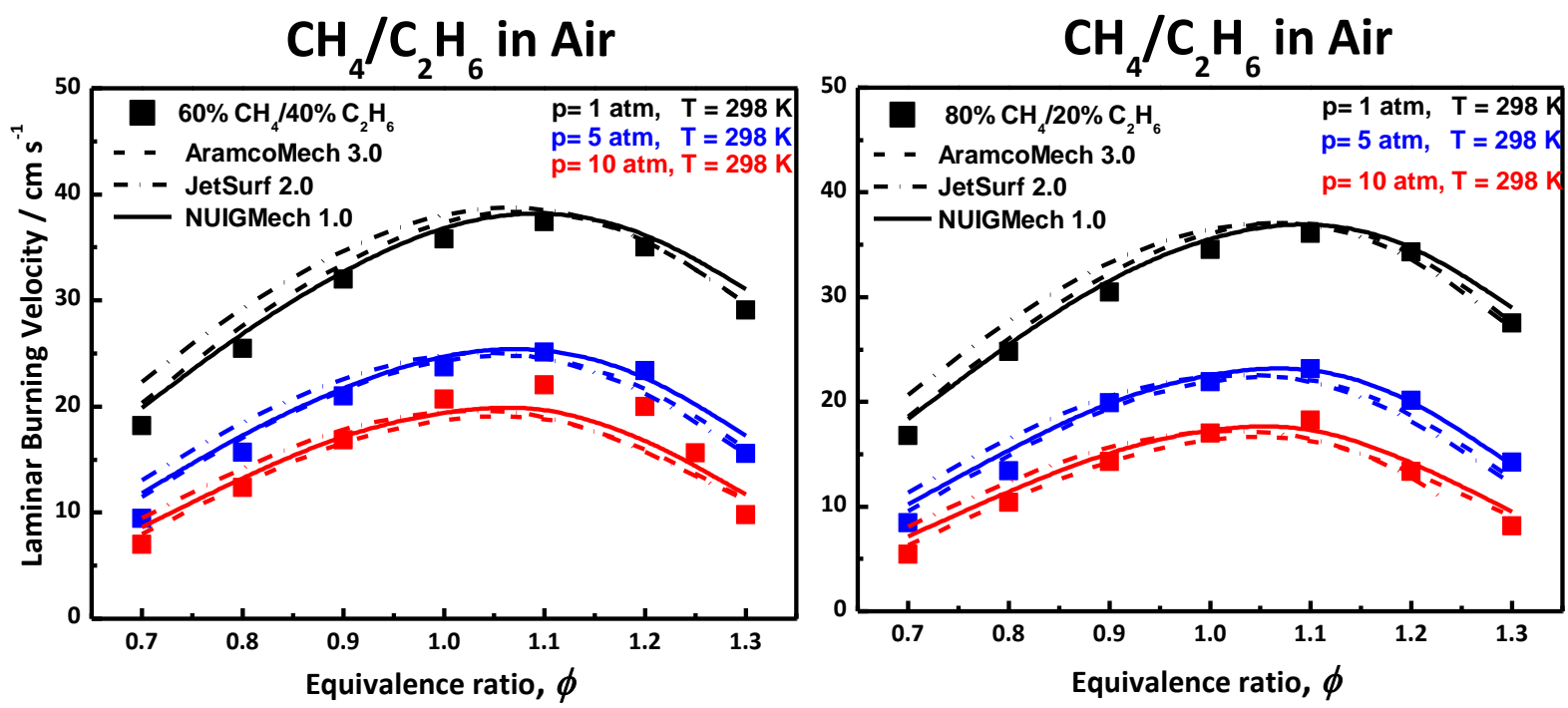

Figure S26. Performance of NUIGMech1.0 for predicting LBVs in comparison to AramcoMech 3.0 and JetSurf II. ${ }^{30}$ 

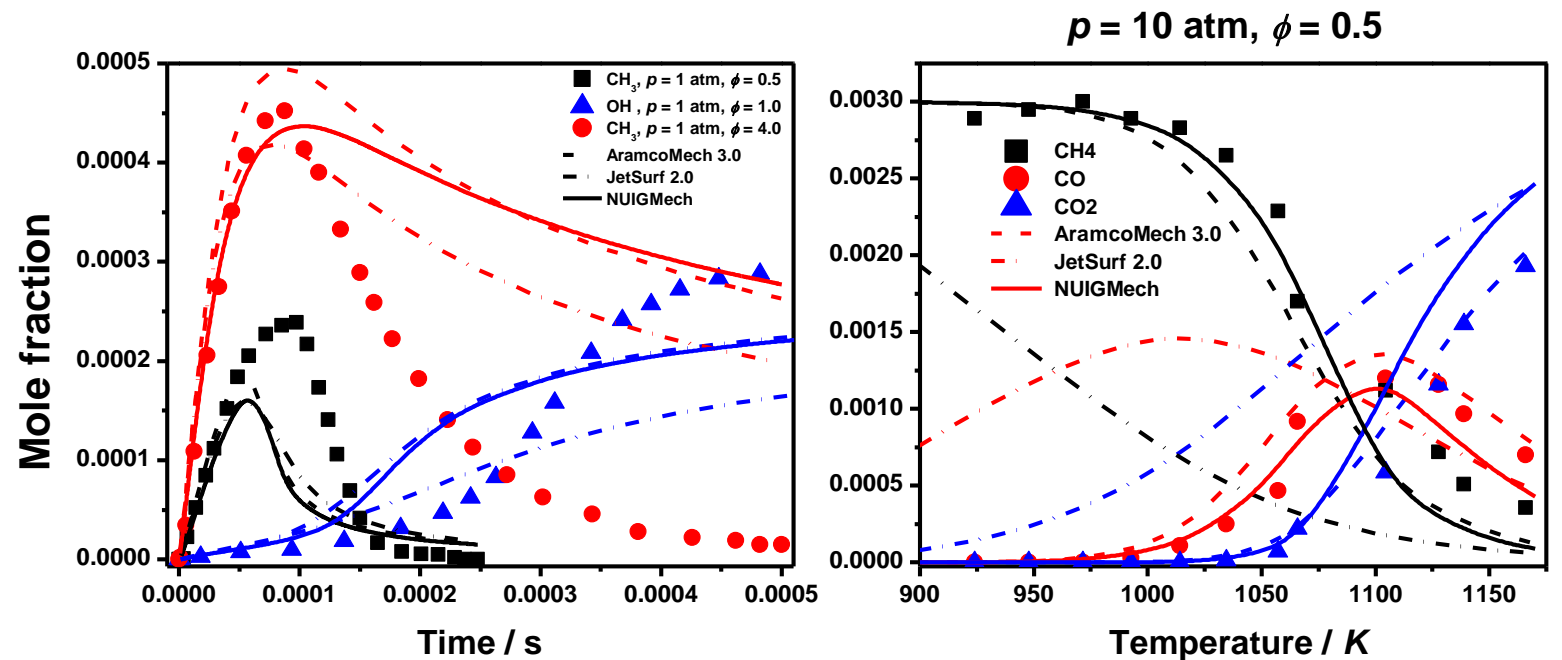

Time / s

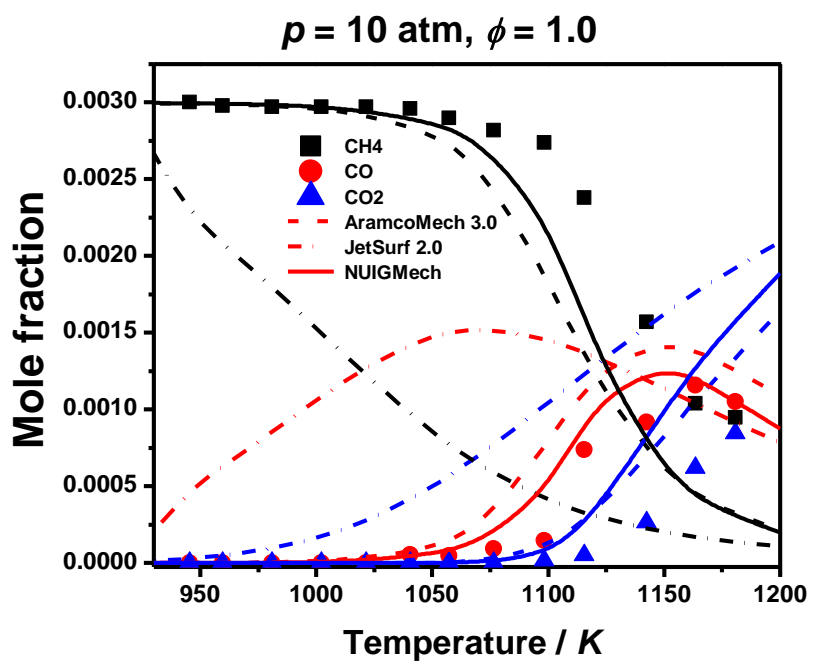

Figure S27. Performance of NUIGMech1.0 for predicting methane's speciation in comparison to AramcoMech 3.0 and JetSurf II. ${ }^{31,32}$ 

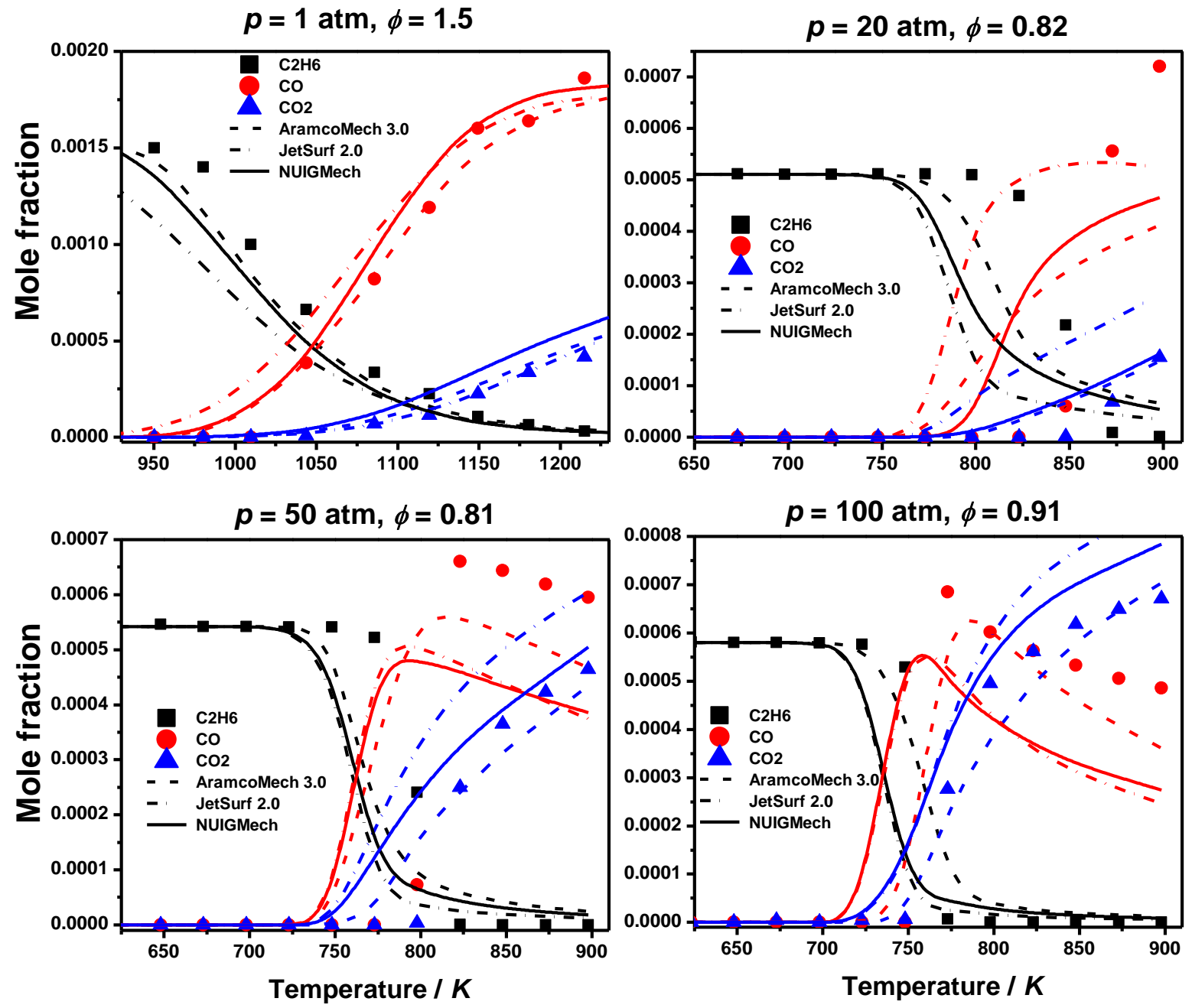

Figure S28. Performance of NUIGMech1.0 for predicting ethane's speciation in comparison to AramcoMech 3.0 and JetSurf II. ${ }^{33,34}$ 

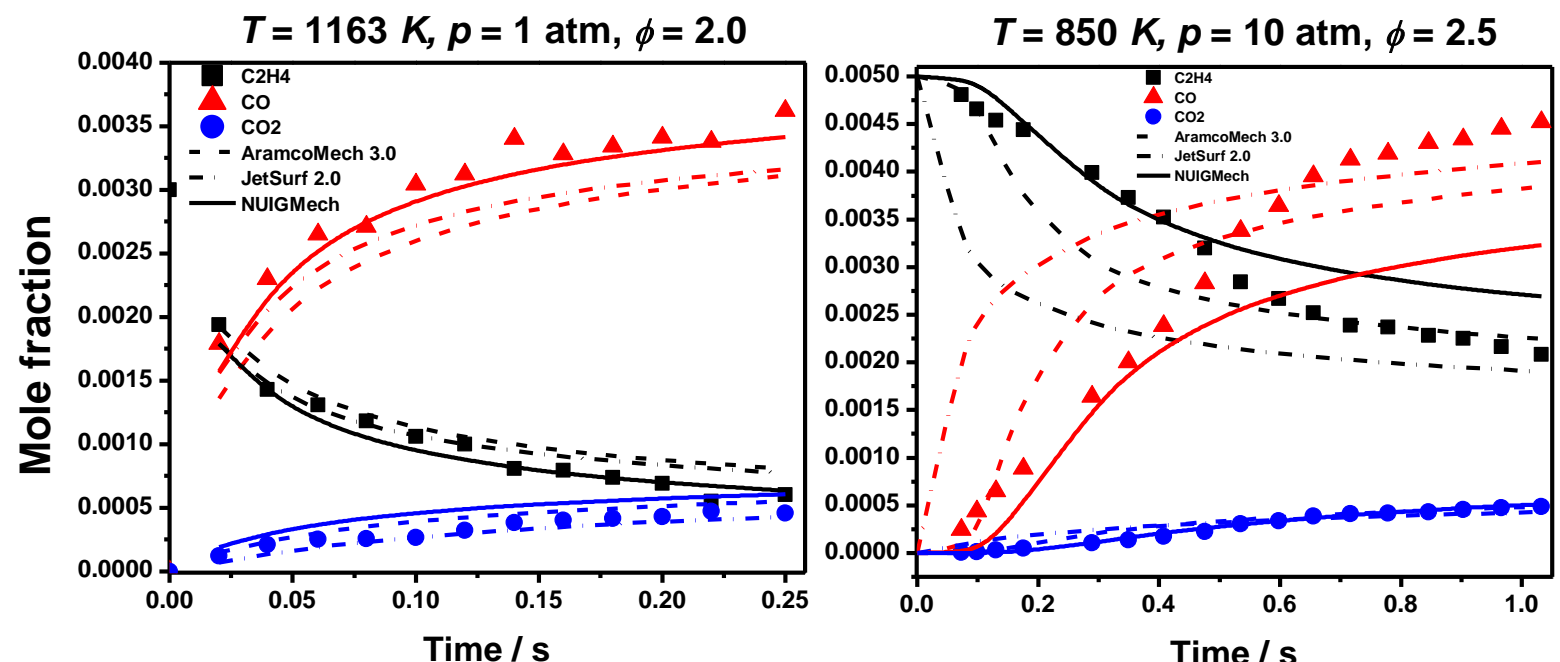

Time / s

Time / s

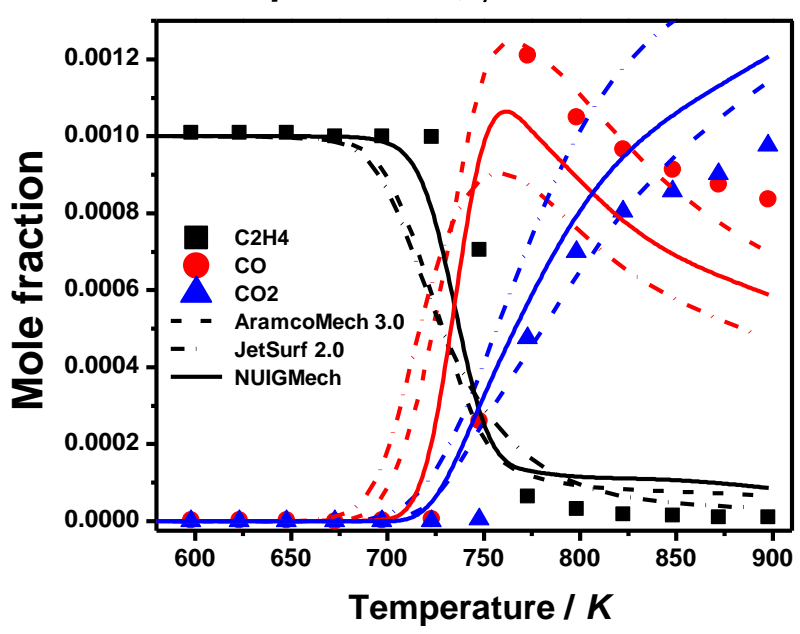

Figure S29. Performance of NUIGMech1.0 for predicting ethylene's speciation in comparison to AramcoMech 3.0 and JetSurf II. ${ }^{32,35,36}$

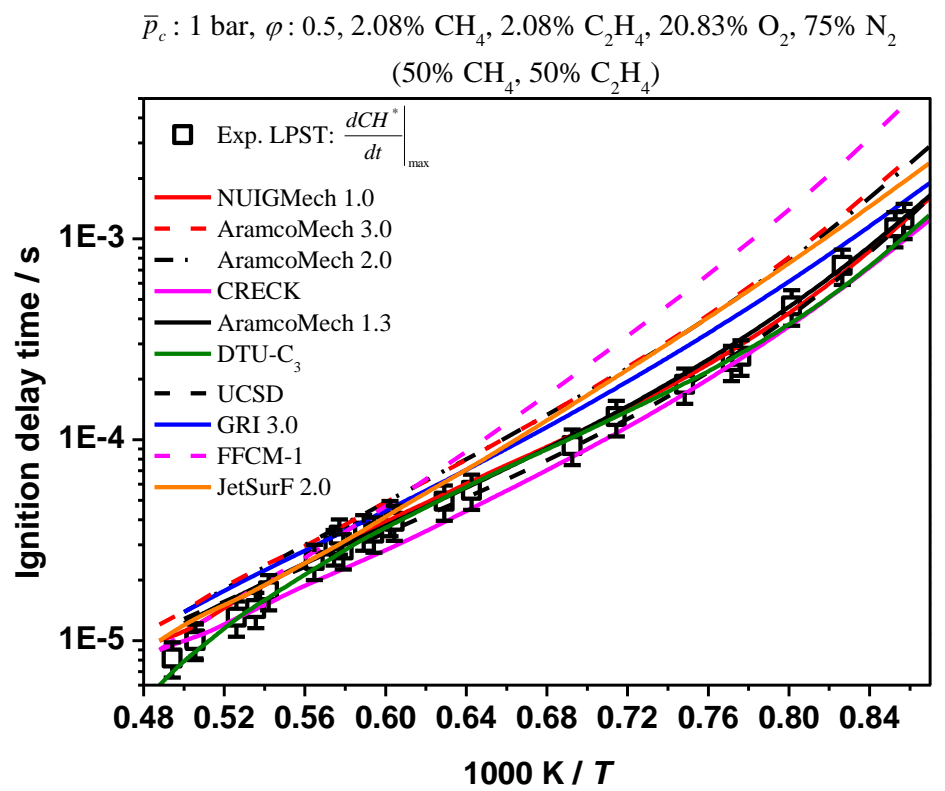



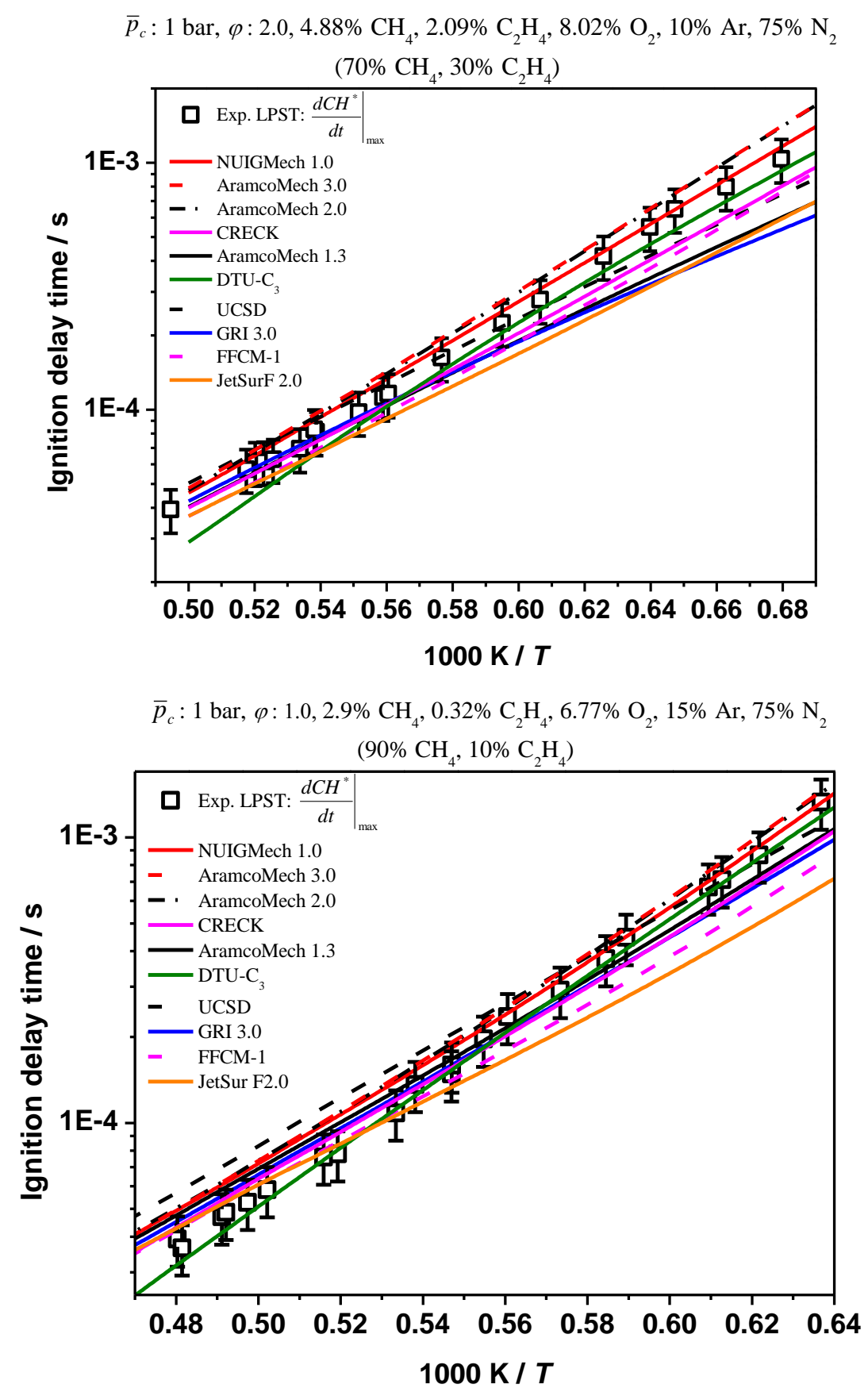

Figure S30. Performance of NUIGMech1.0 for predicting methane + ethylene's IDTs at 1 bar in comparison to the other examined chemical mechanisms. 


\section{Supporting Information}
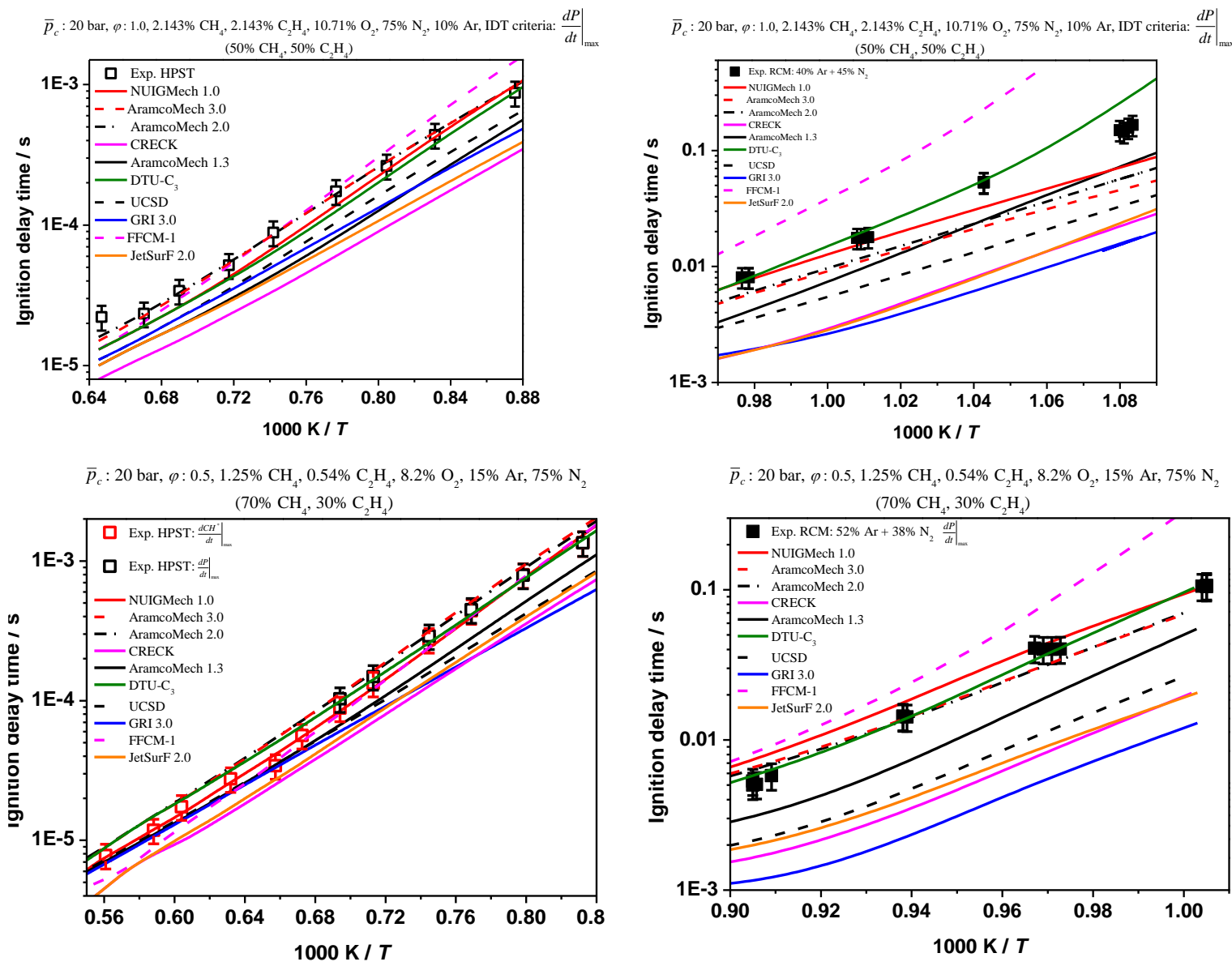

$\bar{p}_{c}: 20$ bar, $\varphi: 2.0,10.976 \% \mathrm{CH}_{4}, 1.22 \% \mathrm{C}_{2} \mathrm{H}_{4}, 12.805 \% \mathrm{O}_{2}, 75 \% \mathrm{~N}_{2}$, IDT criteria: $\frac{d P}{d t} \mid$
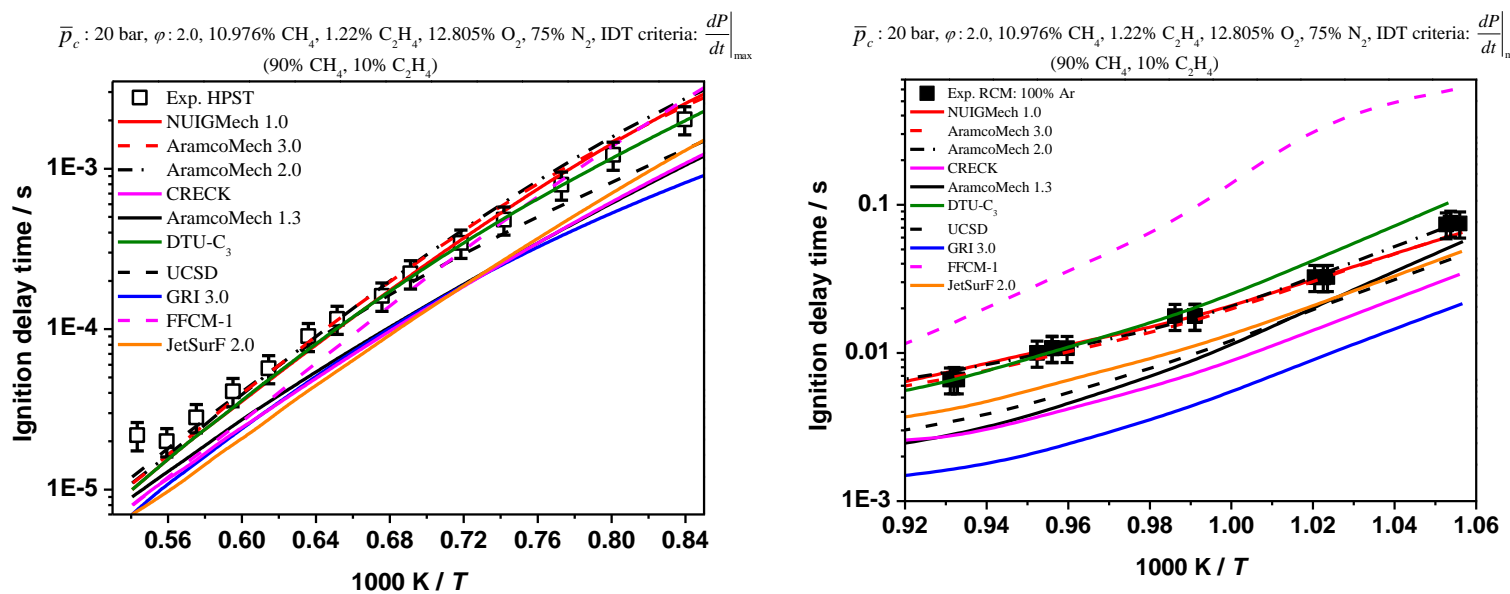

Figure S31. Performance of NUIGMech1.0 for predicting methane + ethylene's IDTs at 20 bar in comparison to the other examined chemical mechanisms. 


\section{Supporting Information}
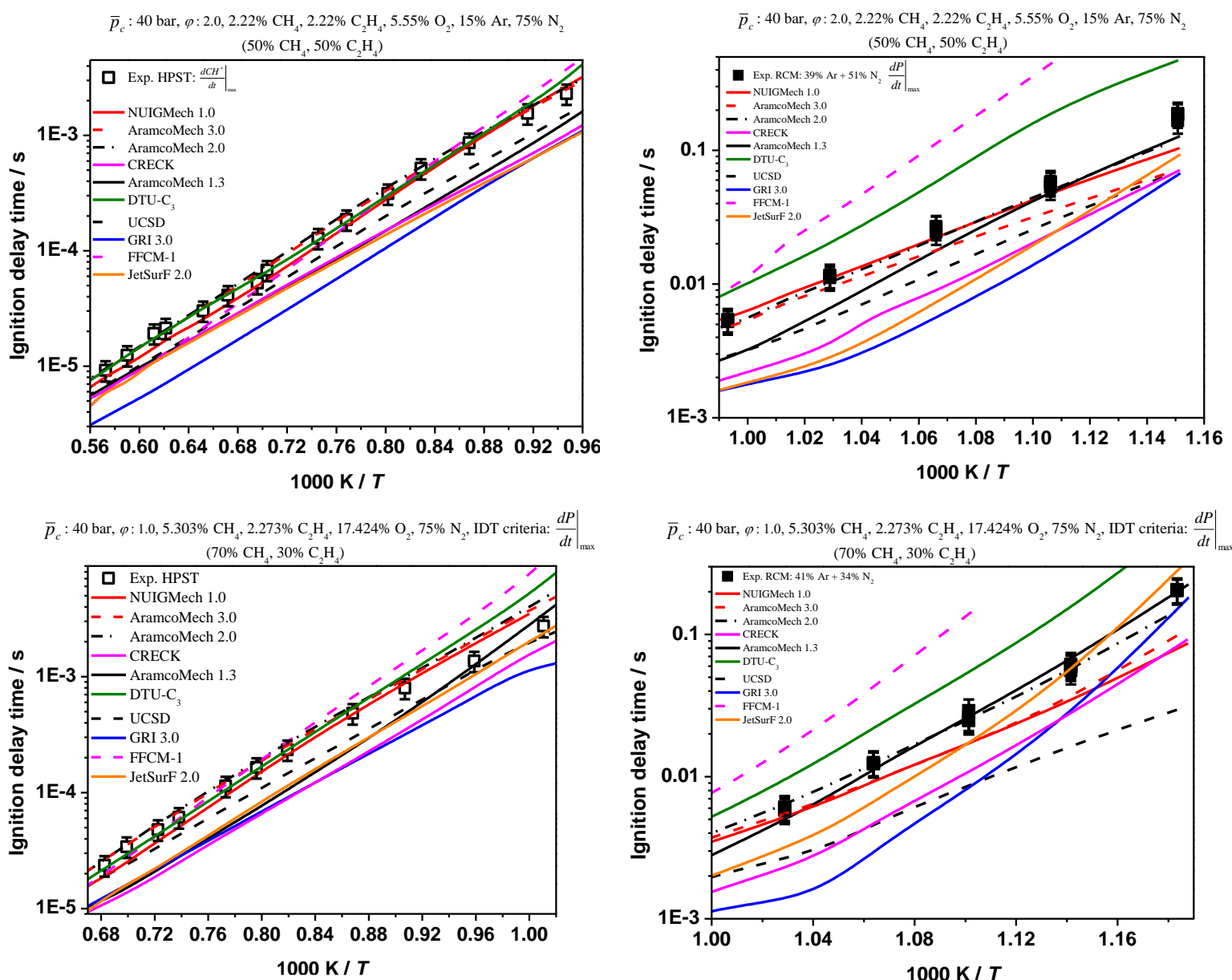

$\bar{p}_{c}: 40 \mathrm{bar}, \varphi: 0.5,2.596 \% \mathrm{CH}_{4}, 0.288 \% \mathrm{C}_{2} \mathrm{H}_{4}, 12.115 \% \mathrm{O}_{2}, 10 \% \mathrm{Ar}, 75 \% \mathrm{~N}_{2}$, IDT criteria: $\left.\frac{d P}{d t}\right|_{\max }$

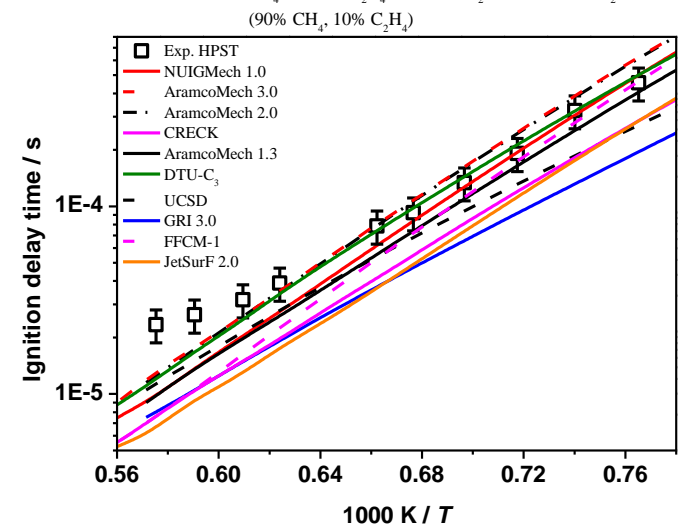

$\bar{p}_{c}: 40$ bar, $\varphi: 0.5,2.596 \% \mathrm{CH}_{4}, 0.288 \% \mathrm{C}_{2} \mathrm{H}_{4}, 12.115 \% \mathrm{O}_{2}, 10 \% \mathrm{Ar}, 75 \% \mathrm{~N}_{2}$, IDT criteria: $\frac{d P}{d t}$

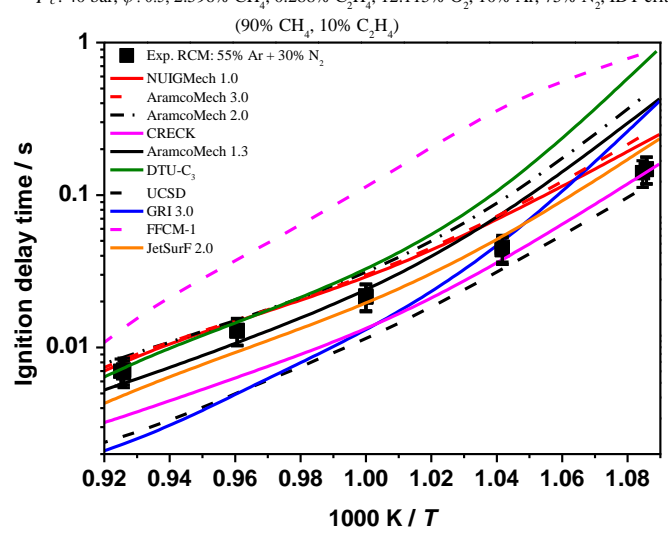

Figure S32. Performance of NUIGMech1.0 for predicting methane + ethylene's IDTs at 40 bar in comparison to the other examined chemical mechanisms. 


\section{Supporting Information}
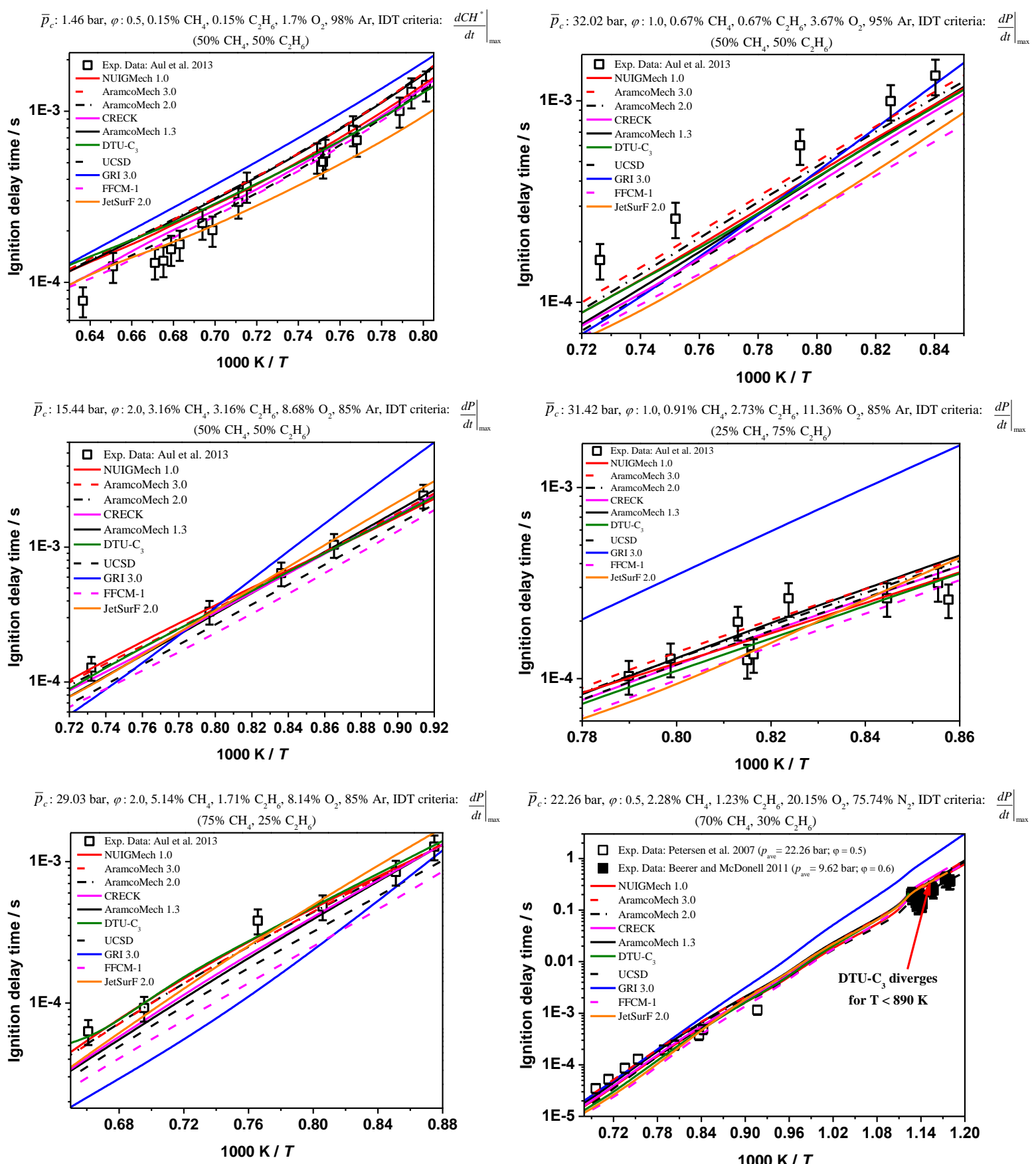

$\bar{p}_{c}: 22.26$ bar, $\varphi: 0.5,2.28 \% \mathrm{CH}_{4}, 1.23 \% \mathrm{C}_{2} \mathrm{H}_{6}, 20.15 \% \mathrm{O}_{2}, 75.74 \% \mathrm{~N}_{2}$, IDT criteria: $\left.\frac{d P}{d t}\right|_{\max }$

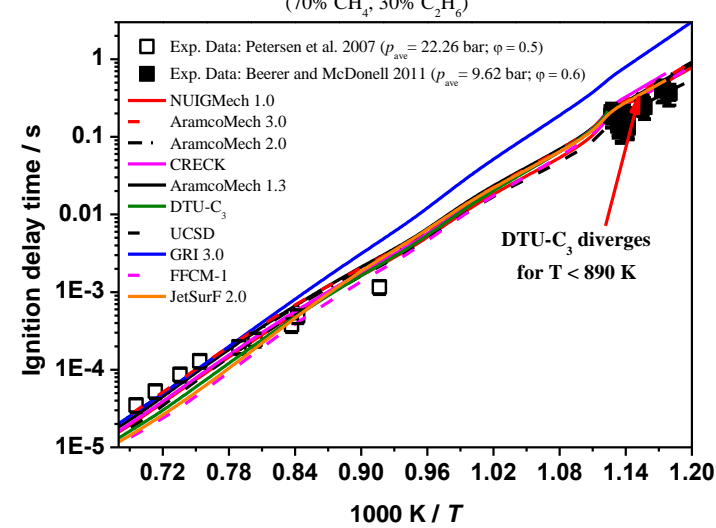

Figure S33. Performance of NUIGMech1.0 for predicting methane + ethane's IDTs in comparison to the other examined chemical mechanisms. ${ }^{37-39}$ 


\section{Supporting Information}
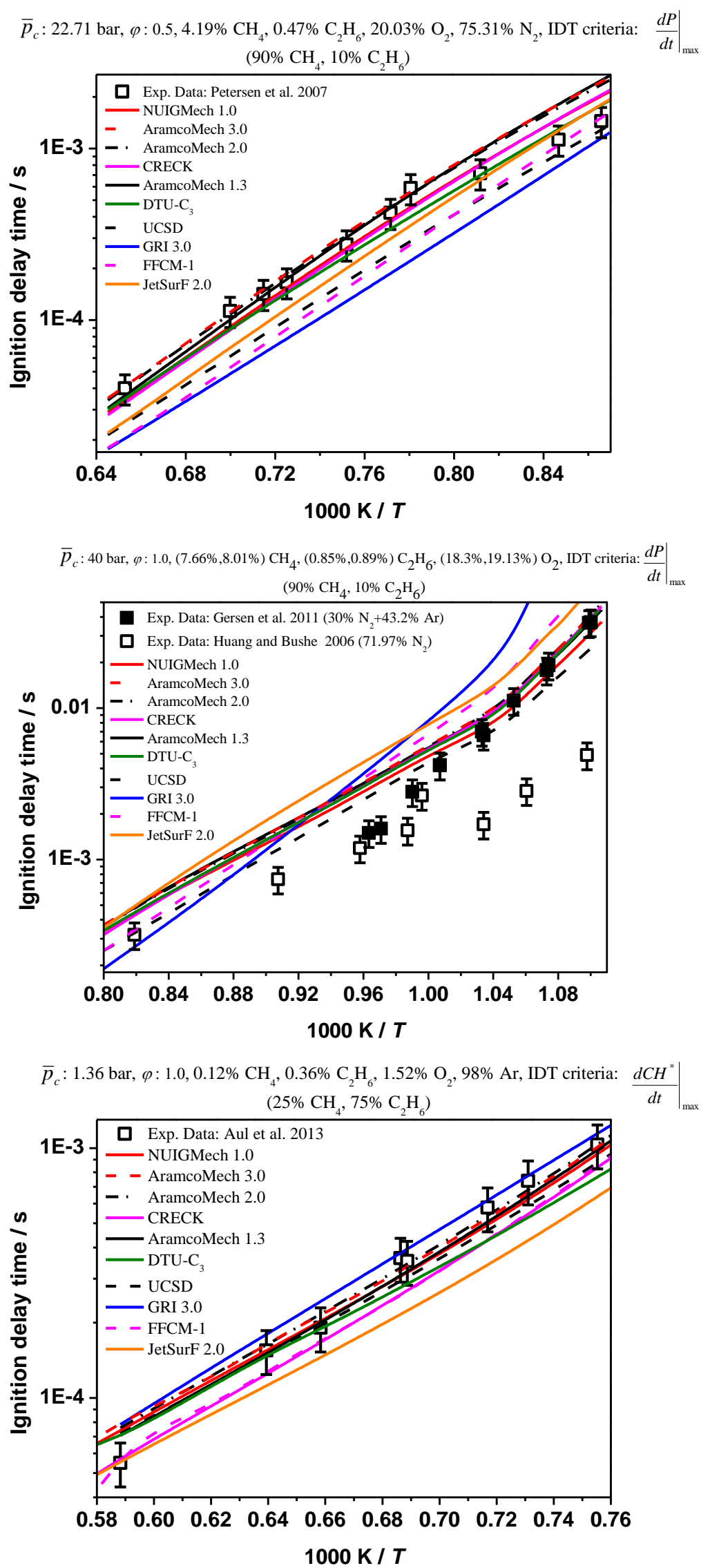

Figure S34. Performance of NUIGMech1.0 for predicting methane + ethane's IDTs in comparison to the other examined chemical mechanisms. ${ }^{37,38,40,41}$ 


\section{Supporting Information}
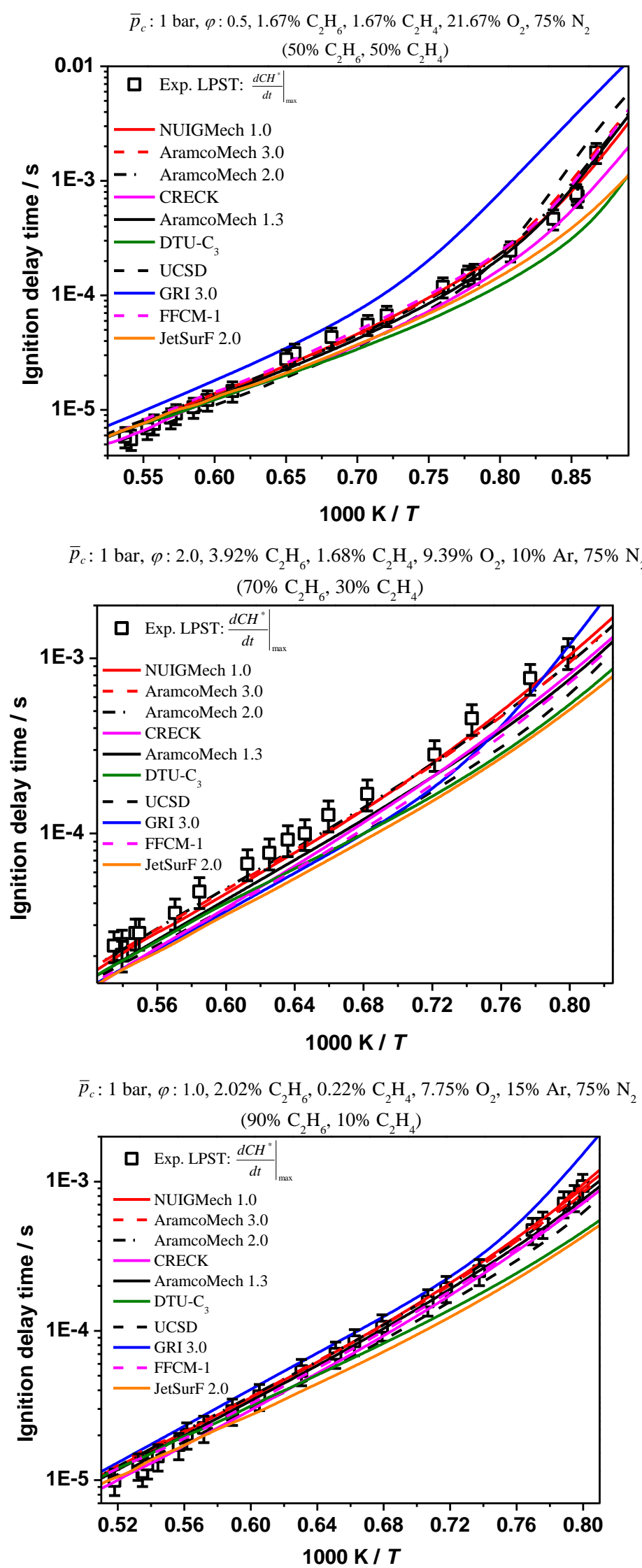

Figure S35. Performance of NUIGMech1.0 for predicting ethane + ethylene's IDTs at 1 bar in comparison to the other examined chemical mechanisms. 


\section{Supporting Information}
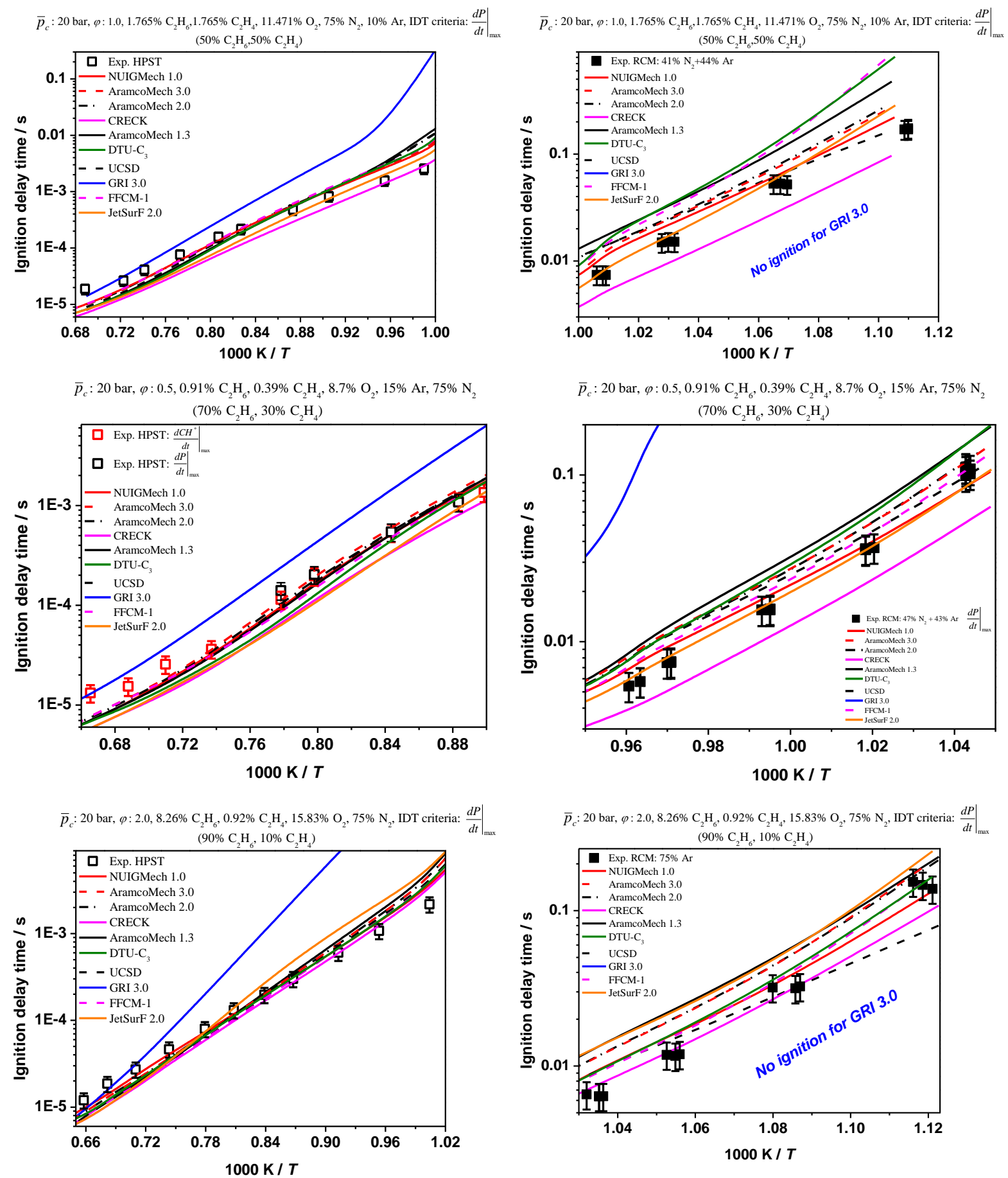

Figure S36. Performance of NUIGMech1.0 for predicting ethane + ethylene's IDTs at 20 bar in comparison to the other examined chemical mechanisms. 
$\bar{p}_{c}: 40$ bar, $\varphi: 2.0,1.90 \% \mathrm{C}_{2} \mathrm{H}_{6}, 1.90 \% \mathrm{C}_{2} \mathrm{H}_{4}, 6.19 \% \mathrm{O}_{2}, 15 \% \mathrm{Ar}, 75 \% \mathrm{~N}_{2}$ $\left(50 \% \mathrm{C}_{2} \mathrm{H}_{6}, 50 \% \mathrm{C}_{2} \mathrm{H}_{4}\right)$

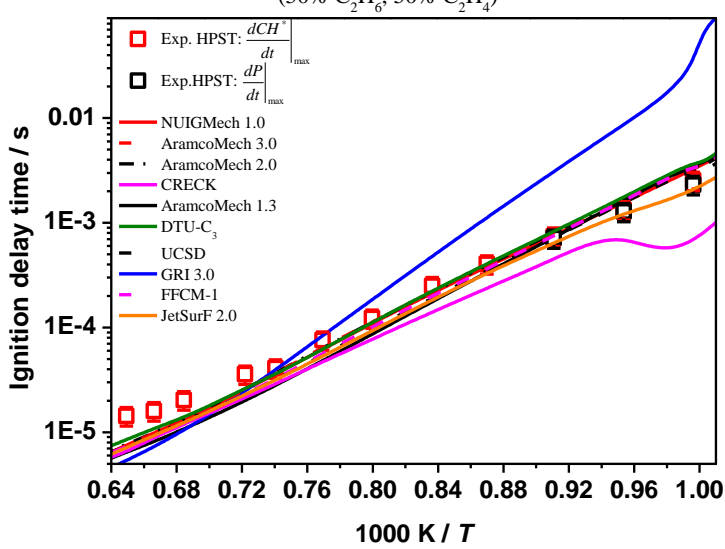

$\bar{p}_{c}: 40$ bar, $\varphi: 1.0,4.023 \% \mathrm{C}_{2} \mathrm{H}_{6}, 1.724 \% \mathrm{C}_{2} \mathrm{H}_{4}, 19.253 \% \mathrm{O}_{2}, 75 \% \mathrm{~N}_{2}$, IDT criteria: $\left.\frac{d P}{\left(70 \% \mathrm{C}_{2} \mathrm{H}_{3}, 30 \% \mathrm{C}_{2} \mathrm{H}_{4}\right)}\right|_{\max }$

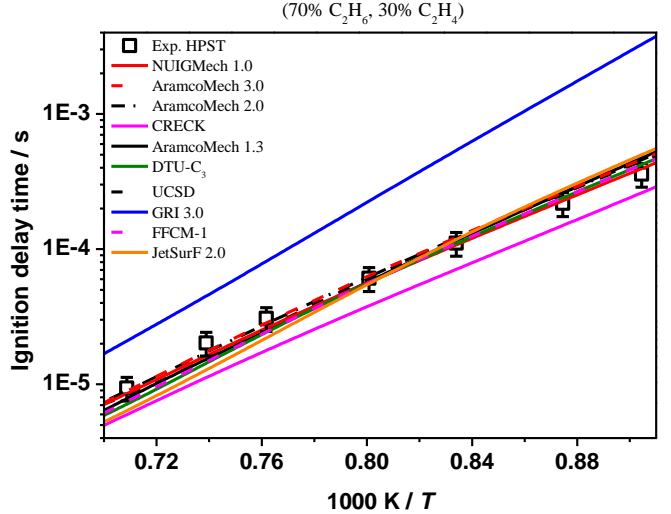

$\bar{p}_{c}: 40$ bar, $\varphi: 0.5,1.71 \% \mathrm{C}_{2} \mathrm{H}_{6}, 0.19 \% \mathrm{C}_{2} \mathrm{H}_{4}, 13.10 \% \mathrm{O}_{2}, 10 \% \mathrm{Ar}, 75 \% \mathrm{~N}_{2}$, IDT criteria: $\left.\frac{d P}{d t}\right|_{\operatorname{mas}}$

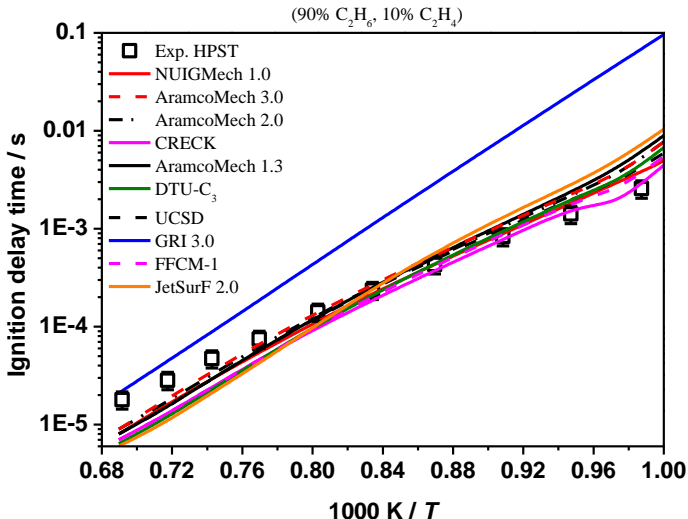

$\bar{p}_{c}: 40$ bar, $\varphi: 2.0,1.90 \% \mathrm{C}_{2} \mathrm{H}_{6}, 1.90 \% \mathrm{C}_{2} \mathrm{H}_{4}, 6.19 \% \mathrm{O}_{2}, 15 \% \mathrm{Ar}, 75 \% \mathrm{~N}_{2}$ $\left(50 \% \mathrm{C}_{2} \mathrm{H}_{6}, 50 \% \mathrm{C}_{2} \mathrm{H}_{4}\right)$

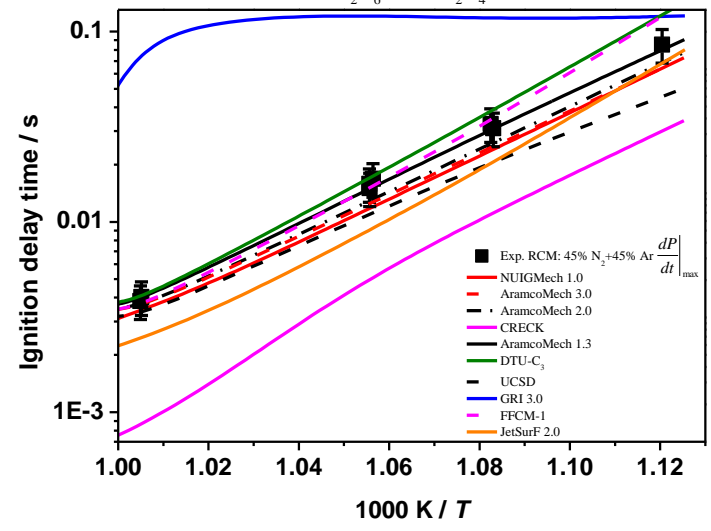

$\bar{p}_{c}: 30$ bar, $\varphi: 1.0,4.023 \% \mathrm{C}_{2} \mathrm{H}_{6}, 1.724 \% \mathrm{C}_{2} \mathrm{H}_{4}, 19.253 \% \mathrm{O}_{2}, 75 \% \mathrm{Ar}$, IDT criteria: $\left.\frac{d P}{d t}\right|_{\text {ma }}$

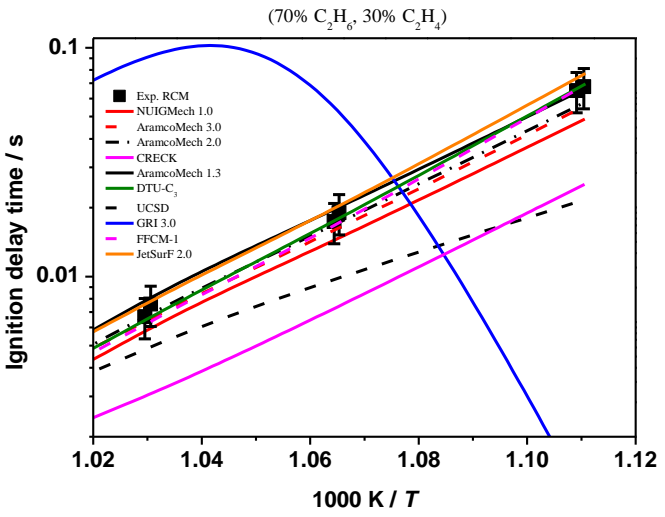

$\bar{p}_{c}: 40$ bar, $\varphi: 0.5,1.71 \% \mathrm{C}_{2} \mathrm{H}_{6}, 0.19 \% \mathrm{C}_{2} \mathrm{H}_{4}, 13.10 \% \mathrm{O}_{2}, 10 \% \mathrm{Ar}, 75 \% \mathrm{~N}_{2}$, IDT criteria: $\left.\frac{d P}{d t}\right|_{\max }$

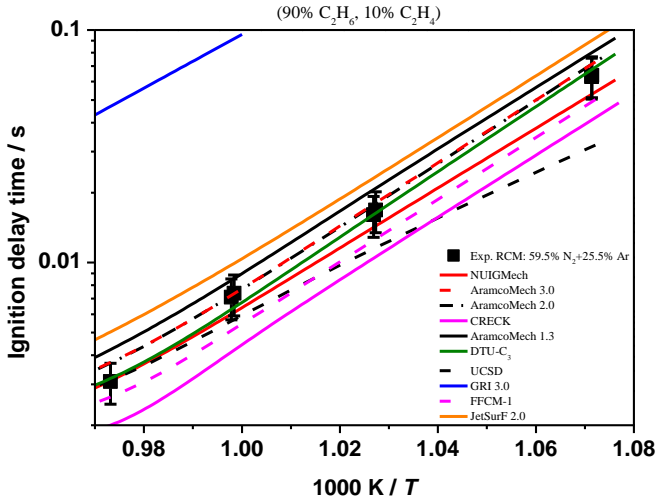

Figure S37. Performance of NUIGMech1.0 for predicting ethane + ethylene's IDTs at 40 bar in comparison to the other examined chemical mechanisms. 


\section{Supporting Information}

\section{Chemical kinetics development}

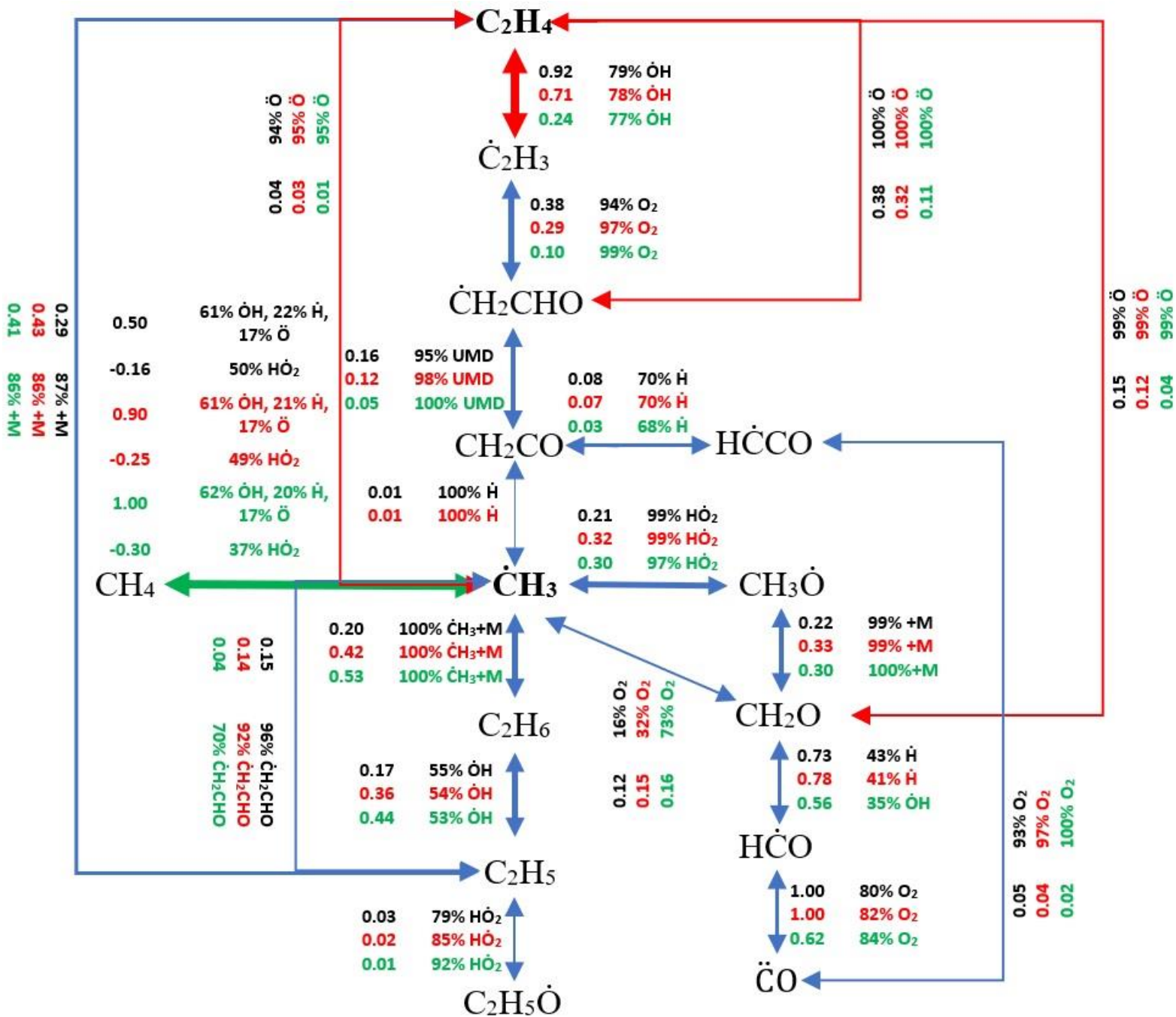

Figure S38. Flux analysis of the ten prominent reactions at $1200 \mathrm{~K}$ in Fig. 5(a) for the methane + ethylene blends at different methane/ethylene combinations; Black numbers: 50/50, Red numbers: 70/30, and Green numbers: 90/10. 


\section{Supporting Information}

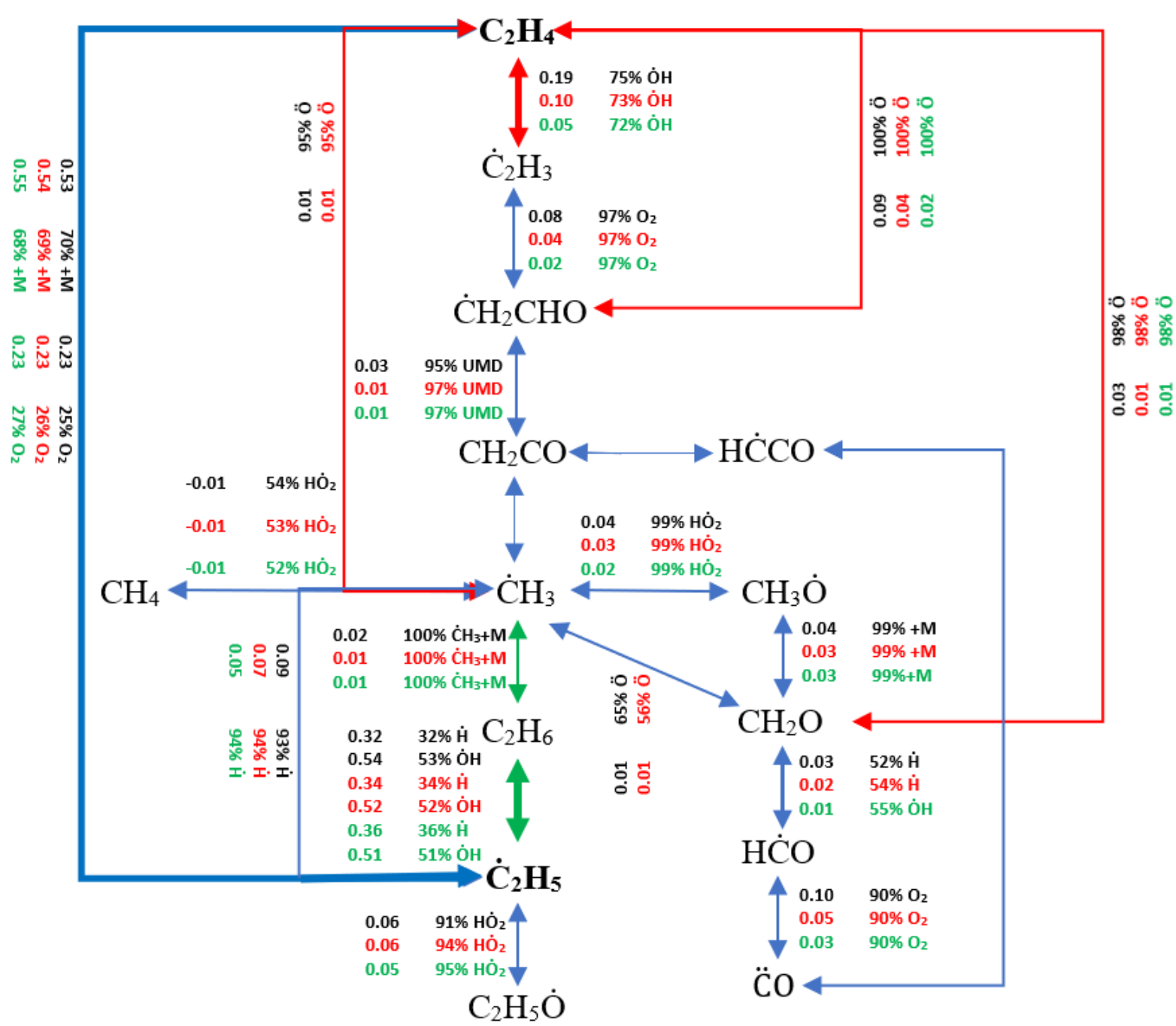

Figure S39. Flux analysis of the ten prominent reactions at $1200 \mathrm{~K}$ in Fig. 5(a) for the ethane + ethylene blends at different ethane/ethylene combinations; Black numbers: 50/50, Red numbers: 70/30, and Green numbers: 90/10. 


\section{Supporting Information}

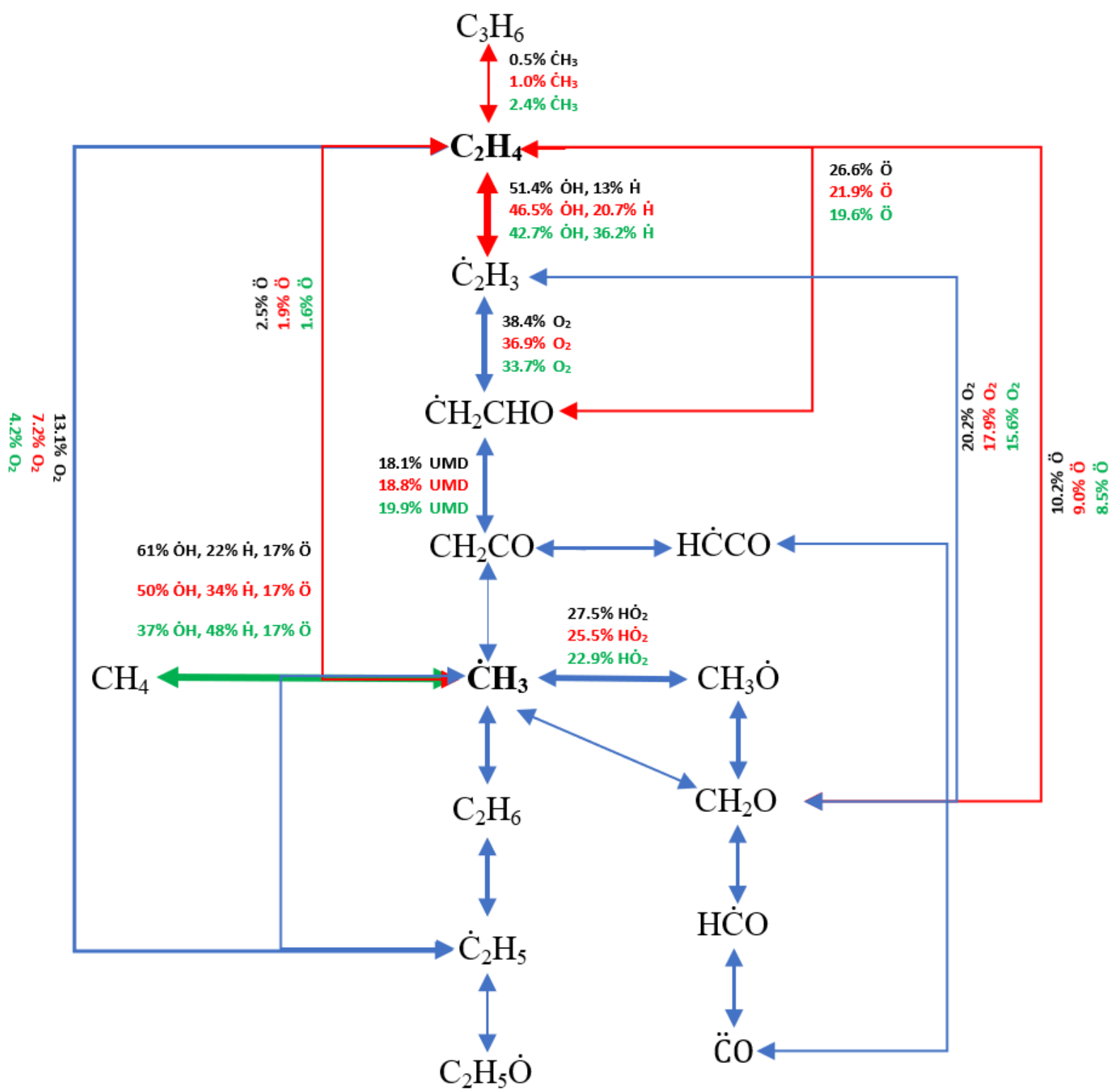

Figure S40. Flux analysis of the ten prominent reactions at $1200 \mathrm{~K}$ in Fig. 5(c) for the methane + ethylene blends at different equivalence ratios; Black numbers: 0.5, Red numbers: 1.0, and Green numbers: 2.0. 


\section{Supporting Information}

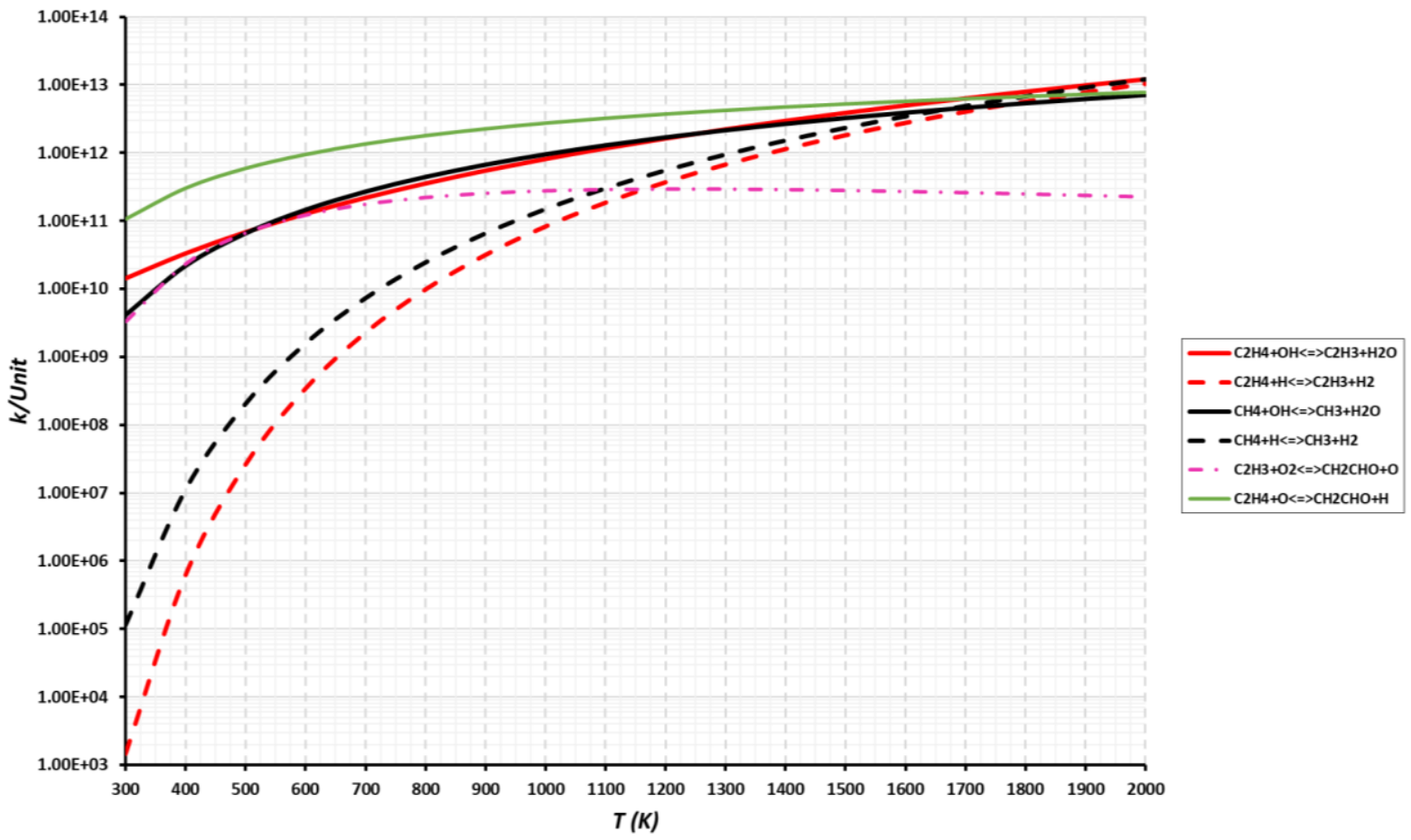

Figure S41. Comparing the rates related to $\dot{\mathrm{H}}-$ abstraction reactions from fuel by $\dot{\mathrm{H}}$ atom or $\dot{\mathrm{OH}}$ radical and also two important reactions for production of vinyloxy radical. 


\section{Supporting Information}

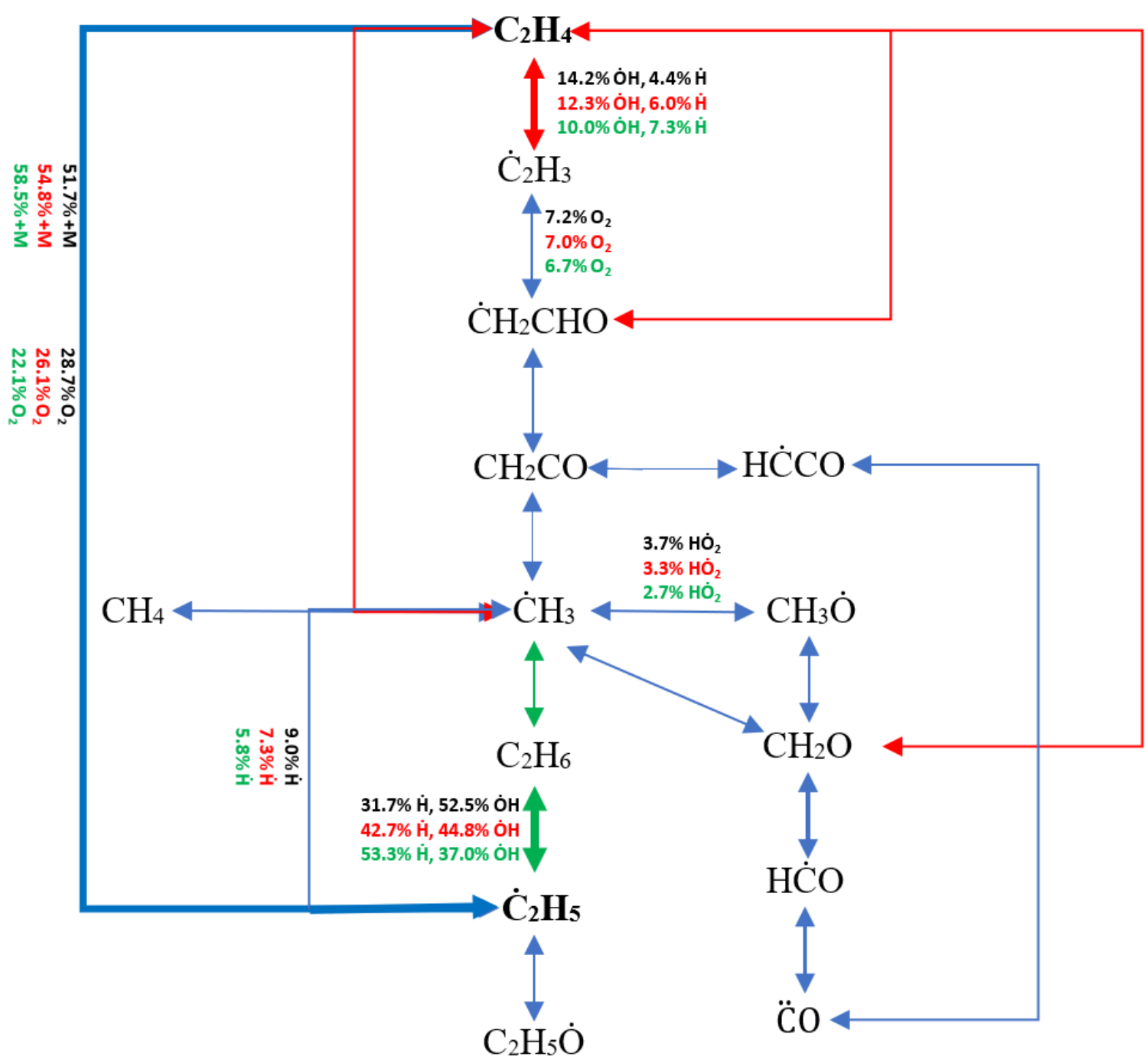

Figure S42. Flux analysis of the ten prominent reactions at $1200 \mathrm{~K}$ in Fig. 5(c) for the ethane + ethylene blends at different equivalence ratios; Black numbers: 0.5, Red numbers: 1.0, and Green numbers: 2.0. 


\section{Supporting Information}

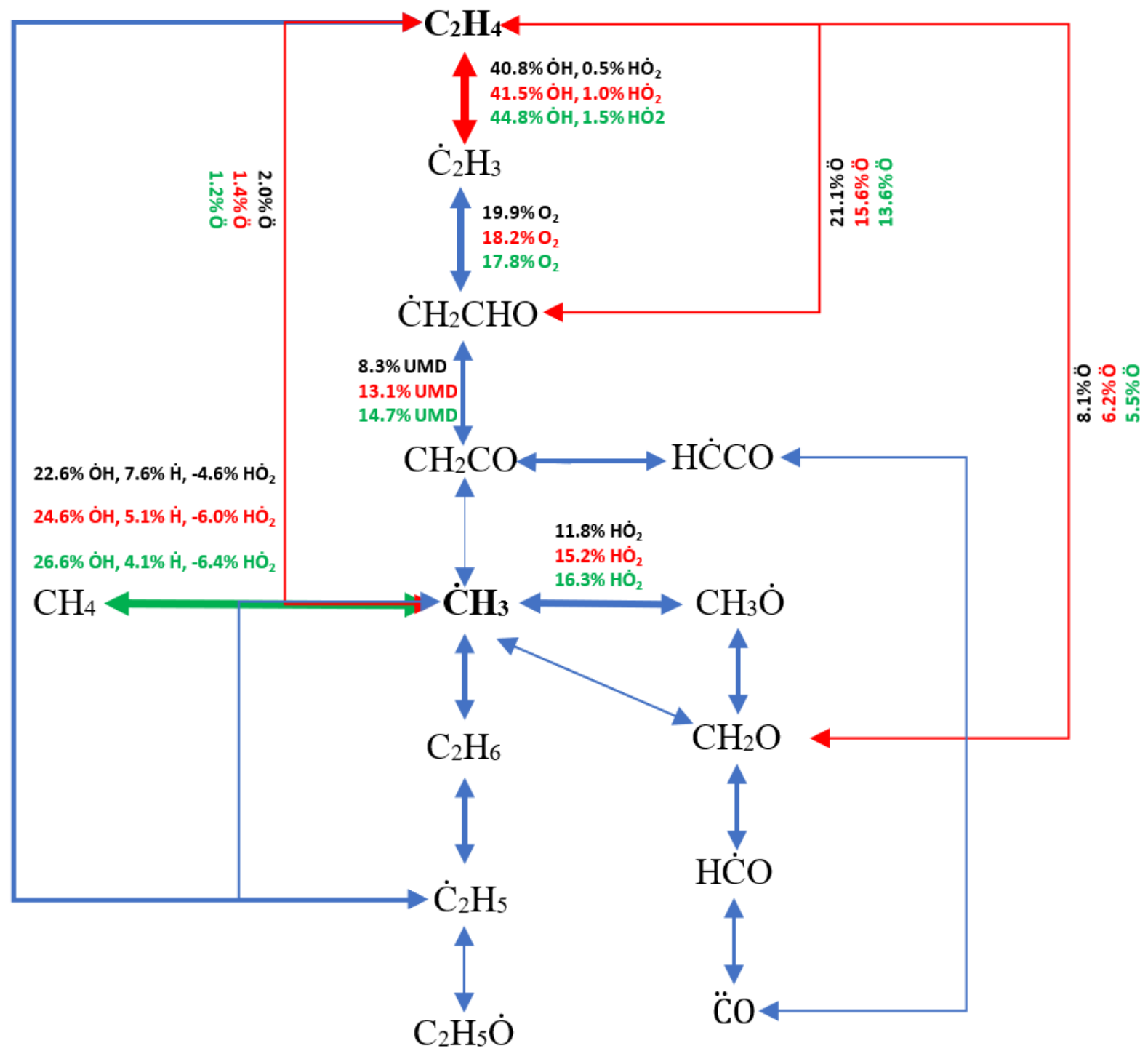

Figure S43. Flux analysis of the ten prominent reactions at $1200 \mathrm{~K}$ in Fig. 5(d) for the methane + ethylene blends at different pressures; Black numbers: 1 bar, Red numbers: 20 bar, and Green numbers: 40 bar. 


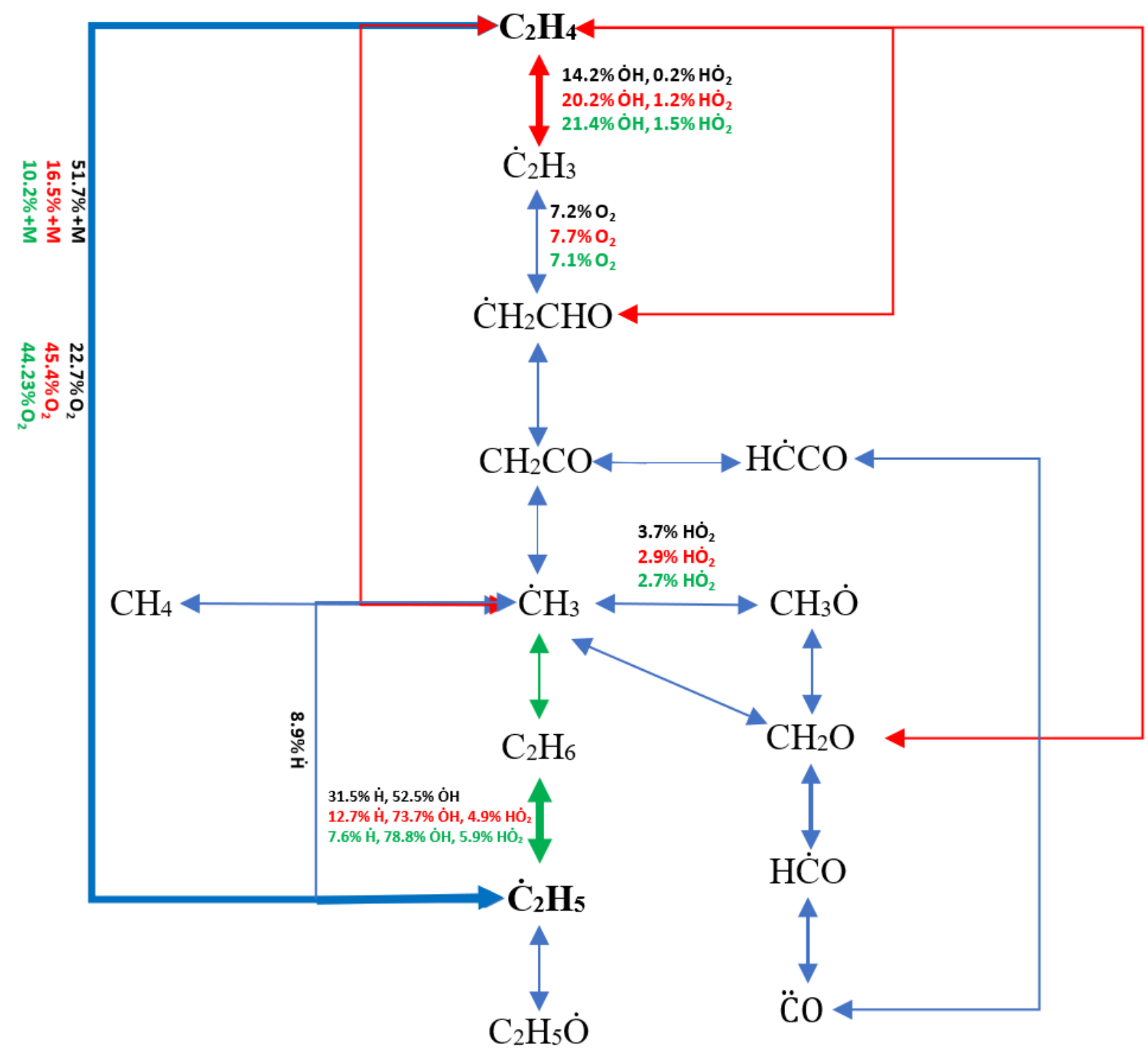

Figure S44. Flux analysis of the ten prominent reactions at $1200 \mathrm{~K}$ in Fig. 5(d) for the ethane + ethylene blends at different pressures; Black numbers: 1 bar, Red numbers: 20 bar, and Green numbers: 40 bar.

\section{References}

1. Baigmohammadi, M.; Patel, V.; Martinez, S.; Panigrahy, S.; Ramalingam, A.; Burke, U.; Somers, K. P.; Heufer, K. A.; Pekalski, A.; Curran, H. J., A Comprehensive Experimental and Simulation Study of Ignition Delay Time Characteristics of Single Fuel $\mathrm{C}_{1}-\mathrm{C}_{2}$ Hydrocarbons over a Wide Range of Temperatures, Pressures, Equivalence Ratios, and Dilutions. Energ Fuel 2020, 34, (3), 3755-3771.

2. Gillespie, F. R. An Experimental and modelling study of the combustion of oxygenated hydrocarbons. National University of Ireland, Galway, National University of Ireland, Galway, 2014.

3. Wurmel, J.; McGuinness, M.; Simmie, J. M., High-temperature oxidation of ethylene oxide in shock waves. J Chem Soc Faraday $T$ 1996, 92, (5), 715-721.

4. Morley, C. http://www.gaseq.co.uk

5. Nakamura, H.; Darcy, D.; Mehl, M.; Tobin, C. J.; Metcalfe, W. K.; Pitz, W. J.; Westbrook, C. K.; Curran, H. J., An experimental and modeling study of shock tube and rapid compression machine ignition of nbutylbenzene/air mixtures. Combust Flame 2014, 161, (1), 49-64.

6. Burke, U.; Somers, K. P.; O'Toole, P.; Zinner, C. M.; Marquet, N.; Bourque, G.; Petersen, E. L.; Metcalfe, W. K.; Serinyel, Z.; Curran, H. J., An ignition delay and kinetic modeling study of methane, dimethyl ether, and their mixtures at high pressures. Combust Flame 2015, 162, (2), 315-330. 


\section{Supporting Information}

7. Ramalingam, A.; Zhang, K. W.; Dhongde, A.; Virnich, L.; Sankhla, H.; Curran, H.; Heufer, A., An RCM experimental and modeling study on $\mathrm{CH}_{4}$ and $\mathrm{CH}_{4} / \mathrm{C}_{2} \mathrm{H}_{6}$ oxidation at pressures up to 160 bar. Fuel 2017, 206, 325-333.

8. Healy, D.; Curran, H. J.; Dooley, S.; Simmie, J. M.; Kalitan, D. M.; Petersen, E. L.; Bourque, G., Methane/propane mixture oxidation at high pressures and at high, intermediate and low temperatures. Combust Flame 2008, 155, (3), 451-461.

9. Healy, D.; Curran, H. J.; Simmie, J. M.; Kalitan, D. M.; Zinner, C. M.; Barrett, A. B.; Petersen, E. L.; Bourque, G., Methane/ethane/propane mixture oxidation at high pressures and at high, intermediate and low temperatures. Combust Flame 2008, 155, (3), 441-448.

10. Metcalfe, W. K.; Burke, S. M.; Ahmed, S. S.; Curran, H. J., A hierarchical and comparative kinetic modeling study of $\mathrm{C}_{1}-\mathrm{C}_{2}$ hydrocarbon and oxygenated fuels. Int. J. Chem. Kinet. 2013, 45, (10), 638-675.

11. Yousefian, S.; Quinlan, N. J.; Monaghan, R. F. D., Simulation of turbulent flow in a rapid compression machine: Large Eddy Simulation and computationally efficient alternatives for the design of ignition delay time experiments. Fuel 2018, 234, 30-47.

12. Hemken, C.; Burke, U.; Lam, K. Y.; Davidson, D. F.; Hanson, R. K.; Heufer, K. A.; Kohse-Hoinghaus, K., Toward a better understanding of 2-butanone oxidation: Detailed species measurements and kinetic modeling. Combust Flame 2017, 184, 195-207.

13. TiePie https://www.tiepie.com/en/oscilloscope-software

14. PicoScope https://www.picotech.com/downloads

15. Petersen, E. L.; Rickard, M. J. A.; Crofton, M. W.; Abbey, E. D.; Traum, M. J.; Kalitan, D. M., A facility for gas- and condensed-phase measurements behind shock waves. Meas Sci Technol 2005, 16, (9), 1716-1729.

16. Weber, B. W.; Sung, C. J.; Renfro, M. W., On the uncertainty of temperature estimation in a rapid compression machine. Combust Flame 2015, 162, (6), 2518-2528.

17. Zhou, C. W.; Li, Y.; Burke, U.; Banyon, C.; Somers, K. P.; Ding, S. T.; Khan, S.; Hargis, J. W.; Sikes, T.; Mathieu, O.; Petersen, E. L.; AlAbbad, M.; Farooq, A.; Pan, Y. S.; Zhang, Y. J.; Huang, Z. H.; Lopez, J.; Loparo, Z.; Vasu, S. S.; Curran, H. J., An experimental and chemical kinetic modeling study of 1,3-butadiene combustion: Ignition delay time and laminar flame speed measurements. Combust Flame 2018, 197, 423-438.

18. Burke, S. M.; Metcalfe, W.; Herbinet, O.; Battin-Leclerc, F.; Haas, F. M.; Santner, J.; Dryer, F. L.; Curran, H. J., An experimental and modeling study of propene oxidation. Part 1: Speciation measurements in jetstirred and flow reactors. Combust Flame 2014, 161, (11), 2765-2784.

19. Li, Y.; Zhou, C. W.; Somers, K. P.; Zhang, K. W.; Curran, H. J., The oxidation of 2-butene: A high pressure ignition delay, kinetic modeling study and reactivity comparison with isobutene and 1-butene. Proc Combust Inst 2017, 36, (1), 403-411.

20. Zhou, C. W.; Li, Y.; O'Connor, E.; Somers, K. P.; Thion, S.; Keesee, C.; Mathieu, O.; Petersen, E. L.; DeVerter, T. A.; Oehlschlaeger, M. A.; Kukkadapu, G.; Sung, C. J.; Alrefae, M.; Khaled, F.; Farooq, A.; Dirrenberger, P.; Glaude, P. A.; Battin-Leclerc, F.; Santner, J.; Ju, Y. G.; Held, T.; Haas, F. M.; Dryer, F. L.; Curran, H. J., A comprehensive experimental and modeling study of isobutene oxidation. Combust Flame 2016, 167, 353-379.

21. Burke, U.; Metcalfe, W. K.; Burke, S. M.; Heufer, K. A.; Dagaut, P.; Curran, H. J., A detailed chemical kinetic modeling, ignition delay time and jet-stirred reactor study of methanol oxidation. Combust Flame 2016, $165,125-136$.

22. $\quad$ Burke, S. M.; Burke, U.; Mc Donagh, R.; Mathieu, O.; Osorio, I.; Keesee, C.; Morones, A.; Petersen, E. L.; Wang, W. J.; DeVerter, T. A.; Oehlschlaeger, M. A.; Rhodes, B.; Hanson, R. K.; Davidson, D. F.; Weber, B. W.; Sung, C. J.; Santner, J.; Ju, Y. G.; Haas, F. M.; Dryer, F. L.; Volkov, E. N.; Nilsson, E. J. K.; Konnov, A. A.; Alrefae, M.; Khaled, F.; Farooq, A.; Dirrenberger, P.; Glaude, P. A.; Battin-Leclerc, F.; Curran, H. J., An experimental and modeling study of propene oxidation. Part 2: Ignition delay time and flame speed measurements. Combust Flame 2015, 162, (2), 296-314.

23. Keromnes, A.; Metcalfe, W. K.; Heufer, K. A.; Donohoe, N.; Das, A. K.; Sung, C. J.; Herzler, J.; Naumann, C.; Griebel, P.; Mathieu, O.; Krejci, M. C.; Petersen, E. L.; Pitz, W. J.; Curran, H. J., An experimental and detailed chemical kinetic modeling study of hydrogen and syngas mixture oxidation at elevated pressures. Combust Flame 2013, 160, (6), 995-1011.

24. Hashemi, H.; Christensen, J. M.; Harding, L. B.; Klippenstein, S. J.; Glarborg, P., High-pressure oxidation of propane. Proc Combust Inst 2019, 37, (1), 461-468.

25. Bagheri, G.; Ranzi, E.; Pelucchi, M.; Parente, A.; Frassoldati, A.; Faravelli, T., Comprehensive kinetic study of combustion technologies for low environmental impact: MILD and OXY-fuel combustion of methane. Combust Flame 2020, 212, 142-155.

26. Chemical-Kinetic Mechanisms for Combustion Applications. http://combustion.ucsd.edu

27. Smith, G. P.; Golden, D. M.; Frenklach, M.; Moriarty, N. W.; Eiteneer, B.; Goldenberg, M.; Bowman, C. T.; Hanson, R. K.; Song, S.; Gardiner, W. C.; Lissianski, V. V.; Qin, Z. http://www.me.berkeley.edu/gri_mech/ 


\section{Supporting Information}

28. Wang, H.; Dames, E. E.; Sirjean, B.; Sheen, D. A.; Tango, R.; Violi, A.; Lai, J. Y. W.; Egolfopoulos, F. N.; Davidson, D. F.; Hanson, R. K.; Bowman, C. T.; Law, C. K.; Tsang, W.; Cernansky, N. P.; Miller, D. L.; Lindstedt, R. P. A high-temperature chemical kinetic model of n-alkane (up to n-dodecane), cyclohexane, and methyl-, ethyl-, n-propyl and n-butyl-cyclohexane oxidation at high temperatures. http://web.stanford.edu/group/haiwanglab/JetSurF/JetSurF2.0/index.html

29. Smith, G. P.; Tao, Y.; Wang, H., Foundational Fuel Chemistry Model Version 1.0 (FFCM-1). In Stanford University, 2016.

30. Lowry, W.; de Vries, J.; Krejci, M.; Petersen, E.; Serinyel, Z.; Metcalfe, W.; Curran, H.; Bourque, G., Laminar Flame Speed Measurements and Modeling of Pure Alkanes and Alkane Blends at Elevated Pressures. Proceedings of the Asme Turbo Expo 2010, Vol 2, Pts a and B 2010, 855-873.

31. Chang, E. J. Shock Tube Experiments for the Development and Validation of Models of Hydrocarbon Combustion. Stanford University, Stanford CA, 1995.

32. Dagaut, P.; Boettner, J. C.; Cathonnet, M., Methane Oxidation - Experimental and Kinetic Modeling Study. Combust Sci Technol 1991, 77, (1-3), 127-148.

33. Hashemi, H.; Jacobsen, J. G.; Rasmussen, C. T.; Christensen, J. M.; Glarborg, P.; Gersen, S.; van Essen, M.; Levinsky, H. B.; Klippenstein, S. J., High-pressure oxidation of ethane. Combust Flame 2017, 182, 150-166. 34. Dagaut, P.; Cathonnet, M.; Boettner, J. C., Kinetics of Ethane Oxidation. Int. J. Chem. Kinet. 1991, 23, (5), 437-455.

35. Lopez, J. G.; Rasmussen, C. L.; Alzueta, M. U.; Gao, Y.; Marshall, P.; Glarborg, P., Experimental and kinetic modeling study of $\mathrm{C}_{2} \mathrm{H}_{4}$ oxidation at high pressure. Proc Combust Inst 2009, 32, 367-375.

36. Carriere, T.; Westmoreland, P. R.; Kazakov, A.; Stein, Y. S.; Dryer, F. L., Modeling ethylene combustion from low to high pressure. Proc Combust Inst 2003, 29, 1257-1266.

37. Aul, C. J.; Metcalfe, W. K.; Burke, S. M.; Curran, H. J.; Petersen, E. L., Ignition and kinetic modeling of methane and ethane fuel blends with oxygen: A design of experiments approach. Combust Flame 2013, 160, (7), 1153-1167.

38. Petersen, E. L.; Hall, J. M.; Smith, S. D.; de Vries, J.; Amadio, A. R.; Crofton, M. W., Ignition of lean methane-based fuel blends at gas turbine pressures. J Eng Gas Turb Power 2007, 129, (4), 937-944.

39. Beerer, D. J.; McDonell, V. G., An experimental and kinetic study of alkane autoignition at high pressures and intermediate temperatures. Proc Combust Inst 2011, 33, 301-307.

40. Huang, J.; Bushe, W. K., Experimental and kinetic study of auto-ignition in methane/ethane/air and methane/propane/air mixtures under engine-relevant conditions. Combust Flame 2006, 144, 74-88.

41. Gersen, S.; Mokhov, A. V.; Darmeveil, J. H.; Levinsky, H. B.; Glarborg, P., Ignition-promoting effect of $\mathrm{NO}_{2}$ on methane, ethane and methane/ethane mixtures in a rapid compression machine. Proc Combust Inst 2011, 33, 433-440. 